SERVIÇO DE PÓS-GRADUAÇÃO DO ICMC-USP

Data de Depósito: 25/04/2000

Assinatura:

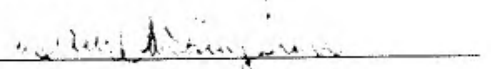

\title{
Pré-processamento para extração de conhecimento de bases textuais ${ }^{1}$
}

\author{
Cristiane Yae-Mi Imamura
}

Orientadora: Profa. Dra. Solange Oliveira Rezende

Dissertação apresentada ao Instituto de Ciências Matemáticas e de Computação - ICMC-USP, como parte dos requisitos para obtenção do título de Mestre em Ciências de Computação e Matemática Computacional.

USP - São Carlos

Setembro/2001

zado com o apoio da CAPES 


\section{A Comissão Julgadora:}

Profa. Dra. Solange Oliveira Rezende

Profa. Dra. Maria Carolina Monard

Prof. Dr. Nelson Francisco liavilla libecken
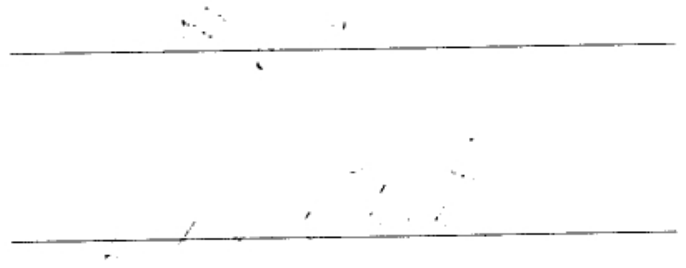

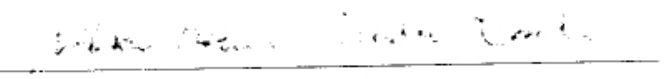


Este documento foi preparado com o formatador de textos $\mathrm{LT}_{\mathrm{E}} \mathrm{X}$. O sistema de citações de referências bibliográficas utiliza o padrão Apalike do sistema BibTeX.

(c) Copyright 2001 por Cristiane Yae-Mi Imamura

Todos os Direitos Reservados 


\section{Dedicatória}

Aos meus pais

Ioshique e Odinez. 


\section{Agradecimentos}

Agradeço a todos os que contribuíram para que este trabalho pudesse ser concretizado, seja através de ensinamentos sobre a pesquisa ou de palavras de incentivo.

Em especial, agradeço primeiramente a minha orientadora Solange, cuja orientação excedeu o escopo deste trabalho e influenciou no meu engrandecimento profissional e pessoal. Meus sinceros agradecimentos também à professora Maria Carolina, que em sua curiosidade sobre o andamento deste sempre contribuiu com algum aspecto necessário para esta pesquisa.

Muito obrigada à professora Maria das Graças Volpe Nunes, que permitiu a utilização de recursos para realização de grande parte deste trabalho. Agradeço ainda a todos os meus professores que não se limitaram a ensinar apenas os conceitos de suas disciplinas, mas lições para uma vida inteira.

E em se tratando de questões de vida, agradeço aos meus queridos pais, que são meıs eternos mestres e que não medem esforços para que eı possa alcançar meus objetivos, e foram imprescindíveis para que eu pudesse chegar até aqui. Agradeço também ao Danival pelo companheirismo, compreensão e infinita paciência nos momentos difíceis, e por ter me oferecido a oportunidade de vivenciar os momentos mais ternos.

À Jaque, Lea, Adriano Pila, Clandinha, Katti, Walter, Valéria, Patricia, Werley, Adriano Cabrera, Rogério, Evely, Nâni, Tati, Gerson, Robson, Valmir, Marcos Paıla, Daniel e amigos do Labic, muitíssimo obrigada pela amizade sincera e apoio em todas as situações. Obrigada também ao Ricardo Hasegawa, Debora, Daniela Godoy e Maria Célia (Coppe - UFRJ), por serem sempre atenciosos.

Obrigada a CAPES, pelo apoio financeiro.

Sobretudo, agradeço a Deıs, pois sem Ele tudo isso não seria possível. 


\section{Sumário}

1 Introdução 1

2 Visão Geral sobre Text Mining 4

2.1 Algumas Aplicações . . . . . . . . . . . . . . . . . . . . . . . . . . 4

2.1 .1 Classificação Automática de Texto . . . . . . . . . . . . . 5

2.1 .2 Extração de Resumos . . . . . . . . . . . . . . . . . 6

2.1.3 Tarefas de Apoio à Inteligência Competitiva . . . . . . . . . . . 7

2.2 Etapas do Processo Text Mining . . . . . . . . . . . . . . . . . . . . . . . 8

2.3 Coleta de Documentos . . . . . . . . . . . . . . . . . 10

2.4 Pré-processamento de Textos . . . . . . . . . . . . . . . . 12

2.5 Extração de Conhecimento . . . . . . . . . . . . . . . . . 14

2.j.1 Algoritmos de Aprendizado de Máquina . . . . . . . . . . . . . 15

$2.5 .2 \quad$ Outros Algoritmos Comumente Utilizados . . . . . . . . . . 18

2.6 Avaliação e Interpretação do Conhecimento . . . . . . . . . . . . . 20

2.7 Algumas Ferramentas de Apoio ao Text Mining . . . . . . . . . . . . . . 24

2.8 Considerações Finais . . . . . . . . . . . . . . . . . . . . . . . . . . . . 29

3 Representação de um Documento 32

3.1 Identificação dos Atributos . . . . . . . . . . . . . . . . . . 33

3.1 .1 A Lista de Stopwords . . . . . . . . . . . . . . . . . . . 33

3.1 .2 Normalização de Palavras . . . . . . . . . . . . . . 35

3.1 .3 Outrass Operaçöes . . . . . . . . . . . . . . . . . 37

3.2 Atribuição do Pesos aos Atributos . . . . . . . . . . . . . . . . . . . . . 39 
3.3 Redução da Representação . . . . . . . . . . . . . . . . . . . 46

3.3 .1 Seleção de Atributos . . . . . . . . . . . . . . . . 47

3.3 .2 Induçăo Construtiva . . . . . . . . . . . . . . . . . . 49

3.4 Consideraçōes Finais . . . . . . . . . . . . . . . . . . 50

4 Módulo de Pré-processamento de Texto 52

4.1 Lista de Stopwords . . . . . . . . . . . . . . . . . . 54

4.2 Abordagens para Normalização das Palavras . . . . . . . . . . . . 55

4.3 Scripts para Identificação dos Atributos . . . . . . . . . . . . . . . 58

4.3 .1 Scripts ScpDStem e ScpDCan . . . . . . . . . . . . 58

4.3 .2 Scripts ScpKStem e ScpKCan _. . . . . . . . . . . . 61

4.3 .3 Scripts ScpNStem e ScpNCan . . . . . . . . . . 64

4.4 Scripts para Atribuição de Pesos . . . . . . . . . . . . 67

4.5 Scripts para Redução do Nímero de Atributos . . . . . . . . . . 68

4.6 Considerações Finais . . . . . . . . . . . . . . . . . . . . . . . . . 69

5 Validação do Módulo de Pré-processamento de Textos Através de Estu$\begin{array}{ll}\text { do de Casos } & 71\end{array}$

5.1 Estudo de Caso 1 - Categorização de Textos sobre Aquisição de Conhecimento e Redes Neurais . . . . . . . . . . . . . . . . 72

5.1 .1 Coleta de Documentos . . . . . . . . . . . . . . . 73

5.1 .2 Preparação de Documentos . . . . . . . . . . . . 74

5.1 .3 Experimentos Realizados e Resultados . . . . . . . . . . 78

5.1 .4 Algumas Considerações. . . . . . . . . . . . . . . . . . 81

5.2 Estudo de Caso 2 - Análise de Patentes Farmoquímicas . . . . . . . . . 84

5.2 .1 Coleta de Documentos . . . . . . . . . . . . . . . 85

5.2 .2 Preparação de Documentos _ . . . . . . . . . . . 86

5.2 .3 Experimentos Realizados e Resultados . . . . . . . . . . . 88

5.2 .4 Algumas Considerações . . . . . . . . . . . . . . . . 90

5.3 Consideraçōes Finais . . . . . . . . . . . . . . . . . . 90

6 Conclusões $\quad 92$ 
Referências Bibliográficas 


\section{Lista de Figuras}

2.1 Etapas do processo Text Mining . . . . . . . . . . . . . . . . . 9

2.2 Algumas atividades realizadas no pré-processamento de texto . . . . . . . . 13

2.3 Ilustração das superfícies que separam duas classes com SVM . . . . . . . . 19

3.1 Exemplo de uma representação bag-of-words usando pesos correspondentes a frequiencia dos termos no documento . . . . . . . . . . . . . . 32

3.2 (a) Distribuição das palavras de um documento segundo a lei de Zipf (b) Resultado da associação da lei de Zipf à ideia de Luhn . . . . . . . . . . . 35

3.3 Seleção de atributos para reduzir a representação em Text Mining . . . . . 48

3.4 Relação entre o tamanho do vocabulário e o tamanho do texto. segundo a lei de Zipf . . . . . . . . . . . . . . . . . . . . . . . . . 51

4.1 Visão geral do ambiente computacional Discover . . . . . . . . . . . 53

4.2 Estrutura do módulo de pré-processamento de texto . . . . . . . . . 53

4.3 Seripts que integram o módulo de pré-processamento de texto do Ambiente Computacional Discover . . . . . . . . . . . . . . . . . 70

5.1 Resultado da aplicação dos scripts para identificação de atributos . . . . 75

J.2 Esquema para preparação de textos utilizada para categorização de textos dos domínios de Redes Neurais e Aquisição de Conhecimento realizado durante o estudo de caso . . . . . . . . . . . . . . . . . . 77

5.3 Exemplo de $11 \mathrm{~m}$ documento de patente disponível no site do INPI. . . . . 85 


\section{Lista de Tabelas}

2.1 Representação dos documentos no formato atributo-valor para a construção de $11 \mathrm{~m}$ classificador supervisionado . . . . . . . . . . . . . 6

2.2 Matriz de confusão para uma tarefa com classe bi-valorada. . . . . . . . 22

2.3 Informaçoes genéricas sobre algumas ferramentas de apoio a Text Mining. 29

3.1 Algumas regras usadas no algoritmo de Porter para o inglês . . . . . . . . 36

3.2 Relação entre documentos, palavras e classes. usada para exemplificação das medidas de atribuição de pesos . . . . . . . . . . . . . . . . 40

3.3 Palavras e correspondentes rótulos . . . . . . . . . . . . . . 41

3.4 Representação bag-of-words utilizando peso booleano . . . . . . . . . . . . 42

3.5 Representação bag-of-words utilizando a frequïencia do atributo como peso 42

3.6 Representação bag-of-words utilizando peso tf $\times$ idf . . . . . . . . . . 43

3.7 Representaçāo bag-of-words utilizando peso tf $\times$ idf normalizado . . . . . . 44

3.8 Representação bag-of-words utilizando log tf $\times$ idf normalizado como peso . 45

3.9 Representação bag-of-words utilizando peso baseado na entropia . . . . . . 46

4.1 Exemplificação da saída do algoritmo para stemming baseado no algoritmo de Porter . . . . . . . . . . . . . . . . . . . . . 57

4.2 Exemplificação da saída do etiquetador . . . . . . . . . . . . . . . 57

4.3 Exemplificação da saída dos scripts ScpDStem e ScpDCan . . . . . . . . . 61

4.4 Exemplificação da saída do script ScpKStem . . . . . . . . . . . . 63

4.5 Exemplificação da saída do script ScpKCan . . . . . . . . . . . . . . 64

4.6 Exemplificação da saída do scripts ScpNStem e ScpNCan . . . . . . . 66 
5.1 Algumas informaçòes sobre os arquivos gerados pelos stripts de identificação de atributos. . . . . . . . . . . . . . . . . . . . . 76

5.2 Resultados obtidos utilizando as representaçóes geradas a partir do conjunto DStem_Set . . . . . . . . . . . . . . . . . . . . . . 79

5.3 Resultados obtidos ntilizando as representaçoes geradas a partir do conjunto DCansSt . . . . . . . . . . . . . . . . . . . . 79

5.4 Resultados obtidos utilizando as representaçooes geradas a partir do conjunto KStem_Set . . . . . . . . . . . . . . . . . . . . 79

5.5 Resultados obtidos utilizando as representaçóes geradas a partir do conjunto KCan_Set . . . . . . . . . . . . . . . . . . . . . 79

5.6 Resultados obtidos utilizando as representações geradas a partir do conjunto NStem_Set . . . . . . . . . . . . . . . . . . 80

5.7 Resultados obtidos utilizando as representações geradas a partir do conjunto NCan_Set . . . . . . . . . . . . . . . . . . . . . . . . . . 80

5.8 Valores obtidos para a medida accuracy . . . . . . . . . . . . . . . . . . 82

5.9 Valores obtidos para a medida precisão . . . . . . . . . . . . . . 83

5.10 Valores obtidos para a medida recall . . . . . . . . . . . . . 83

5.11 Valores obtidos para a medida $F_{1} \ldots \ldots$. . . . . . . . . . . . 84

5.12 Algumas regras extraídas do título e resumo das patentes farmoquímicas . 88

j.13 Algumas regras extraídas da representação híbrida . . . . . . . . . . . . . 89 


\section{Resumo}

A descoberta de conhecimento em bases de dados é uma área de pesquisa que tem crescido rapidamente. e cujo desenvolvimento tem sido dirigido ao beneficio das necessidades práticas. sociais e econômicass. entre ontras. Entretanto. mesmo em bases de dados podem estar presentes campos importantes que nāo sáo considerados na análise. como aqueles preenchidos com informações textuais. Esssas informações não estão presentes apenas em tabelas, mas também em diversos documentos que são disponibilizados e acessados através da Internet. Para tornar a descoberta de conhecimento em textos possivel, tem-se associado estratégias de preparação/pré-processamento de textos e téenicas utilizadas no processo Data Mining. Essa associação vem sendo denominada de processo Text Mining. Tendo em vista a importância da preparação dos textos. neste trabalho foi projetado e construído $11 \mathrm{~m}$ módulo de pré-processamento de textos. com a finalidade de tornar possível a realização do processo Text Mining considerando textos em português. Devido ao fato de que muitas estratégias e/ou ferramentas estarem disponíveis somente para o inglês, a possibilidade de realizar a descoberta de padrões em textos em português pode significar o alcance de novos horizontes em termos de oportunidades e informaçōes desconhecidas. 


\begin{abstract}
The knowledge discovery in data bases is a research area that have been increasing quickly, and which development has been driven to the practical, social and economical needs. However. even data bases can have important fields that are not considered in the analysis. such as those which are fulfill with textnal information. This information is not present only in tables. but also in several documents that are available through the Internet. To be possible the knowledge discovery in text. text preparation/preprocessing strategies are associated with technics used in the Data Mining process. This association have been called Text Mining. Considering the importance of texts preprocessing. in this work was planned and built a module of texts pre-processing, with the objective to make possible the realization of the Text Mining process for Portugnese texts. Due to the fact that many strategies and tools are available only for English. the possibility of realize the pattern discovery in Portuguese texts come to be useful to reach new goals in terms of unknown opportunities and information.
\end{abstract}




\section{Capítulo 1}

\section{Introdução}

A descoberta de conhecimento em bases de dados é um campo de pesquisa que tem crescido rapidamente, e cujo desenvolvimento tem sido dirigido ao benefício das necessidades práticas. sociais e econòmicas. entre outras. A grande motivação para esse crescimento está ligada, principalmente. à existência de uma poderosa tecnologia para coleta e gerenciamento de grande quantidade de dados.

De posse de tal tecnologia, depara-se com a recente "Era da Informação", em que a cada momento mais dados estão sendo computados e acumulados. Muitos desses dados possuem informaçōes valiosas, como tendências e padrões, que poderiam ser usadas para melhorar as decisões de negócios, além de outras aplicações (Goebel and Gruenwald, 1999).

Considerando-se que, em geral. as bases contem muitos dados a ponto de tornar inviável a análise mannal, tornot-se necessário o desenvolvimento de processos de análise automática. como o Processo Data Mining (DM). Esse processo tem despontado por seu desempenho em diversos domínios, na extração de padrões válidos, novos, e potencialmente úteis dos dados (Fayyad et al., 1996).

Contudo, foi percebido que mesmo nas bases de dados podem estar presentes campos que não são considerados na análise, como aqueles preenchidos com informações textuais. Essas informações não estão presentes apenas em tabelas, mas também em diversos documentos que são disponibilizados. acessados e armazenados com grande frequiencia. principalmente. por meio da Internet. 
A dificuldade de analisar textos provém do fato de que os eles são tipos de dados que possitem uma estrutura interna limitada. sendo portanto considerados pouco ou mesmo não estruturados. Tal limitação implica no fato de que esses dados năo podem ser diretamente manipulados pelas técnicas de extração de conhecimento usuais de DM.

Contudo, há estratégias para preparaçäo. on pré-processamento, de textos que permitem que as téenicas utilizadias no processso DM possam ser aplicadas. A associação dessas estratégias ao processo DM é conhecida como processo para Mineração de Textos, também chamado de Text Mining (Tan, 1999), Text Data Mining (Hearst, 1999), ou Knowledge Discovery in. Texts (Feldman and Dagan. 1995).

O pré-processamento de textos consiste em um conjunto de ações realizadas sobre alguma coleção de textos com o objetivo de fazer com que estes passem a ser estruturados em uma representaçăo atributo-valor. A obtenção da representação atributo-valor pode envolver aspectos 11tilizados em Processamento de Língua Natural (PLN), Recuperação de Informação (RI), entre outras áreas.

Por envolver aspectos inter-disciplinares, a fase de preparação dos textos é bastante interessante, porém nào é tão simples. Grande parte dos resultados obtidos ao fim do processo pode depender de quão bem a representação atributo-valor descreve o contexto dos textos. Como nem todas as técnicas utilizadas são adequadas para todos os domínios, a obtenção de uma representação satisfatória pode depender de diversas experimentações e observaçóes empíricas. o que pode ocasionar no despendimento de grande parte do tempo de todo o processo.

Dessa forma, por ser uma das principais etapas do processo Text Mining, esse trabalho está voltado ao estudo das principais técnicas utilizadas no pré-processamento de textos. Para tanto. no trabalho aqui apresentado. incluem-se investigações sobre métodos e/ou ferramentas que possibilitem converter os documentos em uma representação com a qual possam ser empregadas as técnicas utilizadas em DM.

Dentre as técnicas utilizadas na preparação dos textos. algumas são conhecidas como dependente do idioma. Por esse motivo, a maioria dos trabalhos, mencionados na literatura consultada. ́ voltada à análise de textos escritos em inglês. Entretanto. a mineração de documentos em outros idiomas pode ser interessante para alcançar no- 
vos horizontes em termos de oportunidades e informaçōes anteriormente desconhecidas. Assim. neste trabalho. além das técnicas para textos em inglês. também são abordadas possiveis estratégias para os textos escritos em portuguess.

Em virtude da năo disponibilidade de implementaçóes de algumas estratégias, ou por ser necessário combinar algumas já existentes. como parte deste trabalho foi projetado e constrúdo um módulo de pré-processamento de texto. Esse módulo faz parte do Ambiente Computacional para Extração de Conhecimento em Dados e Textos, chamado Discover.

Para a construção do módulo. foram implementados scripts em Perl envolvendo estratégias comumente empregadas combinadas com alguns recursos para apoiar o processamento de textos em português. As técnicas e abordagens. comumente referenciadas e utilizadas no módulo. são discutidas ao longo deste trabalho que está organizado como segue.

No Capítulo 2 é abordado o estado da arte sobre Text Mining. incluindo algumas das principais atividades relacionadas a mineração de texto, aplicaçōes e ferramentas de apoio. Os detalhes sobre as técnicas envolvidas na preparação de textos, que consiste no foco deste trabalho, são apresentados no Capítulo 3.

No Capítulo 4 são detalhados os scripts que compõem o módulo de pré-processamento para textos em portuguess. sendo a avaliação desses mostrada no Capítulo 5 através de alguns experimentos e estudos de casos. Por fim. algumas considerações finais sobre esta dissertação são abordadas no Capítulo 6. 


\section{Capítulo 2}

\section{Visão Geral sobre Text Mining}

Como mencionado no capítulo anterior. o processo do descoberta de conhecimento em textos pode ser visto como uma associação de técnicas para preparação de textos ao processo de Data Mining. Pela natureza dos dados e pelas aplicações a que está freqüentemente relacionado. o processo Text Mining combina muitas das técnicas de Recuperação de Informação e pode também contar com a utilização de al b̧inilas estratégias de Processamento de Língua Natural, ao longo de suas etapas.

Para compreender a razăo do emprego de certas atividades no processo de extração de conhecimento de textos, bem como facilitar o entendimento de como as técnicas de diferentes áreas se interagem. primeiramente. neste capítulo são abordadas algumas aplicaçōes de Text Mining. Nas seções subseqüentes são então descritas as principais etapas do processo e algumas ferramentas de apoio.

\subsection{Algumas Aplicações}

Tendo em vista o grande volume de informações disponíveis principalmente na World Wide $W e b^{2}$ (WWW), o que se pode perceber é que grande parte das aplicações de Text Mining estão voltadas à construção de ferramentas que propiciem melhorias na recuperação de documentos, de forma a tornar esse processo mais preciso. Dessa forma, muitas pesquisas associam a realização desse processo à atividade de classificação de documentos.

\footnotetext{
${ }^{1}$ As palavras texto e documento são usadas indistintamente, nesse trabalho.

Nesse trabalho os termos WWW e Web são usados indistintamente.
} 
Vessa seção. além da classificação de documentos. são abordadas as atividades de extraçào de resumos (normalmente referenciadas na literatura como sumarization) e de apoio à Inteligencia Competitiva. que recentemente vem despertando interesse na (ommidade cientifica.

\subsubsection{Classificação Automática de Texto}

A classificação automática de textos tem sido usada não somente para prover uma melhor organizaçào on facilidade na recuperação de documentos, mas também para dar suporte a realização de outras atividades, tais como. a extraçāo antomática de palavras chaves (Witten et al.. 1999) e a filtragem de e-mail (Cohen. 1996).

De forma geral. a classificação de documentos é feita segundo duas abordagens de aprendizado: supervisionado e não supervisionado. Na abordagem de aprendizado supervisionado um documento novo é classificado de acordo com o resultado de um classificador que foi construído e treinado a partir de documentos rotulados. on seja, que possuem as respectivas classes meta designadas. Em Text Mining, quando a classificação de texto utiliza esse tipo de abordagem e quando pode-se atribuir ao documento mais que uma classe meta. a tarefa é, geralmente, referenciada como categorização de texto (Loh, 1997).

Para construção do classificador, o conjunto de documentos exemplos que são utilizados para seu treinamento e teste devem estar dispostos em uma representação atributovalor tal qual a mostrada na Tabela 2.1. Cada tupla da tabela contém informações sobre 1 m documento $d_{j}$. Essas informações compreendem o peso. definido como $a_{j k}$, que cada termo termo tem em relação a cada documento $d_{j}$. Tratando-se de um aprendizado s11pervisionado. cada documento $d_{j}$ tem adicionado ainda a informaçāo sobre sua respectiva classe $c_{i}$.

Utilizando essa representação, um classificador supervisionado é treinado e classifica um novo documento de acordo com o valor de seus atributos. Mas, há casos em que não se conhece previamente as classes a que os documentos estão associados.

Quando os documentos não estão rotulados. podem ser utilizados sistemas de aprendizado não supervisionado para verificar ou identificar quais documentos se relacionam e/ou poderiam ser agrupados. De acordo com essa abordagem não supervisionada. 


\begin{tabular}{|c||c|c|c|c|c|c|c|c|}
\hline & $\operatorname{ter}_{1}$ & $\ldots$ & $\ldots$ & term $_{k}$ & $\ldots$ & $\ldots$ & term $_{n}$ & classe \\
\hline \hline$d_{1}$ & $a_{11}$ & $\ldots$ & $\ldots$ & $a_{1 k}$ & $\ldots$ & $\ldots$ & $a_{1 n}$ & $c_{i}$ \\
\hline$\ldots$ & $\ldots$ & $\ldots$ & $\ldots$ & $\ldots$ & $\ldots$ & $\ldots$ & $\ldots$ & $\ldots$ \\
\hline$d_{j}$ & $a_{j 1}$ & $\ldots$ & $\ldots$ & $a_{j k}$ & $\ldots$ & $\ldots$ & $a_{j n}$ & $c_{i}$ \\
\hline$\ldots$ & $\ldots$ & $\ldots$ & $\ldots$ & $\ldots$ & $\ldots$ & $\ldots$ & $\ldots$ & $\ldots$ \\
\hline$d_{m}$ & $a_{m 1}$ & $\ldots$ & $\ldots$ & $a_{m k}$ & $\ldots$ & $\ldots$ & $a_{m n}$ & $c_{i}$ \\
\hline
\end{tabular}

Tabela 2.1: Representação dos documentos no formato atributo-valor para a construção de $1 \mathrm{~m}$ classificador supervisionado

a coleção de documentos pode ser segmentada em subconjuntos. chamados clusters, cujos membros possuem alto gran de similaridade.

A medida de similaridade. no caso de conjunto de textos. pode ser obtida pela análise do vocabulário contido nos documentos. Contudo. vale ressaltar que o uso de ıma medida baseada na simples comparação da igualdade (match) dos termos pode ser uma medida muito imprecisa e vaga devido à grande quantidade de ambigüidade léxica existente nas palavras. Idealmente. uma análise semântica dos documentos poderia ser usada para identificar os conceitos mencionados no texto como base para a realização de clustering. Porém. este tipo de análise é muito custosa e depende de grande conhecimento específico do domínio.

\subsubsection{Extração de Resumos}

Resumir documentos consiste em uma tarefa pertinente à criaçào de uma pequena síntese de $11 \mathrm{~m}$ texto. preservando as principais informações nele contidas. Uma utilidade para tal tarefa poderia ser a verificação, de maneira rápida e fácil. do quão relevante é todo o conteúdo de um documento. Isto poderia favorecer, por exemplo, a descrição de documentos contidos na listagem resultante de uma consulta, a fim de auxiliar a escolha daqueles que são mais interessantes.

A realização dessa aplicação envolve o cálculo do graı de importância de cada sentença do texto e a seleção daquelas que obtiverem melhor classificação. O cálculo dessa importância envolve o 11so de regras semânticas pré-definidas. índice de frases, freqüência de palavras chave. estrutura de similaridade entre sentenças, e outras estratégias (Kupiec 
et al.. 1995: Martins et al., 2001).

Para calcular a probabilidade de uma sentença ser inclúda no resumo, pode-se fazer uso de classificadores estatísticos. Este cálculo dependerá de quais atributos são considerados na representação do documento. levando-se em conta se esses fazem parte do tema. do título, ou de alguma outra parte específica do documento.

Para construir os classificadores, é necessário ainda fazer uso de amostras contendo a descriçào de $11 m$ documento e o seu respectivo resumo. geralmente. feito por um profissional. como o engenheiro de informação. A obtenção dessas amostras. porém. muitas vezes é a principal razão que faz com que o processo de extração de resumos seja considerado extremamente caro.

\subsubsection{Tarefas de Apoio à Inteligência Competitiva}

Uma das maiores aplicações de téenicas de inteligência computacional está relacionada ao suporte à descoberta de indicativos que auxiliem empresas e organizações a tomarem um posicionamento mais competitivo em relação a seus concorrefiv's.

Quanto melhor o acesso. a disponibilidade e a qualidade de informação, maior é a chance de acerto no processo de tomada de decisão e a competitividade das organizações capazes de utilizá-la. Desta maneira, as empresas deveriam ser capazes de obter rapidamente a maior quantidade de informaçōes relevantes. Portanto. uma das tarefas que auxilia esse processo é a classificaçăo de textos (Rizzi et al.. 2000).

Além das atividades relacionadas à classificaçào de textos em categorias importantes a uma organização. outras técnicas utilizadas em Data Mining têm sido usadas para a análise de textos e para apoiar o processo de inteligencia competitiva. No trabatho relatado em (Lent et al.. 1997) é tratado o problema da identificação de tendências em textos. fazendo uso de documentos de patentes. Para isso os documentos são particionados de acordo com sua data (de criação, de disponibilidade. etc.). e métodos de mineração de padrões seqüenciais (Agrawal and Srikant, 1995; Srikant and Agrawal, 1996) são utilizados para identificação de frases. As frases e seus indicadores de tempo são então analisados utilizando técnicas apresentadas em (Agrawal et al.. 1995) para identificação de tendências. 
O uso de técnicas de associação também tem sido explorado em Text Mining. Em (Loh et al.. 2000). foram analisadas regras e associações encontradas em documentos disponíveis na Web em nove ferramentas de Text Mining e a distribuição de conceitos presentes nos textos, para ser possível analisar que técnicas disponiveis nas ferramentas são usadias para obter $11 \mathrm{~m}$ certo benefício.

Em geral. nos trabalhos são encontradas asssociaçoes de diversas técnicas utilizadas para descoberta de padrões em dados e de téenicas voltadas para a classificação de texto. Em (Thomas and Sycara. 1999), é descrita a aplicação de duas abordagens: algoritmos de classificação de textos e algoritmos genéticos baseados somente em dados numéricos com intuito de prover uma aplicação para predição sobre dados financeiros.

Independente de qual seja a finalidade do processo Text Mining, alguns conceitos em mais alto nível sobre suas etapas podem ser considerados os mesmos. Esses conceitos são abordados na próxima seção.

\subsection{Etapas do Processo Text Mining}

() processo Text Mining, como ilustrado na Figura 2.1, pode ser dividido em quatro etapas fundamentais: coleta de documentos, pré-processamento, extração de conhecimento e avaliação e interpretação dos resultados.

A coleta de documentos consiste no primeiro passo do processo e tem como função recuperar os documentos que possam ser relevantes para alcançar o objetivo almejado. Como mencionado. tais documentos precisam ser preparados para permitir a extração automática de conhecimento, e portanto, são submetidos a uma etapa de pré-processamento.

Como os documentos coletados podem estar em diferentes formatos, o pré-processamento pode envolver a padronização dos mesmos para $11 \mathrm{~m}$ formato único ${ }^{3}$. Além disso, essa etapa é responsável por obter uma estrutura, tal qual uma tabela atributo-valor, que represente o conteúdo de uma coleção de documentos.

Com a representação de documentos na forma de atributo-valor, é possível aplicar as técnicas de extraçào de padrões. Para isso, na etapa de extração de conhecimento

\footnotetext{
${ }^{3}$ Neste trabalho. foi adotado como padrão os arquivos ASCII, em razão de serem aceitos por muitos métodos computacionais.
} 


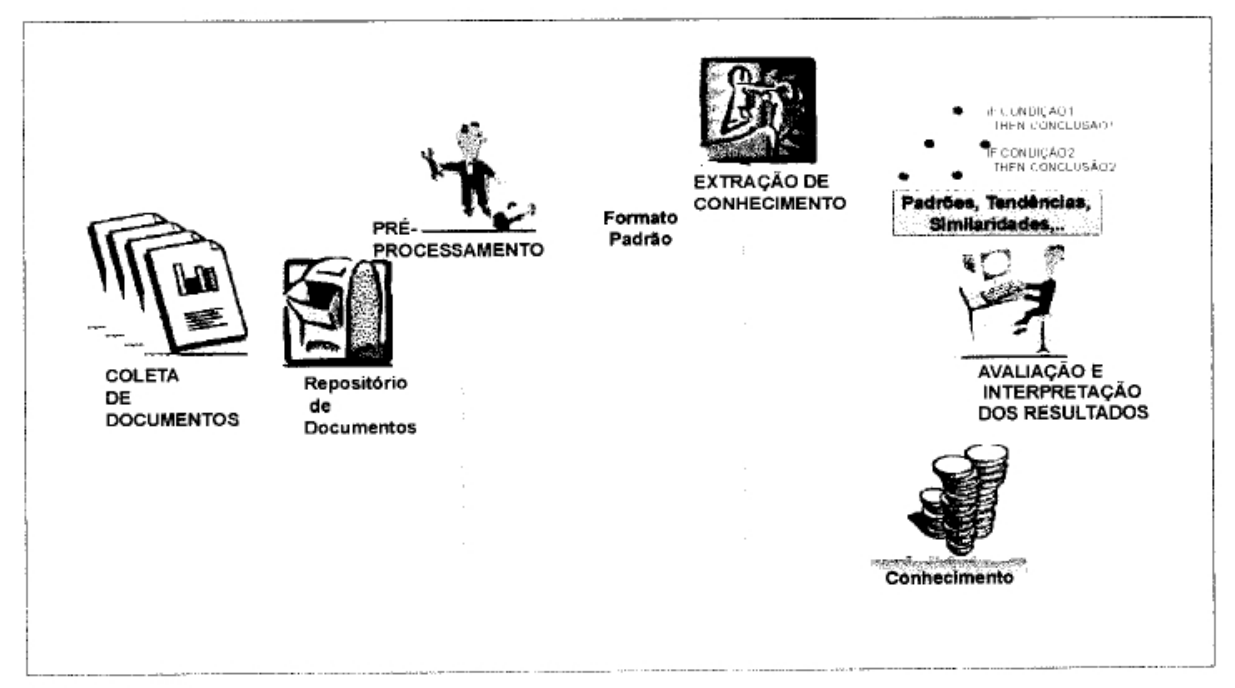

Figura 2.1: Etapas do processo Text Mining

pode ser feita a utilização de sistemas de aprendizado com a finalidade de encontrar padrões/tendências/similaridades de acordo com o objetivo e requisitos do usuário e/ou domínio da aplicação.

Na etapa de Avaliação e Interpretação dos Resultados, assim como no processo DM, os padrões encontrados podem ser analisados junto ao usuário final, ao especialista do domínio e ao analista de dados, que cumprem diferentes atividades importantes e não são necessariamente pessoas distintas. Essa avaliação é necessária, pois a partir da mesma pode ser constatado se o objetivo da aplicação foi alcançado, ou em caso contrário, pode ser realizada uma investigação de quais partes do processo colaboraram para um resultado não satisfatório.

Mediante algumas circunstâncias, como na obtenção de um resultado pouco significativo ao usuário, pode ser necessário que o processo seja refeito adequando-se algumas de suas etapas, seja para contar com uma gama mais informativa de documentos, on mesmo com alguma estratégia que possa melhorar o desempenho do processo. E por essa razão, o processo pode contar com algumas itcrações, como mostrado na Figura 2.1.

Nas seções subseqüentes, cada uma dessas etapas será abordada com mais detalhes. 


\subsection{Coleta de Documentos}

Na etapa de coleta de documentos. i almejada a recuperação de documentos com des(rições textuais que sejam relevantes ao domínio e aplicação do conhecimento a ser extraído. Mediante esse objetivo. podem ser consideradas diversas fontes. tais como. livros (cujas páginas possuem cópias eletrônicas on pelo uso de um scanner), e documentos provenientes da Web

A Web é um dos principais meios para disponibilizar e acessar uma grande gama de documentos. Para facilitar o acesso a esses. muitas ferramentas de apoio têm sido construidas, geralmente fazendo uso de diversas técnicas de RI. A busca de documentos nesse meio pode ser realizada usando cinco abordagens diferentes: Robotic Internet Search Engines. Mega-Indexes. Simultaneous Mega-Indexes. Subject Directories e Robotic Specialized Search Engines (Peterson, 1997).

1. ()s Robotic Internet Search Engines usam uma arquitetura Web robô. também chamado de spider. Web wanderers ou Web worms (Koster. 1997), e percorrem todo o domínio da WWW enviando páginas novas on adaptadas ao servidor a que eles estão indexados (Baeza-Yates, 1998).

Procedendo dessa forma, esses search engines indexam toda a WWW como um completo banco de dados de textos. A recuperaçăo de um número significativo de documentos da WWW. geralmente. é dada por meio da coincidência entre as palavras da consulta e as palavras das páginas WWW indexadas (Weiss, 1996).

Dentro dessa categoria. fazem parte os seguintes sistemas de busca: Altavista ${ }^{4}$, Excite $^{5}$. Lycos ${ }^{6}$. The Open I'ext Index ${ }^{7}$, InfoSeek Guide ${ }^{8}$. InfoSeek Ultra ${ }^{9}$, WebCrawler $^{10}$, ALIWEB ${ }^{11}$. HotBot ${ }^{12}$. entre outros.

\footnotetext{
${ }^{4}$ http://www.altavista.com

${ }^{5}$ http://www.excite.com

${ }^{6}$ http://www.lycos.com

'http://index.opentext net

${ }^{x}$ http://guide.infoseek.com

${ }^{9}$ http://ultra.infoseek.com

${ }^{10}$ http://webcrawler.com

${ }^{11}$ http://aliweb.emnet.co.uk

${ }^{12}$ http://www.hotbot.com
} 
2. A abordagem Mega-Indexes é caracterizada por não possuir sen próprio banco de dados. Ao invés disso. mantém links para os Robotic Search Engines. De acordo com esse conceito. páginas pessoais com indicação de linkis para sistemas de busca podem ser consideradas ım Mega-Indexes. Além dessas páginas. alguns sistemas de busca que podem ser considerados Mega-Indexes sào: Galaxy ${ }^{13}$ e Magellan ${ }^{14}$.

3. Os Simultaneous Mega-Indexes fazem uso de diversos Robotic Search Engines paralelamente. que colaboram para apresentar um pacote correspondente a um resultado unificado. Como exemplo dessa abordagem, pode ser citado o buscador MetaCrawler ${ }^{15}$.

4. Os Subject Directories. também chamados de catálogos. mantém a indexação das páginas de acordo com uma organização conceitual. que é mantida geralmente de forma manual. A arquitetura de diretórios pode ser vista como uma árvore de taxonomias hierárquicas. que classifica o conhecimento humano. O exemplo mais conhecido para essa categoria é o Yahoo! ${ }^{16}$.

5. Os Robotic Specialized Search Engines são Robotic Search Engines que cobrem uma pequena ou especializada porção da Web, que é o caso de listas de discussão, Yellow Pages, White Pages, etc.

Na realidade. essas cinco abordagens podem ser. de forma geral. classificadas em apenas dois grandes grupos: os search engines (tais como Robotic Search Engines e suas variaçoos: Mega-Indexes, Simultaneous Mega-Indexes a Robotic Specialized Search Engines) e os WWW directories (Subject Directories).

() principal problema relacionado aos search engines é a manutenção de páginas novas e modificadas, pois em função da natureza altamente dinâmica da Web os links de comunicação dos servidores de páginas podem se tornar saturados. Já a principal desvantagem dos WWW directories está relacionada ao processo de classificar as páginas na hierarquia, que freqüentemente é realizada por um número limitado de pessoas, e por

\footnotetext{
13 http://www.galaxy.com

${ }^{14}$ http://www.mokinlex:com/magellan/

${ }^{15}$ http://www.metacrawler.com/index.html

${ }^{16}$ http://www. vahoo.com
} 
esse motivo nào consegnem classificar todas as páginas Web. cujo volume de documentos tem crescido muito (Baeza-Yates. 1998). Problemas como esises podem contribuir para a busca resultar em uma grande lista de páginas que muitas vezes não são do interesse do usuário.

Para tornar as buscas mais eficientes. algumas técnicas de outras áreas também têm sido empregadas. como as de PLN e Aprendizado de Máquina (AM). As técnicas de Aprendizado de Máquina têm sido usadas. sobretudo. para prover buscas inteligentes através do mapeamento do perfil do interesse do usuário. Como exemplo, pode-se citar o Web Watcher (Joachims et al.. 1997), que acompanha o nssuário página a página sugerindo hyperlinks apropriados e aprende pelas experiências passadas para melhorar os conselhos a serem dados.

Embora o uso da combinação de técnicas de AM e de RI para determinação de padrões do perfil do usıário seja bastante relevante e interessante para melhorar a coleta de documentos, esse assunto não faz parte do foco deste trabalho, portanto não é detalhado.

Fazendo uso de alguma ferramenta de suporte à recuperaçăo de documentos, a primeira etapa do processo Text Mining pode ser então cumprida. Diante disso, devese dar início a segunda etapa do processo, na qual os documentos recuperados são préprocessados para gerar a possível representação a ser utilizada pelos algoritmos de extração de conhecimento.

\subsection{Pré-processamento de Textos}

Como mencionado, a etapa de pré-processamento é responsável por converter os textos em uma representação atributo-valor que possa ser manipulada pelos métodos de extração de conhecimento. Tal representação é geralmente caracterizada por uma tabela semelhante à apresentada pela Tabela 2.1 .

A obtenção de tal representação pode ser feita através da realização de algumas tarefas como identificação dos atributos, atribuição de pesos e redução da representação. como mostrado na Figura 2.2.

Existem diferentes abordagens para determinar os termos e os pesos que estarão 


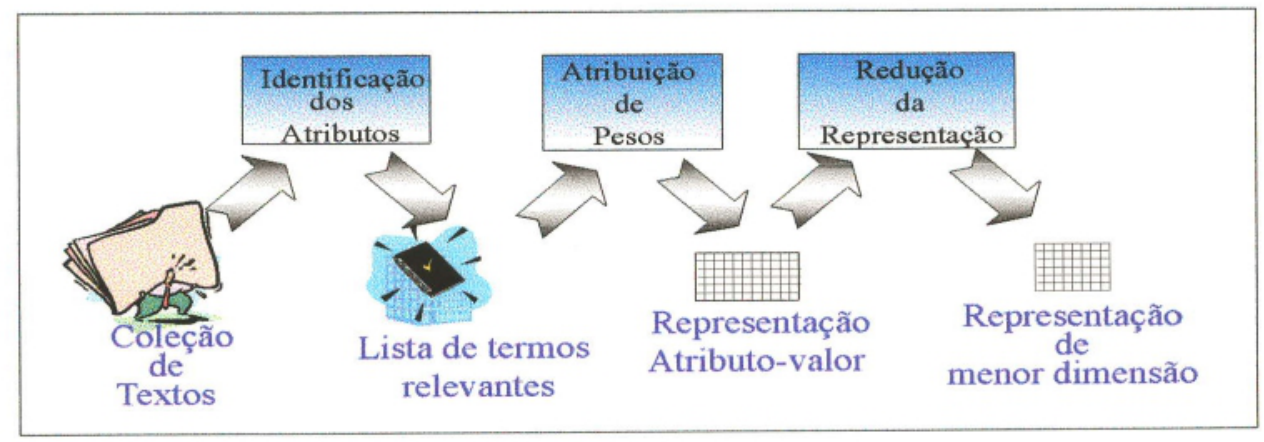

Figura 2.2: Algumas atividades realizadas no pré-processamento de texto

presentes na representação. Freqüentemente as operações realizadas para a escolha dos termos são:

- Substituição de marcadores HTML por símbolos especiais, quando aplicável.

- Reconhecimento de palavras individuais ou compostas que estejam presentes no texto.

- Uso de uma lista de palavras a serem desconsideradas, como artigos, preposições, etc. Essa lista é conhecida como stop list ou lista de stopwords.

- Remoção do sufixo das palavras para mapeá-las na sua forma canônica.

- Organização do valor semântico das palavras por meio do uso de dicionários eletrônicos e mapas de sinônimos, como thesaurus.

As estratégias empregadas na identificação dos atributos, como mostrado na Figura 2.2 são, em geral, dependentes do idioma. Isso porque as palavras que compõem a stop list e os métodos para remover os sufixos dos termos podem variar de acordo com o idioma dos textos.

Para completar a representação dos textos, além das estratégias para identificação dos atributos, deve-se escolher quais serão as abordagens utilizadas para o cálculo do valor do peso de cada atributo, que geralmente pode ser booleano ou numérico (Weiss and Indurkhya, 1997). Os valores booleanos são empregados para indicar a presença ou 
ausencia do termo em cada documento. enquanto que os numéricos são calculados por meio de medidas estatísticas baseadas na freqüência dos termos nos documentos.

Em alguns casos, a representação originalmente obtida possui muitos atributos tornando sua dimensão relativamente grande a ponto de exceder a capacidade de processamento dos algoritmos usados para extração de conhecimento. Desta forma, são empregados métodos para redução da dimensăo. que podem ser classificados em seleção de $u$ subconjunto de atributos e indução construtiva.

Os métodos de seleção de $11 \mathrm{~m}$ subconjunto de atributos são caracterizados por selecionar. a partir da representação original. um subconjunto de atributos que leve à obtenção de uma representação menor e que possa ter um valor preditivo o mais próximo possível da representação original (John et al.. 1994). Já os mótodos de indução construtiva são caracterizados por combinar alguns dos atributos originais almejando a obtenção de novos atribıtos mais efetivos (Michalski. 1978; Lee. 2000). É importante notar que os métodos de indução construtiva inicialmente não promovem a redução da representação. Porém. em alguns experimentos não são considerados os atributos que foram combinados e resultaram na construção de outros novos para permitir a redução.

Em virtude do foco desse trabalho ser a investigação sobre os métodos envolvidos no pré-processamento de texto, maiores detalhes sobre as abordagens de identificação dos termos e atribuição de pesos, bem como sobre os esquemas de redução da dimensão, são apresentados no Capítulo 3.

\subsection{Extração de Conhecimento}

A descoberta de conhecimento na mineração de texto pode ser interpretada como a classificação automática de documentos, ou a descoberta de associações entre textos e autores, ou ainda a determinação de tendências, entre outras atividades. Essas tarefas podem ser realizadas por meio de diversos algoritmos, sendo que grande parte deles também são utilizados em Data Mining.

Em DM. os algoritmos freqüentemente empregados são de Aprendizado de Máquina. Nesta sẹcão são tratados alguns dos paradigmas dessáárea em que podem ser classificados 
alguns dos métodos mais utilizados na realizaçào do Text. Mining. Além dos algoritmos de AM, como muitas das aplicações da extração de conhecimento em textos são dirigidas às tarefas da área de Recuperação de Informação, algoritmos clássicos, como Rochio (Hull, 1994) e mais recentemente Support Vertor Machine (SVM) (Vapnik. 1995), vêm sendo utilizados. Esses algoritmos também são sucintamente descritos nas próxima sub-seções.

\subsubsection{Algoritmos de Aprendizado de Máquina}

Os algoritmos de Aprendizado de Máquina podem ser classificados de acordo com cinco paradigmas: Estatístico. Simbólico. Instance-Based. Conexionista e Genético. A seguir é brevemente abordada a utilização desses paradigmas para Text Mining.

\section{Paradigma Estatístico}

Os métodos estatísticos que vêm sendo empregados nas tarefas de Text Mining, geralment.e. assumem que os atributos possam apresentar valores contínuos ou ordinais.

Em geral, esses métodos procuram através de medicias estatísticas os melhores valores para os parâmetros, de um modelo assumido, que sejam apropriados para fornecer a melhor aproximação sobre o conjunto de dados. Por exemplo, un classificador linear assume que as classes podem ser expressas como combinação linear dos atributos, e dessa forma procura por uma combinação linear particular que forneça a melhor aproximação sobre o conjunto de dados.

O classificador Naive Bayes (Good. 1965) é um dos métodos estatísticos mais conhecidos. Em Text Mining, esse classificador é construído a partir do conjunto de treinamento Train $=d_{1}, d_{2}, \ldots . d_{n}$ e pode estimar a probabilidade de um documento $d_{j}$, em que $j=(1,2, \ldots, \mathrm{n})$, pertencer a cada classe $c_{i}$, presente na coleção $\mathrm{D}$ de documentos, dado os valores de seus atributos on termos (Joachims, 1997). A estimativa da probabilidade é baseada no teorema de Bayes, como na Equação 2.1.

$$
P\left(c_{i} \mid d_{j}\right)=\frac{P\left(c_{i}\right) P\left(d_{j} \mid c_{i}\right)}{P\left(d_{j}\right)}
$$

O termo $P\left(d_{j}\right)$ representa a probabilidade que um documento, aleatoriamente escolhido. seja representado por $d_{j}$, e $P\left(c_{i}\right)$ é a probabilidade de que um documento pertença 
à categoria $c_{;}$

A parte Naive desse modelo é assumir que dada uma classe os atributos são condicionalmente independentes. Embora essa independència condicional não seja geralmente verdadeira. quando se trata das palavras que aparecem em um documento, o classificador Naive Bayes tem sido muito ntilizado em tarefas relacionadas à categorização de documentos (Aas and Eikvil. 1999; Li and Jain. 1998a).

\section{Paradigma Simbólico}

Os métodos de indução probabilísticos são geralmente muito efetivos, porém são considerados difíceis de serem interpretados por humanos, uma vez que possuem natureza essencialmente quantitativa. P'or esssa razão, em alguns casos pode ser preferido utilizar algoritmos simbólicos (Sebastianii. 1999).

Os métodos simbólicos buscam aprender um conceito através da análise de exemplos e contra-exemplos. e o conhecimento obtido é representado por alguma expressão lógica, rede semântica. regras de prodıção ou árvores de decisão (Mitchell. 1996). Embora todas sejam muito importantes. exemplos de aplicaçóes contando com as duas últimas representações são sucintamente descritos, em virtude de serem freqüentemente usadas em tarefas de processamento de texto.

Um modelo gerado por um classificador que utiliza árvore de decisão, voltado para textos. consiste de uma árvore em que os nós internos são rotulados com termos. as aresta que partem dos nós são rotulados com testes sobre o peso que o termo tem na representação de um documento $d_{j}$, e os nós folhas são rotulados com a categoria/classe (Sebastiani, 1999). Dessa forma, um documento $d_{j}$ é comparado com a árvore para determinar quanto o mesmo é ou não relevante ao usuário.

Para tarefa de categorizaçāo de textos, há diversos trabalhos utilizando diferentes algoritmos baseados em árvores de decisăo. Alguns dos algoritmos mais conhecidos e utilizados são o ID3(Quinlan. 1990), o C4.5 (Quinlan, 1993), entre outros.

No caso de um classificador construído com base em um método que utiliza regras de produção, o mesmo consiste de uma regra na forma normal disjuntiva (Disjunctive Normal Form - DNF). isto é, uma conjunção de fórmulas condicionais chamadas cláusulas. As premissas das cláusulas representam a presença ou ausência dos termos no documento 
teste, enquanto a "cabeça" da cláusula denota a decisào quanto a classificar ou não um documento $d_{j}$ lla classe $c_{j}$.

Diversos trabalhos vem utilizando indutores que fazem uso de regras de decisão, para categorização de textos. Alguns dessess são: CHARADE (Moulinier and Ganascia, 1996). DL-ESC (Li and Yamanishi. 1999). RIPPER (Cohen and Hirsch. 1998: Cohen and Singer. 1999) e SWAP1 (Apté et al.. 1994).

Uma importante ressalva a ser feita ć que as regras de produção também podem ser construídas com base na árvore de decisão. Os indutores que utilizam regras de produção geralmente tentam selecionar. a partir de $11 \mathrm{~m}$ conjunto de regras, as melhores de acordo com $11 \mathrm{~m}$ critério de minimalidade (Sebastiani. 1999).

\section{Paradigma Instance-Based}

Os sistemas instance-based classificam casos nunca vistos de acordo com a classificação de casos similares conhecidos (Quinlan, 1993). Para isso armazenam em memória a classificaçào de alguns casos e, quando um novo é apresentado, sao procurados os similares a partir dos quais será induzida a classificação.

Um método que utiliza esse paradigma é o k-Nearest Neighbours (KNN) (Mitchell. 1996). que classifica um novo caso de acordo com a classificação dos $k$ exemplos mais similares. Na identificação dos $k$ elementos, a similaridade pode ser determinada através do 1 so de medidas como coseno, distância Euclidiana. entre outras.

No caso da categorização de texto. para identificar o quanto $11 \mathrm{~m}$ documento novo deve ser classificado em alguma classe $c_{i}$, deve-se calcular o quanto os $k$ documentos mais similares também podem ser classificados sobre nessa classe. Se a resposta for positiva para um número grande o suficiente desse $k$, então uma decisão de categorização positiva é tomada. caso contrário, uma decisão negativa é assumida. Resultados dessa abordagem podem ser encontrados em (Yang, 1999).

\section{Paradigma Conexionista}

() conexionismo descreve a área de estudo que envolve a utilização de algoritmos que se baseiam numa metáfora biológica do sistema nervoso, que é constituído por unidades de processamento altamente interconectadas. 
Inspiradas no modelo biológico do sistema nervoso. uma rede neural é um modelo matemático que consiste de um conjunto de midades de entrada. intermediárias e de saida. que são interconectadas por arestas rotıladas com pesos para representar a relação de dependência condicional. As unidades de entrada que a constituem representam os atributos. enquanto que as unidades de saída representam a classe on classes de interesse (Braga et al.. 2000).

Para categorizar $u m$ novo documento. são apresentados os valores dos atributos ìs suas respectivas unidades de entrada. A ativação dessas unidades é propagada através da rede para as camadas conectadas subsequientemente até alcançar as unidades de saída. Alcançando essa última camada da rede. os valores das unidades de saída ativas são combinados para determinar a classificação. Resultados sobre o uso de redes neurais em Text Mining e categorização de textos podem ser encontrados em (Lagus, 2000).

\section{Paradigma Genético}

Um algoritmo genético consiste de uma população de elementos que competem para fazer a predição. no qual são descartados os que tiverem um desempenho fraco, enquanto que os mais fortes evoluem prodızindo variaçōes entre si. Estas variações são realizadas através de operadores como Reprodução. Cruzamento. Mutação e Inversão (Holland, 1986).

A escolha dos elementos preditivos mais fortes para gerar indutores mais eficientes também tem sido explorada em tarefas de suporte a processos de tomada de decisão e que envolvem manipulação de texto. Um exemplo é o trabalho descrito em (Thomas and Sycara. 1999) em que são combinados algoritmos para classificação de texto e algoritmos genéticos. com a finalidade de prover uma aplicação para predição sobre dados financeiros.

\subsubsection{Outros Algoritmos Comumente Utilizados}

Dentre os métodos utilizados em Text Mining, além daqueles classificados de acordo com os paradigmas de Aprendizado de Máquina, podem ser citados também o SVM e o Rochio, descritos a seguir. 


\section{Support Vector Machines}

SVM é uma abordagem relativamente nova introduzida por Vapnik (Vapnik, 1995) para reconhecimento de padrões em problemas envolvendo duas classes. Ele é baseado no princípio do Structural Risk Minimization, voltado para minimizar a probabilidade de falha na classificação de um exemplo aleatoriamente escolhido.

O SVM é um método definido sobre um espaço vetorial onde o problema é encontrar uma superfície de decisão que melhor separa os dados em duas classes. Para ilustrar o conceito da superfície que melhor separa os dados, considere a ilustração da Figura 2.3 baseada na figura ilustrada em (Yang and Liu, 1999). Para simplificar, nessa figura está sendo mostrado um espaço bi-dimensional com dados que são linearmente separáveis.

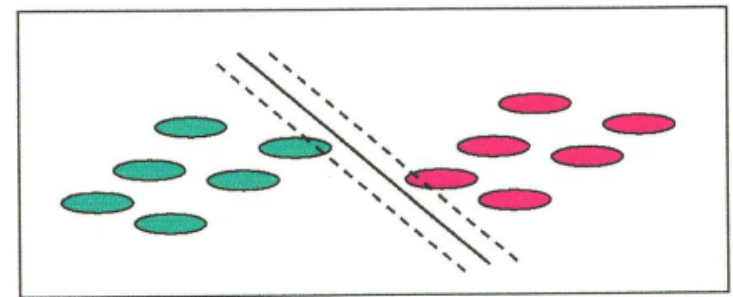

Figura 2.3: Ilustração das superfícies que separam duas classes com SVM

A linha sólida na Figura 2.3 separa corretamente duas possíveis superfícies de decisão. As linhas tracejadas paralelas à linha sólida mostram quanto a superfície de decisão pode ser movida sem causar erro de classificação. A distância entre cada conjunto de linhas tracejadas paralelas é chamada de "margem"e o problema envolvido no SVM é achar a superfície de decisão que maximize a margem entre os dados no conjunto de treinamento.

Embora tenha sido ilustrado um problema envolvendo um espaço bi-dimensional, a idéia pode ser facilmente estendida e generalizada para um espaço de alta dimensão. No caso de um problema envolvendo a categorização de textos, o SVM é utilizado sobre uma representação atributo-valor obtida na etapa de pré-processamento. Alguns resultados sobre sua aplicação em textos podem ser encontrados em (Yang and Liu, 1999). 


\section{Rochio}

() algoritmo Rochio é um método clássico. que tem suas raízes na área de RI. e é freqüentemente utilizado para classificação de documentos (Joachims. 1997). Nesse método, um vetor protótipo é construído para cada classe $c_{i}$ e $u m$ documento $d_{j}$ é classificado por meio do cáleulo da distância do vetor que representa $d_{j}$ e cada vetor protótipo.

O vetor protótipo de cada classe ci é constrúdo a partir da média de todos os vetores do conjunto de treinamento que pertencem a classe $c_{i}$. Já o cálculo da distância pode ser realizado pelo produto vetorial on usando a medida de similaridade de Jaccard, por exemplo (Aas and Eikvil. 1999). Muitos trabalhos tèm ntilizado Rochio como objeto de pesquisa on como base de referência (Joachims. 1997).

É importante ressaltar que não existe $11 \mathrm{~m}$ algoritmo bom que possa ser usado para todas as tarefas de extração de conhecimento e todos os domínios. Assim faz se necessário analisar as características do problema a ser tratado e as características de cada método de modo a ser inferido qual pode prover melhor resultado.

Em alguns casos. os padrões obtidos na etapa de extração de conhecimento podem ser pouco satisfatórios para a aplicação do usuário final. seja porque o conhecimento extraído é de difícil compreensão, pouco útil. ou por outras razões. Para que fatos como esses sejam identificados e possivelmente corrigidos. os resultados alcançados pelos métodos de extração de conhecimento são avaliados e interpretados na próxima etapa do processo Text Mining.

\subsection{Avaliação e Interpretação do Conhecimento}

Assim como no processo de DM, os resultados obtidos durante a etapa de extração de conhecimento ainda não devem ser imediatamente utilizados nas aplicações de interesse do usuário final. É necessário que se faça a verificação dos padrões neles contidos. Essa verificação pode ser realizada pelos participantes do processo (usuário final, especialista do domínio e analista de dados) e visa determinar se os resultados obtidos condizem com o objetivo a ser alcançado por meio do processo Text Mining.

A questão que diz respeito à aplicabilidade não é uma tarefa fácil de ser definida, 
ıma vez que está diretamente relacionada com a noção de quão compreensível. válido. útil e novo é o conhecimento. Em muitos casos, um modelo é considerado compreensível de acordo com a sua simplicidade. porém a análise do que deve ser considerado um modelo complexo on simples. também depende de muitos fatores e contextos.

Com intuito de tornar mais simples. ítil. e até mesmo de facilitar a avaliação e interpretação dos padrões extraídos. muitas abordagens estatísticas e ferramentas de visualizaçào são usadas para identificar e remover padróes redundantes. e pouco ou sem utilidade para a aplicação final.

O fator chave desta etapa, além dessas técnicas e ferramentas de apoio. é a interação de todos os participantes do processo, uma vez que esta pode detectar se houve erros em alguma parte do processo. on mesmo se a aplicação de outros métodos poderia fornecer melhores resultados. Se fatos como estes forem constatados, algumas das etapas anteriores devem ser refeitas. como mostrado na Figura 2.1 (ilustrada na página 9), caso contrário os resultados são validados e podem ser utilizados pelo ısuário final em sua aplicação.

Em AM. a avaliação de um modelo de conhecimento é comumente realizada sobre conjuntos de exemplos. chamados de conjuntos de teste. Os métodos usados geralmente são hold-out e cross-1alidation. Em ambos os métodos os conjuntos de testes são utilizados para estimar a qualidade média do modelo gerado, em que testes são sucessivamente repetidos (por exemplo: 5. 10 vezes). No hold-out $1 \mathrm{~m}$ conjunto de teste de tamanho pré-definido é randomicamente escolhido, e o restante dos exemplos do conjunto é usado para treinamento do modelo. No método cross-validation o conjunto de dados é dividido em tantos conjuntos quanto o número de realizações da fase de teste. e em cada iteração um deles é selecionado como de teste e os demais formam o conjunto de treinamento.

Nas tarefas de classificação que envolvem classes de valores discretos, a maioria das estimativas de qualidade pode ser calculada por meio de uma matriz de confusão gerada a partir dos resultados da classificação. Na matriz de confusão, são confrontados os valores reais dos exemplos com os preditos pelo modelo. Na Tabela 2.2 é mostrado um modelo de classificaçăo bi-valorada. na qual tp é o número de exemplos que pertencem a classe positiva e que foram classificados como positivos (positivo verdadeiro), fp é o número de exemplos da classe negativa que foram classificados como positivos (falso positivos), $f n$ é 
o número de exemplos positivos que foram classificados como negativos (falso negativo) e tn é o número de exemplos negativos que foram classificados corretamente (negativo verdadeiro).

\begin{tabular}{|c|c|c|}
\hline & Predito como positivo & Predito como negativo \\
\hline \hline Exemplos positivos & $t p$ & $f p$ \\
\hline Exemplos negativos & $f n$ & $t n$ \\
\hline
\end{tabular}

Tabela 2.2: Matriz de confusão para uma tarefa com classe bi-valorada.

Para avaliar a efetividade de $u$ m classificador. em Text Mining, são geralmente empregadas medidas utilizadas em RI. como a Precisão. Recall ${ }^{17}$. e Accuracy que se baseiam nos valores da matriz de confusão.

\section{Precisão, Recall e Accuracy}

A precisão de um modelo é a porção de exemplos positivos que foram classificados corretamente. No caso de um problema de classe bi-valorada, usando a informação da matriz de confusāo, a Precisão pode ser calculada pela Equação 2.2.

$$
\text { Precisão }=\left(\frac{t p}{t p+f p}\right)
$$

A medida Recall é definida como a porção classificada corretamente como exemplos positivos. Utilizando a informação da matriz de confusão, essa medida pode ser estimada por meio da Equação 2.3.

$$
\text { Recall }=\left(\frac{t p}{t p+f n}\right)
$$

A medida Accuracy denota a proporção de predições corretas. com base na Equação 2.4

$$
\text { Accuracy }=\left(\frac{t p+t n}{t p+f p+t n+f n}\right)
$$

\footnotetext{
${ }^{17}$ Na iiteratura. a medida Recall. também é referenciada como medida de cobertura.
} 
As medidas de Precisào. Recall e Accuracy são bastante usadas. principalmente pela simplicidade. Porém. existem situações em que 1 m classificador pode predizer apenas uma classe para qualquer exemplo e assim o valor dessas medidas podem se tornar altos. cmbora năo representem uma boa estimativa. Para contornar esse tipo de problema, em RI. é utilizada a medida F-measuri, que também é bastante usada em Text Mining.

\section{F-measuri}

F-measuri é uma medida que combina a Precisão e Recall. mas adiciona um parâmetro para indicar uma importância relativa. Como pode ser observado na Equação 2.5, o parâmetro que simboliza essa importância é denominado de B.

$$
F_{B}\left(M . c_{i}\right)=\frac{\left(1+B^{2}\right) \times \operatorname{Precisão}\left(M . c_{i}\right) \times \operatorname{Recall}\left(M . c_{i}\right)}{B^{2} \times \operatorname{Precisão}\left(M, c_{i}\right)+\operatorname{Recall}\left(M, c_{i}\right)}
$$

O paràmetro $B$ pode ter valores entre () e infinito é é definido pelo usuário. Quando o valor 0 for assumido. F assumirá apenas o valor da medida Precisão, e se o valor for igual a infinito essa medida assumirá o valor de Recall. Geralmente. são usados valores como 0.5. que significa que o valor da precisão tem mais relevância que recall; 1,0 , que atribui a mesma relevância para precisão e recall; ou 2.0, que faz com que Recall tenha relevância maior que precisão. Levando-se em consideração a matriz de confusão, para um problema com classe bi-valorada a medida $F$ pode ser estimada pela Equação 2.6.

$$
\frac{\left(1+B^{2}\right) \times t p}{\left(1+B^{2} t p+f p+B^{2} f n\right)}
$$

Como pode ser observado pela descrição das medidas e por todos os conceitos abordados até o momento neste capítulo. o processo de Text Mining está voltado principalmente para aplicações de classificação de textos. Recentemente. atividades relacionadas à inteligência competitiva também têm sido almejadas. Isso vem comprovar que a importancia do processo vêm aumentando como um todo. De fato, em virtude dessa importância. muitas ferramentas têm sido desenvolvidas para dar apoio à realização do processo de descoberta de conhecimento em textos. 


\subsection{Algumas Ferramentas de Apoio ao Text Mining}

A necessidade de extraçào automática de conhecimento útil de grandes quantidades de dados e textos tem levado ao desenvolvimento de muitas ferramentas de análise automática. Muitas dessas ferramentas tem sido usadas em ambientes do pesquisas, mas grande parte das aplicaçōes săo voltadas para fins comerciais.

Nessa seção são descritas algumas das ferramentas comumentes citadas e utilizadas na literatura consultada. Muitass dessas dão suporte a realização de parte do processo Text Mining, e podem contar com diferentes abordagens e métodos para atingir os objetivos propostos. como pode ser observado segundo as descriçoes que se seguem.

- InQuizit ${ }^{T M}$ (Inquisit, 2001) é um search engine que utiliza Processamento de Língua Natural para possibilitar que as consultas sejam representadas em língua natural e que os termos sejam interpretados, a fim de que se possa realizar uma busca de acordo com seus significados.

Para tanto, ele identifica a estrutura das sentenças contidas na consulta e nos textos a serem pesquisados, por meio de um parser. Associado a isso, com auxílio de um analisador léxico, são analisados os significados dos termos da consulta e textos. Por ser $11 \mathrm{~m}$ sistema construído utilizando processamento lingüístico. ele é dependente de idioma e está atıalmente disponível somente para o tratamento de textos em inglês.

- FOCI (Flexible Organizer for Competitive Intelligence) (FOCI. 2001) é um software desenvolvido para apoiar processos de inteligência competitiva. fornecendo um meio entre a busca de resultados e informaçós competitivas organizadas através de uma plataforma que suporta as atividades chaves, como. agrupamento, organização e disseminação de informaçóes competitivas. Ele se caracteriza ainda por ser $1 \mathrm{~m}$ software projetado para textos em inglês e chinês, e que pode ser estendido para aceitar o idioma japonês.

Para prover resultados satisfatórios, a ferramenta recupera informações de forma integrada, a partir de múltiplos search engines. Além disso. incorpora métodos de clustering, que permitem ao usuário definir e personalisar a organização da informação dos clusters de acordo com suas necessidades e preferências. 
- Scatter/Gatter (Cutting et al.. 1992) é um sistema para busca de documentos baseado em clustering. Através de uma abordagem híbrida. combina a eficiência do algoritmo $\mathrm{K}$-means e a qualidade dos resultados providos pelo algoritmo de clustering hierárquico. para oferecer maior precisão na recuperaçăo e classificação dos documentos disponiveis no idioma ingles. Para disponibilizar os resultados, a ferramenta possibilita ainda representá-los por rosumos on TileBars (Hearst, 1995). () paradigma Tile Bars permite aos usuários visualizar o tamanho relativo dos documentos recuperados, a freqüencia relativa dos termos presentes na consulta, e suas propriedades em relação aos documentos.

- TextTiling (Hearst. 1994) é um algoritmo que particiona o texto em segmentos (que representam seus possíveis subtópicos. Os limites de um subtópico é definido de acordo com a repetição de padrões, uma vez que é considerado que os termos que descrevem um subtópico co-ocorrem localmente e que a passagem para um novo subtópico pode ser sinalizada pelo final da co-ocorrência de um conjunto de termos e o começo da co-ocorrência de $u$ m conjunto diferente de termos. Sua funcionalidade tem sido usada para melhorar o processo de classificação de textos, como por exemplo na ferramenta Scatter/Gather. Atualmente, o algoritmo está construído para manipulação de documentos em inglês.

- Intelligent Miner for Text(IBM, 1998), versão 2.3. constitui-se de um conjunto de quatro componentes principais: Text Analysis Tools. Text Search Engine, Web Crawler e NetQuestion Solution. que apresentam diferentes funcionalidades.

O componente Text Analysis Tools é constituído por ferramentas que podem ser aplicadas à realização de mineração de texto, como a Language Identification que identifica os idiomas presentes na entrada dada pelo usuário. Para designar quanto do texto está escrito em determinados idiomas, faz-se uso de dicionários para 16 idiomas e é permitido ao usuário estender uma língua já suportada pelo software ou adaptar o arquivo para incluir uma nova língua.

Outra ferramenta incorporada nesse componente é a Feature Extraction que reconhece automaticamente itens significantes no texto. como nomes, termos técnicos e 
abreviaturas. Ela pode ser útil para um pré-processamento de texto. uma vez que produz estatísticas para cada item do vocabulário presente no texto. e ainda associa os termos em sua forma canonica. Através dessa ferramenta. também é possível encontrar relaçós entre os termos. como a relação de nomes próprios com as respectivas profissoess. on abreviações e suas formas completas. É importante notar que todas as funcionalidades dessa ferramenta só estäo disponíveis para o inglês.

Além dessas funcionalidades. o componente possui uma ferramenta denominada Clustering que agrupa documentos similares. com base no conteúdo dos textos neles presentes. () agrupamento é realizado de duas formas: hierárquico on relacional binário. No método hierárquico, uma abordagem bottom up é usada, em que a cada passo da iteração do processo os clusters similares são agrupados hierarquicamente dois a dois. Já no binário relacional. $11 \mathrm{~m}$ método investiga os tópicos implícitos nos documentos e então estabelece as relações entre esses tópicos.

A ferramenta Classification/Categorization, incluída nesse componente, organiza os documentos em categorias pré-definidas pelo usuário. Htravés de um conjunto de treinamento, em que são dados exemplos de documentos pertencentes às categorias definidas. o classificador utilizado é treinado e $11 \mathrm{~m}$ modelo é gerado. O classificador, então, pode classificar novos documentos utilizando o modelo obtido. Faz uso da ferramenta de extração de atributos (Feature Extraction), para prover comparações entre os documentos de forma mais eficiente. Entretanto. como tal ferramenta só está disponível para o inglês, o processo de classificaçăo de documentos em outros idiomas é prejudicado. Além disso, vale ressaltar que na bibliografia disponível sobre a ferramenta. não há especificaçāo sobre o algoritmo ntilizado para categorizar os documentos.

Por último, a ferramenta Summarization que provê a extração de resumos dos documentos, selecionando as sentenças que farão parte do resumo com base na estrutura do mesmo e nos atributos/itens relevantes extraídos.

() componente Text Search Engine é baseado (m uma arquitetura cliente/servidor, que pode ser usado para buscar documentos. Através dele, pode-se realizar diversos 
tipos de busca. tais como: booleana. fuzzy. texto livre e híbrida. Também é possível fazer uso das ferramentas de mineraçăo para prover uma busca mais eficiente. como disponibilizar o resultado da busca en chusters e realizar o refinamento do processo de busca baseado nas consultas anteriores do usuário. No entanto. tais funções de mineração estão disponiveis apenas para documentos em inglês.

() componente Web Crawler é um robô que coleta páginas HTML para indexação. Ele pode ser personalizado para indicar quais links serăo buscados e seus resultados podem ser armazenados como objetos de dados no sistema de arquivo AIX/NT on ainda, como metadados no DB2 ${ }^{18}$. Permite ainda que a coleta de documentos seja feita de forma paralela e que os resultados possam ser combinados. Além disso. automaticamente monitora as mudanças ocorridas nas páginas de interesse do usuário.

Finalmente, o componente NetQuestion Solution é $11 \mathrm{~m}$ domínio multi-servidor baseado nos componentes Text Search Engine e Web Crawler. A sua função é auxiliar as aplicações de busca e coleta de documentos disponíveis em $1 \mathrm{~m}$ servidor de Web local.

- TextSmart(SPSS, 2001), versão 1.0. é uma ferramenta que faz análise de informações textuais dispostas na forma de questionários com perguntas e uma série de respostas. Por meio dessas informaçōes. o software indica as categorias presentes através da identificação de clusters.

Para processar as informações, o TextSmart utiliza as seguintes estratégias: stemming. lista de álias (onde termos relevantes estão relacionados a possíveis sinônimos), e remoção de palavras triviais, como preposições, para prover análise dos termos que possam colaborar para a construção de categorias significativas.

Todos esses recursos estão disponibilizados para o inglês. As listas de sinônimos e de palavras a serem removidas também são fornecidas apenas para esse idioma. Entretanto, a ferramenta possibilita que o usuário altere tais listas, ou crie e use a sua própria lista de sinônimos e de palavras irrelevantes. Quanto às características

\footnotetext{
${ }^{18}$ Banco de dados da IBM.
} 
para a mineração dos textos. referente à categorização automática. o sistema utiliza uma matriz de similaridade e cluster hierárquico e identifica as categorias utilizando informações sobre as frequiências dos termos.

- TextAnalyst (Froelich. 2000), versão 2.0. tem como principal objetivo auxiliar o 11suário a encontrar de forma mais rápida e eficaz os principais conceitos presentes em um documento orı uma coleção de documentos. Para isso. o Text.Analyst realiza automaticamente uma análise semântica dos textos com a qual torna-se possível montar uma estrutura de árvore contendo os principais conceitos encontrados e os relacionamentos entre eles. Através da rede semântica obtida, o usuário pode vir a navegar sobre seus nós e links. e visualizar em quais sentenças do texto original elas aparecem. Além disso, a ferramenta também permite a criação de resumos contendo as sentenças mais importantes do texto dado como ent rada. Caso o usuário esteja interessado, ainda, por algum termo on conceito específico do texto original, é possível realizar consultas convencionais ou em língua natural.

Para prover todas essas funçòes a ferramenta conta, ainda, com o uso de um dicionário, onde estão presentes as palavras a serem descartadas, as palavras que seriam interessantes para o usuário e por ele designadas, as palavras que representam os radicais de outras e assim possa ser realizado o processo de stemming, e uma lista de palavras com seeıs respectivos sinônimos. () dicionário está disponível para o inglês. contudo é permitido que o usuário o altere ou crie um novo para outros idiomas.

- $\boldsymbol{S} \boldsymbol{V} \boldsymbol{M}^{\text {ligth }}$ (Joachims, 2000) é uma implementação do algoritmo Support Vector Machines para o problema de reconhecimento de padrōes para classificação. Segundo seu desenvolvedor. o Prof. Thorsten Joachims, algumas propriedades do SVM que fazem dele excelente reconhecedor de padrões para texto, são: trabalham bem com espaço hiper-dimensional e de exemplos com muitos atributos. além disso, aceitam vetores esparsos. que é uma propriedade comum aos vetores de documentos. Essa ferramenta independe de idioma, uma vez que suas entradas correspondem às representações obtidas numa etapa de pré-processamento (externa à ferramenta) que serão 11tilizadas para treinamento e teste. 
- Kea (Witten et al. 1999) é uma ferramenta que prove a extraçào de palavraschave. Ela faz uso da análise léxica para identificar as palavras-chave candidatas c atribuir valores à mesmas. P'ara a construçào de um modelo que prediga quais palavras-chave seräo selecionadass a ferramenta utiliza Naive Baves.

Uma síntese sobre as ferramentas abordadas é mostrada na Tabela 2.3. Na segunda coluna é descrita a organização on empresa responsável pelo software. Na terceira coluna são identificadas as etapas do processo Text Mining (mostradas na Figura 2.1, 9) que podem ser apoiadas pela ferramenta. As etapas de coleta. pré-processamneto, descoberta de conhecimento e avaliação estão numeradas de 1 a 4 , respectivamente. Na quarta coluna, está designado se a ferramenta possui demo (S) ou não $(\mathrm{N})$.

\begin{tabular}{|c|c|c|c|}
\hline Ferramenta & Comp/Org & Suporte/Etapa & Demo \\
\hline Inquizit $^{T M}$ & $\mathrm{IQ}$ & 1 & $\mathrm{~N}$ \\
\hline Scatter/Gather & Xerox PARC & 1 & $\mathrm{~N}$ \\
\hline Text Tiling & UC Berkeley & 2 & $\mathrm{~S}$ \\
\hline FOCI & KRDL & 1.3 & $\mathrm{~N}$ \\
\hline Inteligent Miner for Text & IBM & 1.2 .3 .4 & $\mathrm{~S}$ \\
\hline Text Smart & SPSS & 2.3 & $\mathrm{~N}$ \\
\hline Text Analyst & Megaputer & 2.3 & $\mathrm{~S}$ \\
\hline $\mathrm{SVM}^{\text {ligth }}$ & -- & 3.4 & $\mathrm{~S}$ \\
\hline Kea & - & 2.3 & $\mathrm{~S}$ \\
\hline
\end{tabular}

Tabela 2.3: Informações genéricas sobre algumas ferramentas de apoio a Text Mining.

\subsection{Considerações Finais}

Neste capítulo foram abordados alguns aspectos pertinentes às principais etapas do processo Text Mining. Como mencionado, para realização desse processo, conta-se com a utilização de métodos de diversas áreas, como Recuperação de Informação, Processamento de Língua Natural e Aprendizado de Máquina.

Os métodos de Processamento de Língua Natural podem ser usados para preparar os dados de forma a permitir que se obtenha uma representação mais consistente 
em relação ao conteúdo dos documentos. Enquanto que os métodos de Aprendizado de Máquina são geralmente empregados para a descoberta de padrões nos textos.

Por ser a categorização de textos uma das principais atividades em Text Mining, freqüentemente são empregadas diversas estratégias da área de RI na maioria, senão em todas. das etapas do processo. A importância dessa tarefa também é sentida quando se investigam as diversas ferramentas existentes. como algumas que foram reportadas neste trabalho.

Como pode ser observado, muitas das ferramentas não dão suporte à realização de todo o processo, mas parte dele. A ferramenta Intelligent Miner for Text da IBM é ıma das mais completas. Utilizando a versão 2.3 para investigação pôde-se concluir que o reconhecimento do idioma inglês é muito satisfatório, enquanto que considerando frases em português e espanhol não foi conseguido um bom resultado. chegando por volta de $20 \% 19$. Utilizando textos com mais frases, a porcentagem de acertos na identificação do idioma aumenta para esses idiomas.

Utilizando as páginas da base do $\mathrm{WebKB}^{20}$, pôde ser observado que a identificação de termos como nomes de pessoas, nome de empresas, abreviaturas e até mesmo a identificaçào de relacionamentos entre os termos é bastante eficaz. Entretanto, o mesmo não pode ser dito quando os textos não estão escritos em inglês, uma vez que as funções básicas de extração de atributos não estão implementadas para idiomas diferentes do inglês, e portanto não se consegue identificar nas sentenças o que pode ser nome próprio, pessoas e empresas, e até mesmo o que seria verbo. Assim. relacionamentos simples como os mostrados pela ferramenta, quando o texto é inglês. na forma Pessoa X (nome da pessoa) faz ação Y (verbo) em lugar Z (nome da empresa) não se tornam possíveis em ontros idiomas.

Utilizando as páginas dessa mesma base, foram testadas as ferramentas Classification/Categorization e Clustering. Aparentemente, quando os assuntos são correlacionados

\footnotetext{
${ }^{19}$ Como parte deste trabalho, a aluna realizou pequenos experimentos para avaliar a ferramenta Inteligent Miner for Text. no COPPE - Universidade Federal do Rio de Janeiro. Dessa investigação também participou a aluna Daniela Godoy da Universidad Nacional del Centro de la Provincia de Buenos Aires Argentina.

${ }^{20}$ World Wide Knowledge Base. http://www-2.cs.cmu.edu/afs/cs.cmu.esu/project/theo$11 / \mathrm{www} / \mathrm{wwkb} /$
} 
e apresentam muitos termos em comum. ambas as ferramentas năo apresentam bons resultados. Ao analisar a ferramenta Summarization não se pode concluir como as sentenças foram extraídas. A primeira vista parece que há algumas convenções como posição no texto que podem indicar se uma frase é ou não importante para ser inchusa no resumo. Essa característica de "caixa preta" prevalece em todos os componentes e ferramentas do Inteligent. Miner for Text. o que certamente dificulta uma análise mais específica.

Como pode ser percebido. as características nativas de muitas ferramentas não cobrem o processamento de textos em idiomas que não sejam o inglês. Algumas delas possibilitam que cortas características sejam aprimoradas on adicionadas para o processamento de textos em diferentes idiomas. Apesar disso. em uma análise inicial da Ferramenta Text Analyst os resultados obtidos năo foram muito satisfatórios quando alterados o dicionário de sinònimos e a lista de radicais.

Em suma, se forem verificadas todas as ferramentas disponíveis, pode ser percebido que há uma carência de ferramentas que possam tornar possível a descoberta de conhecimento em textos em outros idiomas, como o português. Em virtude disso, neste trabalho. houve a necessidade de ser investigado quais técnicas de pré-processamento poderiam ser associadas para que torne possível a realização do processo de Text Mining em tal idioma. Uma descrição das técnicas que podem ser empregadas, de forma geral, na preparação de dados textuais é abordada no próximo capítulo. 


\section{Capítulo 3}

\section{Representação de um Documento}

Como mencionado. na fase de preparação dos dados textıais, 1 m dos grandes objetivos é a obtenção de uma representação atributo-valor que possa ser considerada a mais informativa possível e que melhor reflita o contexto dos documentos. de forma que resultados satisfatórios possam ser obtidos. Geralmente, essa representação é chamada de bag-ofwords, e possui alguns termos que aparecem nos textos como at ibutos e associados a esses um valor que indica seu peso em relação ao documento, como mostrado na Figura 3.1.

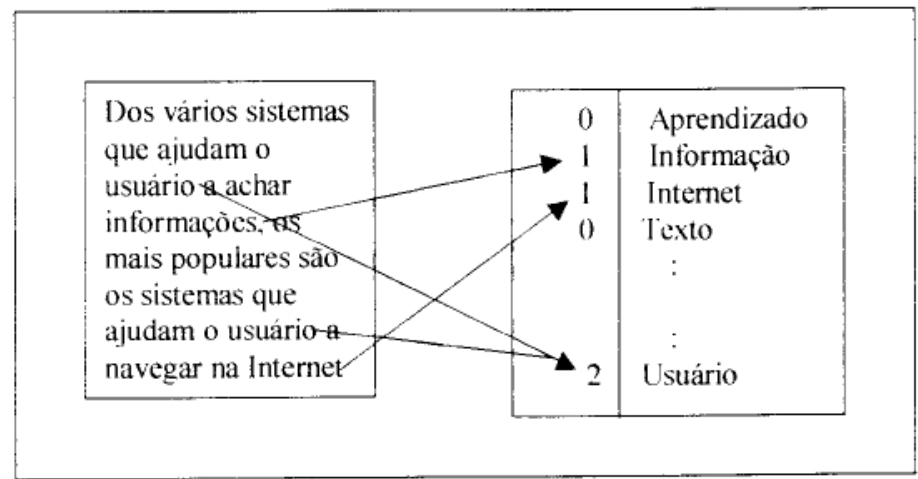

Figura 3.1: Exemplo de uma representação bag-of-words usando pesos correspondentes a frequiência dos termos no documento

Existem uma série de estratégias para obter a representação do documento. A escolha de qual estratégia utilizar. normalmente. pode ser influenciada por benchmarks, ou por uma análise ompírica levando-se em conta também um conhecimento prévio do domínio. Por sua vez. como parte do embasamento teórico desse trabalho. nesse capítulo 
são abordadas algumas das técnicas mais conhecidas e que freqüentemente são utilizadas nas pesquisas envolvidas na bibliografia consultada.

Essas técnicas fazem parte da fase de preparação dos dados, também referenciada como etapa de pré-processamento. Como visto no Capítulo 2. essa etapa pode ser dividida em subtarefas. como a identificação dos atributos, a atribuição de pesos e a diminuição da representação obtida. sendo cada uma descrita nas próximas subseções.

\subsection{Identificação dos Atributos}

Identificar quais termos podem compor a representação dos documentos não é uma tarefa simples. tendo em vista a necessidade de escolher aqueles que melhor identificam o contexto de um documento. Por convenção, para representar os documentos que pertençam a uma classe $c_{i}$, normalmente. são escolhidas as palavras que mais freqüentemente aparecem nos mesmos.

Intuitivamente, se uma palavra aparece com muita freqüência no texto, a probabilidade de que ela esteja fortemente ligada ao contexto do documento possivelmente seja maior, justificando o fato dela ser escolhida como um possível atributo. Entretanto, palavras como artigos, preposições, conjunções e até mesmo alguns verbos, estão presentes em alta escala no texto e não são interessantes para distinguir documentos de diferentes classes. Como consequiencia. tais palavras podem ser desconsideradas na construção da representação, e assim sendo. $11 \mathrm{~m}$ possível passo a ser realizado para identificação dos atributos é a designação dos termos que não devem fazer parte da representação, que são chamados de stopwords.

\subsubsection{A Lista de Stopwords}

A lista de stopwords geralmente depende do idioma presente no texto e do domínio a que os documentos pertencem. Portanto, algumas das palavras inclusas podem ser identificadas por meio do conhecimento do especialista, ou mesmo do usuário. Em contrapartida, muitas das stopwords podem ser utilizadas em qualquer domínio. como é caso dos artigos, preposições. etc. A remoção dessas palavras pode ser realizada de uma forma bastante 
simples utilizando um analisador léxico. uma ve\% que ele pode automaticamente identificar a função gramatical de cada palavra do texto.

De acordo com muitos trabalhos na área de Recuperaçăo de Informaçāo (Zipf, 1949; Luhn. 1958; VanRijsbergen, 1979: Losee. 2001), a lista de stopwords pode ainda ser constrúda a partir das palavras que tendem a aparecer mais freqüentemente em documentos dos mais variados assuntos e daquelas palavras que raramente são utilizadas. De fato. segundo a lei de Zipf (Zipf, 1949), se as palavras forem ordenadas de acordo com o número de vezes que aparecem em $11 \mathrm{~m}$ certo texto, a palavra mais comum será aquela que aparece mais vezes e a freqüiência da segunda palavra mais comum será a metade da primeira. Consequientemente, a ocorrência da terceira palavra mais comum será um terço, e assim por diante.

Seguindo esse raciocínio, se for construído um gráfico confrontado a freqüência das palavras e a sua classificação quando ordenada descendentemente, uma curva pode ser obtida. como mostrado na Figura 3.2 (a). Luhn (Luhn, 1958) utilizou essa hipótese para estabelecer pontos de corte, superior e inferior, que excluíssemi palavras não relevantes. Segundo essa abordagem, as palavras que excedem ao corte superior podem ser consideradas muito comuns, enquanto aquelas que não alcançam o corte inferior são muito raras, e portanto. não contribuem significativamente para o contexto de um documento. Além disso. segundo sna análise, a ordem das palavras de maior importância é aproximadamente o valor médio entre os pontos de corte. como mostrado na Figura 3.2 (b)(VanRijsbergen, $1979)$.

Para verificar a relevância de extrair as stopwords. considere a seguinte frase ${ }^{1}$ sobre Text Mining.

-A descoberta de conhecimento tradicional em textos utiliza técnicas já testadas e consagradas. Nesta abordagem. os dados são extraídos dos textos e formatados em bases de dados estruturadas. com o auxílio de técnicas de Extração de Informações. Depois, são aplicadas técnicas e algoritmos de KDD (mineração de dados estruturados) para descobrir conhecimento útil para o usuário".

\footnotetext{
${ }^{1}$ Trecho extraido de http://www.uibra.tche.br/loh/kdt_comp.htm
} 


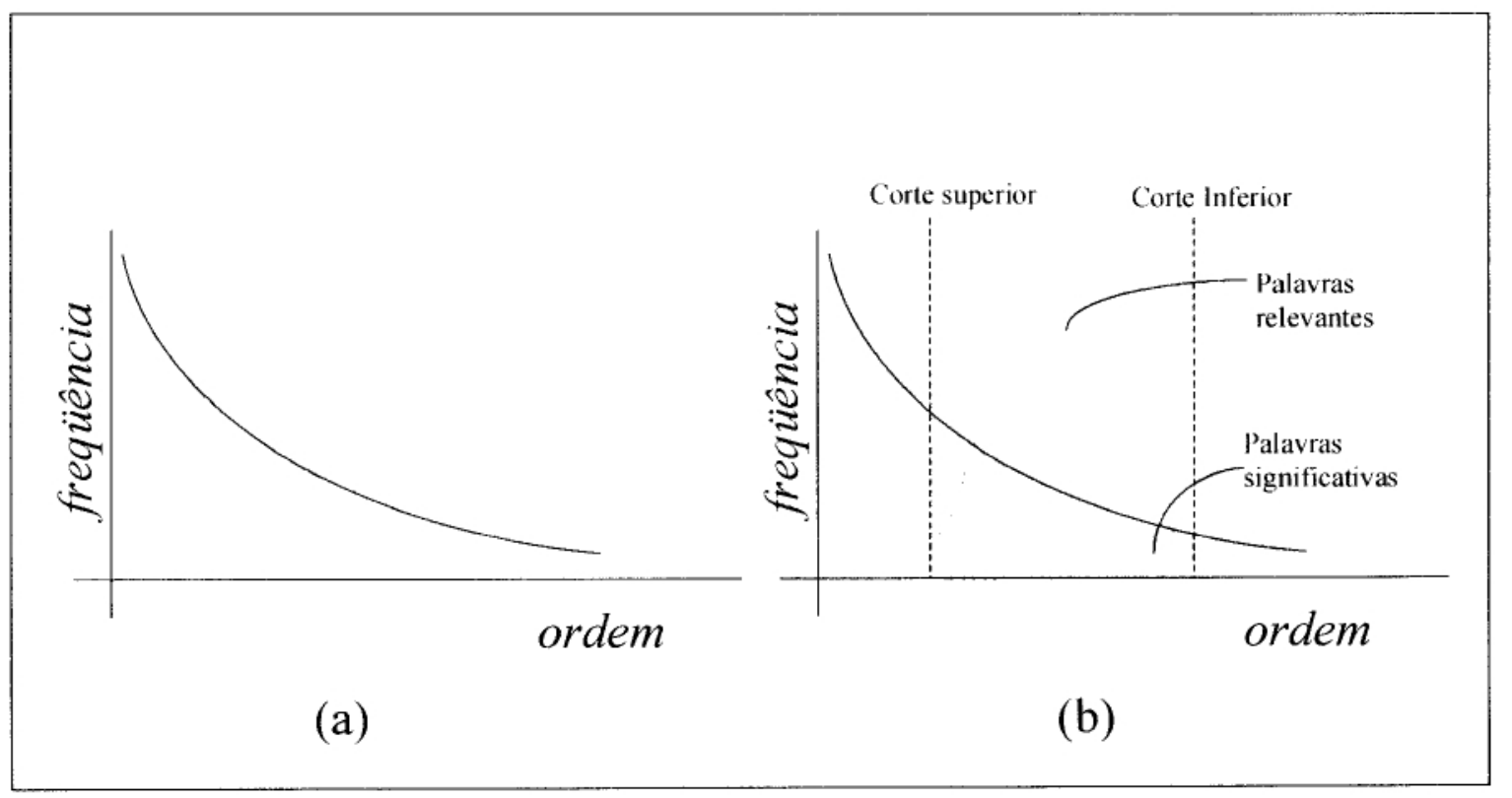

Figura 3.2: (a) Distribuição das palavras de um documento segundo a lei de Zipf (b) Resultado da associação da lẹi de Zipf à ideia de Luhn

Sem desconsiderar alguma palavra, esse trecho contribui com quarenta e uma palavras distintas para sua representação. Porém, palavras cono: a, antes, com, de, dos, e, em, já, o, os, são, para e utiliza, podem ser consideradas ponco significativas nesse domínio, e portanto, podem pertencer à lista de stopwords. Com a retirada de tais palavras, obtém-se uma redução para 28 termos distintos e significativos.

Além da remogão das stopwords, uma outra estratégia que também deve ser levada em consideração ć o mapeamento de palavras para um termo comum, realizado muitas vezes com base na análise das flexões das mesmas. Tal mapeamento pode ser obtido por moio da normalização das palavras.

\subsubsection{Normalização de Palavras}

A normalização das palavras é uma estratégia que visa agrupar palavras, possivelmente correlacionadas, em um ínico termo para a obtenção de uma representação mais adequada.

O termo a que as palavras são mapeadas geralmente é extraído com base na mor- 
fologia das mesmas e sua identificaçào năo precisa envolver o uso de análise gramatical on mesmo etimológica. Dessa forma. nem sempre a normalizaçào produz o mapeamento para o radical das palarras. também conhecido como forma canônica. Cm radical de uma palavra é o termo que dá origem à mesma. sendo que para sıa identificação pode ser necessário o uso de alguma análise léxica on sintática.

Grande parte dos trabalhos utiliza técnicas menos complexas que, através de algruma métrica c/on lista de sufixos. obtém um termo denominado stem que pode se aproximar da provável forma canônica. Um algoritmo bastante conhecido e utilizado ć o de Porter (Porter. 1980), que se baseia primeiramente em determinar o quanto de ıma palavra pode ser considerado suficiente para designar 11 m provável stem. Para isso, é assumido que uma palavra pode ser representada como uma sequêencia $[C](V C)^{m}[V]$, em que $V$ refere-se à uma sequiência de uma ou mais vogais e $C$ à uma lista de uma ou mais consoantes. ( $\mathrm{m}$. por sua vez, auxilia a identificar o ponto onde a palavra pode ser cortada.

Associado ao valor de $m$, o algoritmo utiliza regras que comparam as terminaçōes das palavras com alguns sufixos comumente empregados. c então, caso a regra seja satisfeita, ć realizada a açào para obter o stem. Para o inglês, algumas possíveis regras e seus efeitos são ilustrados na Tabela 3.1. Nessa tabela, as regras são da forma antecedente $\rightarrow$ conseqüente. sendo que o antecedente indica qual a condição para se encontrar um possível sufixo, o o consequiente indica por qual termo esse sufixo deve ser substituido.

\begin{tabular}{|l||l|}
\hline Regras & Exemplos \\
\hline \hline$(m>0)$ ATIONAL $\rightarrow$ ATE & relational $\rightarrow$ relate \\
\hline$(m>0)$ ICATE $\rightarrow$ IC & triplicate $\rightarrow$ triplic \\
\hline$(m>1)$ ENT $\rightarrow$ & dependent $\rightarrow$ depend \\
\hline
\end{tabular}

Tabela 3.1: Algumas regras usadas no algoritmo de Porter para o inglês 


\subsubsection{Outras Operações}

Além da normalização das palavras. ontras operações também colaboram para obtenção de uma representação mais efetiva. Esse é o caso do uso de dicionários eletrônicos ou thesaurus para realizar a associação de palavras não apenas morfologicamente semelhantes. mas que possam ser sinonimas em algum domínio. Em trabalhos direcionados para textos em inglês. essa conversào tem sido apoiada pelo WordNet (Miller et al., 1990).

Com base no uso de alguma das estratégias citadas, pode-se identificar os atributos simples formados na maioria das vezes por apenas um termo. Entretanto, para um agente humano. os atributos compostos, formados por mais de um termo. fornecem uma melhor compreensão do contexto de um texto que a análise de termos simples. Intuitivamente. pode-se conchuir então que o uso de atributos compostos também contribui para a construção de nma representação mais significativa.

Por questão de convenção. nesta seção é adotada a nomenclatura n-gram, freqüientemente mencionada na literatura consultada. em que $n$ indica a quantidade de termos que compõe ım atributo. Dessa forma. os atributos designauis como 1-gram referem-se aos atributos simples. e qualquer valor de $n>1$ refere-se a atributos compostos.

Diante dos prováveis benefícios, aparentemente agrupar as palavras para formação de n-gram pode ser bastante útil. Por outro lado. será que agrupar uma sequiência qualquer de palavras é interessante? Para uma boa representação, não basta apenas agrupar as palavras que aparecem consecutivamente, deve-se também ident ificar quais termos podem ou não formar um atributo e como esses serão agrupados.

Mladenić: (Mladenić, 1998) em seus experimentos utilizon um algoritmo para encontrar os atributos compostos. formados por uma seqü̈encia de até 5 gram. Nesse algoritmo iterativo, cada i-gram é gerado no i-ésimo passo de iteração com base apenas nos grams de tamanho i-1 gerados na iteração anterior. Portanto, na primeira iteração são encontrados os atributos simples, que não sejam stopwords e que ocorram mais que três vezes no documento. A partir desses, são geradas os 2-grams e o algoritmo processa as iteraçŏes até no máximo os j̃-grams serem construídos. Uma versão do algoritmo baseado em (Mladenić. 1998) pode ser observada no Algoritmo L. 


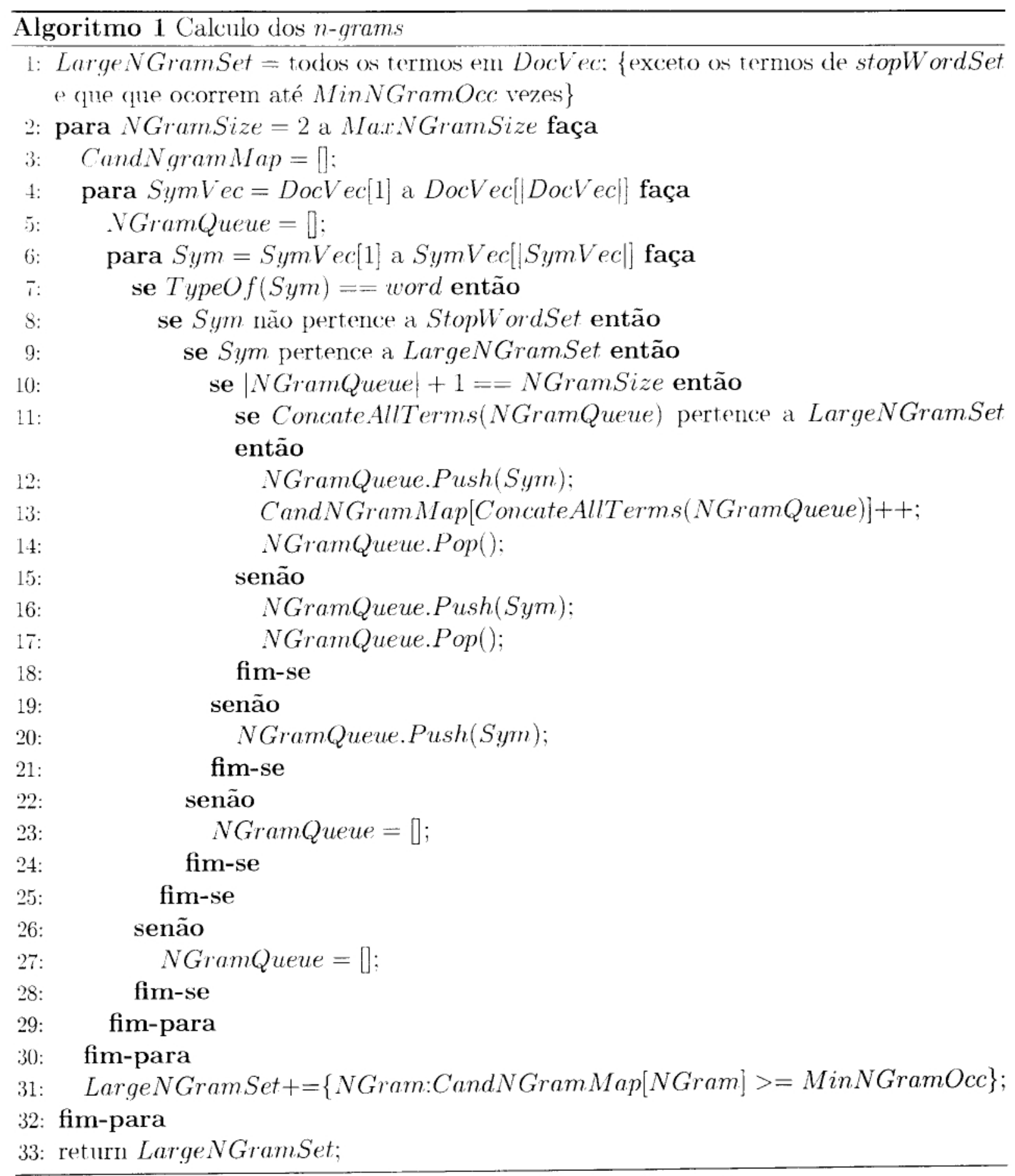

As entradas para o algoritmo apresentado são MinNGramOcc, que refere-se ao número mínimo que cada i-gram deve ocorrer para poder participar da formação de outros atributos na próxima iteração, e o tamanho máximo dos n-grams é representado por Max.VGramSize. Além desses. também são necessários StoplVordSet, DocVec e SymVec que designam. respectivamente. a lista de termos a serem desconsiderados, o 
conjunto de documentos da coleção e o vetor de símbolos léxicos que podem ser associados a cada elemento do documento.

Como estruturas temporárias. são utilizadas Sym, que representa o símbolo léxico no documento (possíveis tipos de valores: substantivo. número. etc.) e CandNGramMap, que é o mapeamento do n-gram candidato para o setu contador de ocorrencia. Além desses. conta-se com $N$-GramQueue que corresponde à fila dos termos construídos mais recentemente e que não pertencem à StoplliordSet. Como saída. o algoritmo retorna LargeNGramSet. que representa o conjunto dos n-grams que ocorrem mais que um número de vezes especificado por MinNGramOce.

Embora o uso de termos compostos seja interessante. o processo para gerá-los pode ser bastante custoso. principalmente considerando textos de grande dimensão. Assim, dependendo do domínio da tarefa a ser desempenhada, utiliza-se apenas atributos simples.

\subsection{Atribuição de Pesos aos Atributos}

Após a identificação dos atributos, como excmplificado na Figura 3.1, deve-se associar a cada um desses um valor que permita expressar o seu peso em relação a cada documento, de forma a obter a representação bag-of-word. As estratégias utilizadas para esse fim são commmente baseadas em medidas estatísticas e podem ser consideradas independentes de idiomas. pois geralmente não utilizam um processamento lingüístico, ao contrário de muitas estratégias de identificação de atributos.

As abordagens utilizadas para a determinação do peso de um atributo em relação a $11 \mathrm{~m}$ documento são baseadas, geralmente. em duas importantes observações empíricas relacionadas aos textos: a quantidade de vezes na qual o termo aparece em um documento e a quantidade de vezes na qual o termo é encontrado em todos os documentos da coleção.

A primeira observação refere-se ao fato de que se uma palavra é usada com muita frequiência em um texto, provavelmente ela está fortemente relacionada ao contexto nele descrito. Assim, quanto mais vezes um termo estiver presente. maior a probabilidade de que o mesmo seja relevante para representar a categoria a que o documento pertence.

A segunda observação leva em consideração o fato de que se uma palavra ocorre 
muitas vezes em diversos documentos. e estes pertencem a diferentes categorias, então a palavra talvez não seja tão relevante para ser considerada na representação. Isso porque pode não ser possível distinguir os documentos pertencentes a categorias distintas pelo uso de um termo que ocorre em grande parte deles.

A partir destas duas observaçoes. são descritas seis medidas diferentes de atribuição de pesos. abordados em (Aas and Eikvil, 1999). Para isso são empregadas as seguintes nomenclaturas: $f_{k j}$ para designar a frequiencia do atributo term $m_{k}$ no documento $d_{j}, m$ como o número de documentos na coleção. $n_{\text {total }}$ como o número de palavras presentes na coleção e $n_{k}$. como o número de vezes que o atributo term $m_{k}$ ocorre na coleção inteira.

Para exemplificar a diferença entre as medidas. considere a Tabela 3.2 na qual é ilustrado o conjunto de palavras contidas em cada documento $d_{j}$ em que $j=[1, \ldots, 4]$ pertencentes a categoria $c_{i}$ no qual $i=[1,2]$. Para simplificar. é considerado que já foi realizada a remoção de stopwords e que as palavras foram convertidas para a forma canônica. Vale ressaltar que as palavras relacionadas a $c_{1}$ são geralmente referenciadas em documentos abordando o assunto de Text Mining, enquanto aquelas pertencentes à classe $c_{2}$ são normalmente, citadas em documentos que abordam aspectos sobre Data Mining.

\begin{tabular}{|c|c|c|}
\hline Documento & Palavras. freqüêencia & Classe \\
\hline$d_{1}$ & $\begin{array}{l}\text { data. 2: mining, 32; manipular. 3; extrair, 5; conhecimento, 10; } \\
\text { busca. 20; dado, 15; estruturado, } 2 \text {; metodologia. } 3 ; \\
\text { ferramenta, 10; operacional, } 1 \text {; projeto. 3; text, 30; } \\
\text { inteligencia. 4; competitivo. } 3\end{array}$ & $c_{1}$ \\
\hline$d_{2}$ & $\begin{array}{l}\text { text, } 40 \text {; mining, } 40 \text {; busca, } 10 \text { : informação, } 20 \text {; web, } 5 \text {; } \\
\text { recuperar. 10: conhecimento. 10: linguagem. 5; natural, } 5 \text {; }\end{array}$ & $c_{1}$ \\
\hline$d_{3}$ & $\begin{array}{l}\text { volume. } 3 \text {; dado, 30; informação, } 15 \text {; analisar, } 10 \text {; extrair, } 10 \text {; } \\
\text { algoritmo, 10; ferramenta, } 5 \text {; data, } 30 \text { : mining, } 30 \text {; } \\
\text { descobrir, 15; padrão. 20; relacionamento, } 3 \text {; correlação, } 3 \text {; } \\
\text { tendencia, 10; }\end{array}$ & $c_{2}$ \\
\hline$d_{4}$ & $\begin{array}{l}\text { data. 40; mining, } 40 \text {; mineração, } 20 \text {; dado, } 45 ; \text { processo, } 35 \text {; } \\
\text { extrair. } 15 \text {; informação, } 30 \text {; banco, } 15 \text {; aprendizado, } 5 ; \\
\text { máquina. } 5 \text {; reconhecimento. } 3 \text {; padrão. 10; tecnologia, } 5 \text {; } \\
\text { negócio. } 10 \text {; conhecimento, } 25\end{array}$ & $c_{2}$ \\
\hline
\end{tabular}

Tabela 3.2: Relação entre documentos, palavras e classes, usada para exemplificação das medidas de atribuição de pesos 
Para tornar mais fácil a representação dos resultados alcançados pelas medidas de atribuição de pesos, a cada palavra considerada nos textos da Tabela 3.2 está associado um rótulo que corresponde à sua ordem alfabética. A disposição desses rótulos pode ser vista na Tabela 3.3 e é justificada pelo fato de que a quantidade total de palavras distintas é grande e torna difícil ilustrar a correspondente representação do documento.

\begin{tabular}{|l||c|}
\hline Palavra & rótulo \\
\hline algoritmo & 1 \\
\hline analisar & 2 \\
\hline aprendizado & 3 \\
\hline banco & 4 \\
\hline busca & 5 \\
\hline competitivo & 6 \\
\hline Conhecimento & 7 \\
\hline correlação & 8 \\
\hline dado & 9 \\
\hline data & 10 \\
\hline descobrir & 11 \\
\hline estruturado & 12 \\
\hline
\end{tabular}

\begin{tabular}{|l||c|}
\hline Palavra & rótulo \\
\hline \hline extrair & 13 \\
\hline forramenta & 14 \\
\hline informação & 15 \\
\hline inteligência & 16 \\
\hline linguagem & 17 \\
\hline Manipular & 18 \\
\hline máquina & 19 \\
\hline metodologia & 20 \\
\hline mineração & 21 \\
\hline mining & 22 \\
\hline natural & 23 \\
\hline negócio & 24 \\
\hline
\end{tabular}

\begin{tabular}{|c|c|}
\hline Palavra & rótulo \\
\hline operacional & 25 \\
\hline padrão & 26 \\
\hline processo & 27 \\
\hline projeto & 28 \\
\hline reconhecimento & 29 \\
\hline recuperar & 30 \\
\hline relacionamento & 31 \\
\hline tecnologia & 32 \\
\hline tendência & 33 \\
\hline text & 34 \\
\hline volime & 35 \\
\hline web & 36 \\
\hline
\end{tabular}

Tabela 3.3: Palavras e correspondentes rótulos

A seguir são descritas as medidas para atribuição de pesos freqüentemente empregadas.

Peso Booleano é a abordagem mais simples, no qual os pesos são designados aos atributos de acordo com a presença ou ausência dos mesmos no documento. Se um atributo term $k$ está presente no documento $d_{j}$ então o peso $a_{j k}$ obtém valor 1 (um), caso contrário, é atribuído valor igual a 0 (zero), como especificado pela Equação 3.1.

$$
a_{j k}=\left\{\begin{array}{l}
1 \text { se } f_{k j}>0, \\
0 \text { caso contrário. }
\end{array}\right.
$$

Na Tabela 3.4 cada tupla representa um vetor bag-of-word referente aos documentos exemplificados na Tabela 3.2 com os rótulos descritos na Tabela 3.3, utilizando-se o peso booleano. 


\begin{tabular}{|l||c|c|c|c|c|c|c|c|c|c|c|c|c|c|c|c|c|c|}
\hline documento & 1 & 2 & 3 & 4 & 5 & 6 & 7 & 8 & 9 & 10 & 11 & 12 & 13 & 14 & 15 & 16 & 17 & 18 \\
\hline doc $_{1}$ & 0 & 0 & 0 & 0 & 1 & 1 & 1 & 0 & 1 & 1 & 0 & 1 & 1 & 1 & 0 & 1 & 0 & 1 \\
\hline doc: $_{2}$ & 0 & 0 & 0 & 0 & 1 & 0 & 1 & 0 & 0 & 0 & 0 & 0 & 0 & 0 & 1 & 0 & 1 & 0 \\
\hline doc $_{3}$ & 1 & 1 & 0 & 0 & 0 & 0 & 0 & 1 & 1 & 1 & 1 & 0 & 1 & 1 & 1 & 0 & 0 & 0 \\
\hline doc $_{4}$ & 0 & 0 & 1 & 1 & 0 & 0 & 1 & 0 & 1 & 1 & 0 & 0 & 1 & 0 & 1 & 0 & 0 & 0 \\
\hline
\end{tabular}

\begin{tabular}{|c|c|c|c|c|c|c|c|c|c|c|c|c|c|c|c|c|c|}
\hline 19 & 20 & 21 & 22 & 23 & 24 & 25 & 26 & 27 & 28 & 29 & 30 & 31 & 32 & 33 & 34 & 35 & 36 \\
\hline 0 & 1 & 0 & 1 & 0 & 0 & 1 & 0 & 0 & 1 & 0 & 0 & 0 & 0 & 0 & 1 & 0 & 0 \\
\hline 0 & 0 & 0 & 1 & 1 & 0 & 0 & 0 & 0 & 0 & 0 & 1 & 0 & 0 & 0 & 1 & 0 & 1 \\
\hline 0 & 0 & 0 & 1 & 0 & 0 & 0 & 1 & 0 & 0 & 0 & 0 & 1 & 0 & 1 & 0 & 1 & 0 \\
\hline 1 & 0 & 1 & 1 & 0 & 1 & 0 & 1 & 1 & 0 & 1 & 0 & 0 & 1 & 0 & 0 & 0 & 0 \\
\hline
\end{tabular}

Tabela 3.4: Representação bag-of-words utilizando peso booleano

O peso booleano é ítil para indicar se um determinado termo está ou não presente nos documentos de uma categoria, mas pode não ser adequado para mensurar quão forte é a relação entre os termos e os documentos a que pertencem. Para isso são utilizadas outras medidas que são calculadas em função do número de ocorrências do termo.

Peso pela Freqüência do Atributo é uma outra abordagem bastante simples, que usa a freqüiencia $f_{k j}$, que é o número de vezes que o atributo term $m_{k}$ aparece no documento $d_{j}$, como peso. O cálculo de $a_{j k}$ pode ser realizado com base na Equação 3.2.

$$
a_{j k}=f_{k j}
$$

Considerando os documentos utilizados como exemplos, a representação dos mesmos utilizando essa estratégia de peso é ilustrada na Tabela 3.5.

\begin{tabular}{|l||c|c|c|c|c|c|c|c|c|c|c|c|c|c|c|c|c|c|}
\hline documento & 1 & 2 & 3 & 4 & 5 & 6 & 7 & 8 & 9 & 10 & 11 & 12 & 13 & 14 & 15 & 16 & 17 & 18 \\
\hline \hline doc $_{1}$ & 0 & 0 & 0 & 0 & 20 & 3 & 10 & 0 & 15 & 2 & 0 & 2 & 5 & 10 & 0 & 4 & 0 & 3 \\
\hline doc $_{2}$ & 0 & 0 & 0 & 0 & 10 & 0 & 10 & 0 & 15 & 2 & 0 & 0 & 0 & 0 & 20 & 0 & 5 & 0 \\
\hline doc $_{3}$ & 10 & 10 & 0 & 0 & 0 & 0 & 0 & 3 & 30 & 30 & 15 & 0 & 10 & 5 & 15 & 0 & 0 & 0 \\
\hline doc $_{4}$ & 0 & 0 & 5 & 15 & 0 & 0 & 25 & 0 & 45 & 40 & 0 & 0 & 15 & 0 & 30 & 0 & 0 & 0 \\
\hline
\end{tabular}

\begin{tabular}{|c|c|c|c|c|c|c|c|c|c|c|c|c|c|c|c|c|c|}
\hline 19 & 20 & 21 & 22 & 23 & 24 & 25 & 26 & 27 & 28 & 29 & 30 & 31 & 32 & 33 & 34 & 35 & 36 \\
\hline \hline 0 & 3 & 0 & 32 & 0 & 0 & 1 & 0 & 0 & 3 & 0 & 0 & 0 & 0 & 0 & 30 & 0 & 0 \\
\hline 0 & 0 & 0 & 40 & 5 & 0 & 0 & 0 & 0 & 0 & 0 & 10 & 0 & 0 & 0 & 40 & 0 & 5 \\
\hline 0 & 0 & 0 & 30 & 0 & 0 & 0 & 20 & 0 & 0 & 0 & 0 & 3 & 0 & 10 & 0 & 3 & 0 \\
\hline 5 & 0 & 20 & 40 & 0 & 10 & 0 & 10 & 35 & 0 & 3 & 0 & 0 & 5 & 0 & 0 & 0 & 0 \\
\hline
\end{tabular}

Tabela 3.5: Representação bag-of-words utilizando a freqüência do atributo como peso

Utilizando-se apenas a freqüência do atributo como peso, pode-se obter uma re- 
presentação pouco adequada se a freqüência elevada de um atributo não está concentrada em poucos documentos. mas prevalece na coleção inteira (Yang and Chute. 1994). Esse aspecto está relacionado com a segunda observação sobre a distribuição das palavras, comentado no início dessa seção. Para evitar esse problema, existem medidas que associam ao cálculo outros tipos de fatores que favorecem atributos concentrados em poucos documentos de uma coleção, como é o caso da medida tf $\times$ idf.

Peso tf $\times$ idf. ao contrário dos esquemas anteriores, leva em consideração a freqüência do atributo em todos os documentos. Esta abordagem atribui o peso $a_{j k}$ considerando a proporção do número de ocorrências do atributo no documento, que é designado como o termo tf (term frequency), multiplicado pela proporção inversa ao número de documentos na coleção na qual o atributo ocorre ao menos uma vez, que é representado pelo termo idf (inverse document frequency) (Yang and Chute, 1994). () cálculo para a determinação do valor de $a_{j k}$, segundo esta abordagem, é realizado com base na Equação 3.3 .

$$
a_{j k}=f_{k j} \times \log \left(\frac{m}{n_{k}}\right)
$$

Na Tabela 3.6 é ilustrada a representação obtida por meio do uso da medida tf $\times$ idf. Essa representação é mais precisa quando comparada às duas primeiras, uma vez que leva em consideração aspectos relacionados às duas observações: o número de vezes que $11 \mathrm{~m}$ atributo ocorre no documento e o número de vezes que ele ocorre na coleção de documentos.

\begin{tabular}{|l||c|c|c|c|c|c|c|c|c|c|c|c|c|c|c|c|c|c|}
\hline documento & 1 & 2 & 3 & 4 & 5 & 6 & 7 & 8 & 9 & 10 & 11 & 12 & 13 & 14 & 15 & 16 & 17 & 18 \\
\hline \hline doc $_{1}$ & 0 & 0 & 0 & 0 & 6 & 2 & 1 & 0 & 2 & 0 & 0 & 1 & 1 & 3 & 0 & 2 & 0 & 2 \\
\hline doc $_{2}$ & 0 & 0 & 0 & 0 & 3 & 0 & 1 & 0 & 0 & 0 & 0 & 0 & 0 & 0 & 2 & 0 & 3 & 0 \\
\hline doc $_{3}$ & 6 & 6 & 0 & 0 & 0 & 0 & 0 & 2 & 4 & 4 & 9 & 0 & 1 & 2 & 2 & 0 & 0 & 0 \\
\hline doc $_{4}$ & 0 & 0 & 3 & 9 & 0 & 0 & 3 & 0 & 6 & 5 & 0 & 0 & 2 & 0 & 4 & 0 & 0 & 0 \\
\hline
\end{tabular}

\begin{tabular}{|c|c|c|c|c|c|c|c|c|c|c|c|c|c|c|c|c|c|}
\hline 19 & 20 & 21 & 22 & 23 & 24 & 25 & 26 & 24 & 28 & 29 & 30 & 31 & 32 & 33 & 34 & 35 & 36 \\
\hline \hline 0 & 2 & 0 & 0 & 0 & 4 & 1 & 1 & 0 & 2 & 0 & 0 & 2 & 0 & 0 & 9 & 0 & 0 \\
\hline 0 & 0 & 8 & 0 & 3 & 0 & 0 & 0 & 0 & 0 & 0 & 6 & 0 & 0 & 5 & 12 & 0 & 3 \\
\hline 0 & 0 & 0 & 0 & 0 & 0 & 0 & 6 & 0 & 0 & 0 & 0 & 2 & 0 & 6 & 5 & 2 & 0 \\
\hline 3 & 0 & 12 & 0 & 0 & 6 & 0 & 3 & 25 & 4 & 2 & 0 & 0 & 3 & 0 & 0 & 0 & 0 \\
\hline
\end{tabular}

Tabela 3.6: Representação bag-of-words utilizando peso tf $\times$ idf

A medida tf $\times$ idf é muito utilizada, embora não leve em consideração o tamanho 
que os documentos podem apresentar. Em muitas situações. documentos pequenos são representados por vetores com poucos atributos. enquanto um conjunto maior de atributos são atribuídos a documentos de tamanho maior. Desta forma. as categorias que possuem documentos maiores podem ser privilegiadas no treinamento, em detrimento daquelas que são representadas por documentos pequenos. Diante desse raciocínio, pode-se utilizar também um fator de normalização no cálculo do peso para equilibrar as diferenças entre os tamanhos dos documentos.

Peso tf $\times$ idf Normalizado, descrito na Equaçăo 3.4, é semelhante ao anterior exceto pela característica de usar em seu cálculo a soma dos valores, obtidos pelo uso da abordagem tf $\times$ idf, de todos os atributos que descrevem um documento como parâmetro normalizador. Assim, todos os documentos relevantes podem ser tratadas com a mesma importância (Salton. 1988).

$$
a_{j k}=\frac{f_{k j} \times \log \left(\frac{m}{n_{k}}\right)}{\sqrt{\sum_{w=1}^{n_{\text {total }}}\left[f_{w j} \times \log \left(\frac{m}{n_{w}}\right)\right]^{2}}}
$$

Na Tabela 3.7 é ilustrada a representação obtida com uso dessa medida.

\begin{tabular}{|l||c|c|c|c|c|c|c|c|c|c|c|c|}
\hline documento & 1 & 2 & 4 & 4 & 5 & 6 & 7 & 8 & 9 & 10 & 11 & 12 \\
\hline \hline$d o c_{1}$ & 0 & 0 & 3 & 0 & 0,48 & 0.14 & 0,1 & 0 & 0,15 & 0,02 & 0 & 0,09 \\
\hline$d o c_{2}$ & 0 & 0 & 0 & 0 & 0,2 & 0 & 6,08 & 0 & 9 & 0 & 0 & 0 \\
\hline$d o c_{3}$ & 0.36 & 0,36 & 0 & 0 & 6 & 0 & 0 & 0,1 & 0,22 & 0.22 & 0,54 & 0 \\
\hline$d o c_{4}$ & 0 & 0 & 0,1 & 0,31 & 0 & 0 & 0,1 & 0 & 0.19 & 0,17 & 0 & 0 \\
\hline
\end{tabular}

\begin{tabular}{|c|c|c|c|c|c|c|c|c|c|c|c|}
\hline 13 & 14 & 15 & 16 & 17 & 18 & 19 & 20 & 21 & 22 & 23 & 24 \\
\hline \hline 0,05 & 5,24 & 0 & 0,19 & 0 & 0,14 & 0 & 0,14 & 0 & 0 & 0 & 0 \\
\hline 0 & 0 & 0,36 & 8 & 0,20 & 0 & 8 & 0 & 0 & 0 & 0.2 & 0 \\
\hline 0,07 & 0,09 & 0,10 & 0 & 0 & 0 & 0 & 0 & 0 & 0 & 5 & 0 \\
\hline 0,00 & 0 & 0,13 & 0 & 0 & 0 & 0,1 & 0 & 0,41 & 0 & 0 & 0,2 \\
\hline
\end{tabular}

\begin{tabular}{|c|c|c|c|c|c|c|c|c|c|c|c|}
\hline 25 & 26 & 27 & 28 & 29 & 30 & 31 & 32 & 33 & 34 & 35 & 36 \\
\hline \hline 0,04 & 0 & 0 & 0,11 & 4 & 0 & 0 & 0 & 0 & 0,72 & 0 & 0 \\
\hline 0 & 0 & 0 & 0 & 0 & 0,4 & 0 & 0 & 0 & 0,2 & 0 & 0,2 \\
\hline 0 & 0,36 & 0 & 0 & 0 & 0 & 0,1 & 0 & 0,56 & 0 & 0,10 & 0 \\
\hline 0 & 0,10 & 0,73 & 0 & 0,06 & 0 & 0 & 0.10 & 0 & 0 & 0 & 0 \\
\hline
\end{tabular}

Tabela 3.7: Representação bag-of-words utilizando peso tf $\times$ idf normalizado

()s pesos dos termos em relação a um mesmo documento também podem variar bastante. e para diminuir essa diferença pode-se utilizar também um novo fator, como o 
uso do logaritmo.

Peso log tf $\times$ idf Normalizado ${ }^{2}$ é baseado na medida tf $\times$ idf Normalizado, descrita anteriormente. A diferença significativa é o emprego do logaritmo dos termos que compõem a equação, como forma de reduzir grandes diferenças nas frequiências dos termos (Buckley et al., 1994).

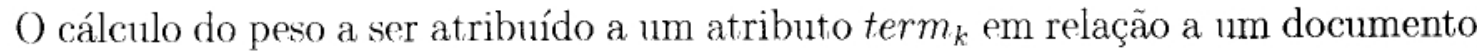
$d_{j}$ é realizado com base na Equação 3.5.

$$
a_{j k}=\frac{\log \left(f_{k j}+1.0\right) \times \log \left(\frac{m}{n_{k}}\right)}{\sqrt{\sum_{u=1}^{n_{t o t a l} l}\left[\log \left(f_{k w}+1.0\right) \times \log \left(\frac{m}{n_{w}}\right)\right]^{2}}}
$$

Os valores obtidos como peso. utilizando essa medida. são referenciados na Tabela 3.8.

\begin{tabular}{|l||c|c|c|c|c|c|c|c|c|c|c|c|c|c|c|c|c|c|}
\hline documento & 1 & 2 & 9 & 4 & 5 & 6 & 7 & 8 & 2 & 10 & 11 & 12 & 13 & 14 & 15 & 16 & 17 & 18 \\
\hline \hline$d o c_{1}$ & 0 & 0 & 0 & 0 & 6,1 & 0,1 & 0 & 7 & 0 & 7 & 0 & 0,1 & 0 & 0,1 & 0 & 0,1 & 0 & 0 \\
\hline$d o c_{4}$ & 0 & 0 & 0 & 0 & 9,1 & 0 & 0 & 3 & 0 & 0 & 0 & 0 & 0 & 0 & 0,1 & 5 & 0,1 & 0 \\
\hline$d o c_{3}$ & 0 & 0,1 & 0 & 0 & 4 & 0 & 0 & 0,1 & 0 & 0 & 0,1 & 0 & 1 & 8 & 0 & 0 & 0 & 0 \\
\hline$d o c_{4}$ & 0 & 0 & 0,1 & 0,1 & 0 & 0 & 0 & 0 & 0 & 0 & 0 & 0 & 0 & 0 & 0 & 0 & 0 & 0 \\
\hline
\end{tabular}

\begin{tabular}{|c|c|c|c|c|c|c|c|c|c|c|c|c|c|c|c|c|c|}
\hline 19 & 20 & 21 & 22 & 23 & 24 & 25 & 26 & 27 & 28 & 29 & 30 & 31 & 32 & 33 & 34 & 35 & 36 \\
\hline \hline 0 & 0,1 & 0 & 1 & 0 & 0 & 0 & 0 & 0 & 0,1 & 0 & 0 & 0 & 0 & 0 & 0,0 & 0 & 0 \\
\hline 0 & 0 & 0 & 0 & 0 & 0 & 7 & 0 & 4 & 0 & 0 & 0,2 & 0 & 0 & 0 & 0,8 & 0 & 0,1 \\
\hline 0 & 0 & 0 & 8 & 0 & 0 & 0 & 0,1 & 0 & 0 & 0 & 0 & 0,1 & 1 & 0,1 & 0 & 0,1 & 0 \\
\hline 0,1 & 0 & 0 & 0 & 0 & 0,1 & 9 & 0,1 & 0.2 & 0 & 0,1 & 0 & 0 & 0,1 & 0 & 0 & 0 & 0 \\
\hline
\end{tabular}

Tabela 3.8: Representação bag-of-words utilizando $\log \mathrm{tf} \times \mathrm{idf}$ normalizado como peso

Nas medidas apresentadas. se um termo ocorrer 8 vezes em dois documentos terá o mesmo peso que $1 \mathrm{~m}$ termo que ocorre apenas uma vez no primeiro documento e 7 vezes no segundo documento. porque não dependem da distribuição dos termos, ao contrário do peso baseado em entropia.

Peso Baseado em Entropia é uma abordagem centrada na idéia de informação teórica e constitui o esquema mais sofisticado de atribuição de pesos. Para efetuar o cálculo do

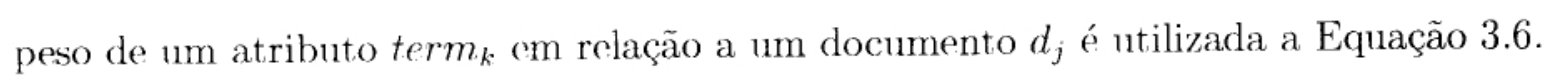

\footnotetext{
${ }^{2}$ Essa medida é referenciada como ltc em (Salton, 1988).
} 


$$
a_{j k}=\log \left(f_{k j}+1.0\right) \times(1+I M)
$$

() termo $I M$ corresponde à incerteza média ou entropia do atributo $k$. e assume o valor -1 se o mesmo está igualmente distribuído em todos os documentos e 0 se ocorre em apenas um documento. Para os demais casos, este termo pode ser calculado com base na Equação 3.7.

$$
I M=\frac{1}{\log (m)} \sum_{j=1}^{m}\left[\frac{f_{k j}}{n_{k}} \log \left(\frac{f_{k j}}{n_{k}}\right)\right]
$$

Os resultados da aplicação dessa medida podem ser vistos na Tabela 3.9.

\begin{tabular}{|l||c|c|c|c|c|c|c|c|c|c|c|c|}
\hline documento & 1 & 2 & 0 & 4 & 5 & 5 & 7 & 8 & 9 & 10 & 11 & 12 \\
\hline \hline doc $_{1}$ & 0 & 0 & 0 & 0 & 31 & 0,6 & 19,6 & 0 & 63,5 & 20.2 & 0 & 0,5 \\
\hline doc $_{2}$ & 5 & 8 & 0 & 0 & 24.8 & 2 & 19,6 & 0 & 0 & 0 & 0 & 0 \\
\hline doc $_{3}$ & 7,0 & 1,0 & 0 & 0 & 0 & 1 & 18,5 & 6 & 78,6 & 63,1 & 1,2 & 0 \\
\hline doc $_{4}$ & 0 & 0 & 0,8 & 1,2 & 0 & 0 & 21 & 0 & 87,7 & 68.0 & 0 & 0 \\
\hline
\end{tabular}

\begin{tabular}{|c|c|c|c|c|c|c|c|c|c|c|c|}
\hline 13 & 14 & 15 & 16 & 17 & 18 & 19 & 20 & 21 & 22 & 23 & 24 \\
\hline \hline 8 & 8,8 & 7 & 0 & 0 & 0,6 & 0 & 0,6 & 0 & 86,2 & 0 & 8 \\
\hline 0 & 0 & 43 & 0 & 0,8 & 0 & 0 & 0 & 0 & 92,1 & 0,8 & 0 \\
\hline 10,7 & 6,5 & 39,2 & 0 & 0 & 0 & 0 & 0 & 0 & 85,2 & 0 & 0 \\
\hline 13,4 & 0 & 48,5 & 2 & 0 & 0 & 0,8 & 0 & 1,3 & 92,1 & 0 & 1,0 \\
\hline
\end{tabular}

\begin{tabular}{|c|c|c|c|c|c|c|c|c|c|c|c|}
\hline 25 & 26 & 27 & 28 & 29 & 30 & 31 & 32 & 33 & 34 & 35 & 36 \\
\hline \hline 0.3 & 0 & 0 & 0,6 & 3 & 0 & 0 & 0 & 0 & 1,5 & 0 & 0 \\
\hline 0 & 0 & 0 & 0 & 4 & 0 & 0 & 0 & 0 & 1.9 & 0 & 1.8 \\
\hline 0 & 01 & 0 & 0 & 0 & 0 & 0,6 & 0 & 1,0 & 0 & 0,6 & 0 \\
\hline 0 & 24,4 & 1,6 & 5 & 0,6 & 0 & 6 & 0,8 & 0 & 0 & 0 & 0 \\
\hline
\end{tabular}

Tabela 3.9: Representação bag-of-words utilizando peso baseado na entropia

\subsection{Redução da Representação}

Fazendo uso de algumas técnicas de identificação de atributos e atribuição de pesos, a representação dos textos na forma de bag-of-words pode ser obtida. Entretanto, em algumas situações essa representação ainda é consideravelmente grande para ser empregada na tarefa de Text Mining. Isso se deve ao fato de que representações de alta dimensão podem exceder a capacidade de processamento de muitos dos algoritmos utilizados para extração de conhecimento. 
Como citado anteriormente. no que concerne à área de Aprendizado de Máquina. a redução de atributos em uma base de dados pode ser realizada utilizando duas abordagens: seleção de um subconjunto de atributos e indução construtiva.

Na primeira abordagem, a partir da representação original com n atributos, são escolhidos n' atributos, descartando-se os termos pouco informativos ou pouco preditivos para promover a redução da representação (John et al., 1994). Já na segunda abordagem. os atributos originais são combinados com o propósito de obter atributos com valores preditivos maiores que os originais (Michalski, 1978; Lee, 2000).

No caso do aprendizado em textos. as medidas para redução da representação dos documentos também podem ser classificadas de acordo com os conceitos envolvidos nessas duas abordagens. Nessa seção, são abordados alguns dos métodos mais utilizados para redução da representação, sendo inicialmente descritos aqueles que pertencem a abordagem de seleção de atributos.

\subsubsection{Seleção de Atributos}

Segundo Mladenić (Mladenić, 1998), em tarefas de descoberta de conhecimento para classificação de texto, a abordagem de seleção de atributos pode ser ilustrada como mostrado na Figura 3.3. Os atributos da representação original são avaliados independentemente, sendo atribuído um valor de pontuação a cada um deles. A partir desse valor, os atributos são ordenados e um número $t$ predefinido de atributos é considerado para formar a nova representação. Nessa seção são abordados alguns métodos para seleção de atributos, comparados em (Yang and Pedersen, 1997).

Freqüência de documento é uma função simples que designa a quantidade de documentos que um atributo aparece como valor de sua relevância. Assim a relevância de um atributo term $m_{k}$ é igual a $n_{k}$.

Ganho de informação é ıma abordagem que mede o ganho de informação obtido para a predição de uma categoria, tendo conhecimento da presença ou ausência de um atributo no documento. Assim, é geralmente calculado pela diferença da entropia de uma classe $c_{i}$ antes e depois do uso de um atributo term . $_{\text {. }}$ 


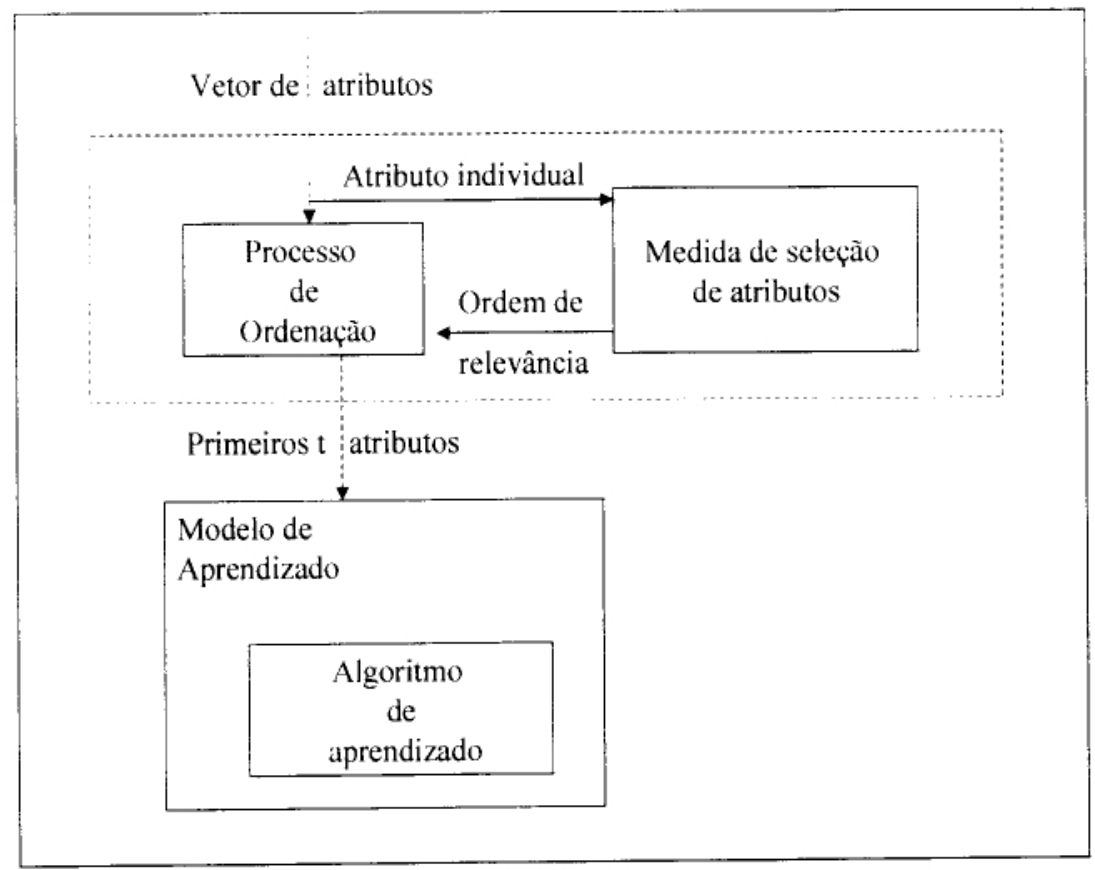

Figura 3.3: Seleção de atributos para reduzir a representação em Text Mining

Seja $C=\left(c_{1}, \ldots, c_{q}\right)$ o conjunto de classes possíveis. O ganho de informação $(I G)$ de 1 m atributo term p $_{\text {. }}$ pode ser calculado em função da Equação 3.8 .

$$
\begin{aligned}
& I G\left(\text { term }_{k}\right)=-\sum_{i=1}^{q} P\left(c_{i}\right) \log P\left(c_{i}\right)+P\left(\text { term }_{k}\right) \sum_{i=1}^{q} P\left(c_{i} \mid \text { term }_{k}\right) \log P\left(c_{i} \mid \text { term }_{k}\right)+ \\
& P\left(\overline{\text { term } m_{k}}\right) \sum_{i=1}^{q} P\left(c_{i} \mid \overline{\text { term }_{k}}\right) \log P\left(c_{i} \mid \overline{\text { term }_{k}}\right) \text {. }
\end{aligned}
$$

A probabilidade da classe $c_{i}, P\left(c_{i}\right)$, pode ser estimada a partir da fração de documentos da coleção total que pertencem a classe $c_{i}$, e $P\left(\right.$ term $\left._{k}\right)$ pode ser inferido através da fração

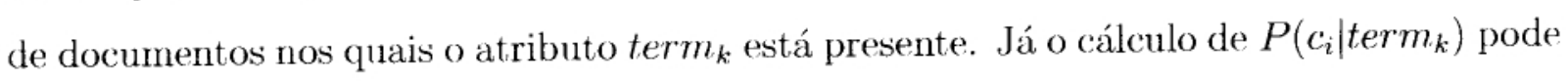
ser determinado pela fraçāo de documentos da classe $c_{i}$ que tem ao menos uma ocorrência de term $_{k}$ e $P\left(c_{i} \mid \overline{\text { term }_{k}}\right)$ pela fração de documentos da classe $c_{i}$ nos quais o atributo term $m_{k}$ está ausente.

Informação mútua é um critério freqüentemente usado na modelagem estatística de as-

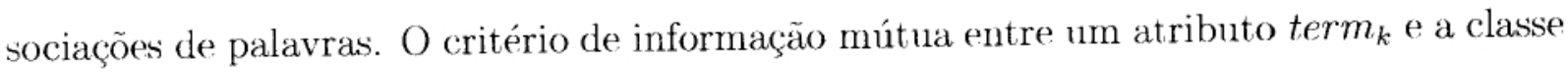
$c_{i}$ é definido em função da Equação 3.9 . 


$$
I\left(\text { term }_{k}, c_{i}\right) \approx \log \frac{A \times m}{(A+C) \times(A+B)}
$$

() termo $A$ é o número de documentos da classe $c_{i}$ em que term $k$ está contido, $B$ é o número de documentos que não pertencem a classe $c_{i}$ e que contém term ${ }_{k}$ e $C$ é o número

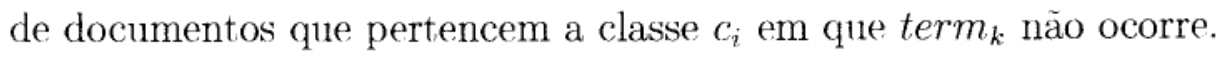

$\chi^{2}$ - estatístico é uma das estratégias mais conhecidas para a scleção de atributos, através da qual é possível medir a falta de independência entre um atributo term $m_{k}$ e a classe $c_{i}$. Para isso é realizado um cálculo com base na Equação 3.10 .

$$
\chi^{2}\left(\text { term }_{k}, c_{i}\right)=\frac{m \times(A D-C B)^{2}}{(A+C) \times(B+D) \times(A+B) \times(C+D)}
$$

na qual o $D$ é o número de documentos que não pertencem a classe $c_{i}$ nem contem term ${ }_{k}$.

\subsubsection{Indução Construtiva}

Os métodos de construção indutiva, também referenciados como de extração de atributos, o1 ainda de reparametrização (Sebastiani, 1999), tem como propósito obter novos atributos através da combinação dos atributos originais, que maximizem a precisão dos resultados. Dessa abordagem, clustering é um dos métodos citados na literatura.

Clustering, é uma estratégia que visa agrupar dados com alto grau de similaridade. No caso, para redução da dimensão, esse método é usado para agrupar os atributos originais de acordo com o grau de relacionamento semântico que possa haver entre os mesmos. Os clusters, ou os centróides, podem ser então usados como novos atributos. Desta forma, costuma-se remover termos redundantes.

Li e Jain (Li and Jain, 1998b) utilizaram a medida de similaridade semântica em termos da co-ocorrência e co-ausência dos atributos no conjunto de treinamento. Seus experimentos mostraram reduzida melhoria em relação a representação com atributos originais. Entretanto, a redução da representação foi consideravelmente significativa. 


\subsection{Considerações Finais}

Como mencionado no Capítulo 2. para a obtençăo de uma representaçăo que possa ser utilizada pelos algoritmos de descoberta de padrõos. na fase de pré-processamento podem ser desempenhadas três atividades: identificação de atributos, atribuição de pesos e redução da dimensão. que se interagem conforme ilustrado na Figura 2.2. Algumas das principais operações realizadas em cada uma dessas atividades foram abordadas nesse capítulo.

Tendo em vista que grande parte das pesquisas sobre Text Mining são relacionadas com a categorização de textos. muitas dessas operações podem ser consideradas técnicas clássicas da área de Recuperação de Informação. Outras técnicas de Processamento de Língua Natural também tem sido úteis para identificar atributos. contribuindo para a formação de unna representação mais coesa em relação ao contexto dos documentos. Talvez por cansa da complexidade das técnicas lingiiísticas. on mesmo em função de ser bastante conhecido e simples, o algoritmo para stemming, como o de Porter (Porter, 1980), ainda vem sendo muito utilizado.

No caso da atribuição de pesos. existem diferentes métricas que possibilitar mensurar o quanto um atributo contribui para representar um documento. Como mostrado, as medidas são geralmente baseadas em cálculos que usam a frequiência do atributo. Cálculos probabilísticos também são feitos quando se deseja reduzir a dimensão da representação originalmente obtida.

Os métodos para reduçăo dos atributos são importantes, pois no caso dos textos em que as palavras são normalmente indicadas como atributos, a possibilidade de se ter uma representação de grande dimensão é bastante alta. Isso pode ser observado também com base na lei de Zipf (Zipf, 1949), que não é útil apenas para a elaboração de stopwords. Segundo Zipf. a relação entre o tamanho do vocabulário e o tamanho do texto pode variar de acordo com a Figura 3.4 .

Com base no que foi descrito aqui, pode-se observar que a etapa de preparação de dados textuais é bastante custosa. Além disso. muitas das pesquisas tem sido direcionadas para textos de diversos idiomas. embora em número bastante reduzido para aqueles diferentes do inglês. Para esse idioma, muitos dos utilitários necessários já estão construídos e disponíveis. como por exemplo. listas de stopwords. algoritmos para normalização de

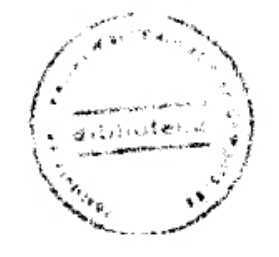




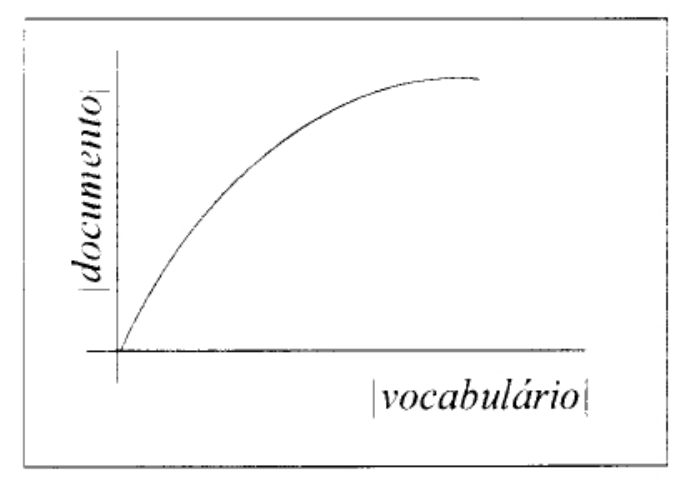

Figura 3.4: Relação entre o tamanho do vocabulário e o tamanho do texto, segundo a lei de Zipf

palavras de diferentes abordagens, dicionários cletronnicos, etc.

Contando com alguns recursos para o portugnês. foi projetado e construído um módulo para apoiar a ctapa de pré-processamento de textos em português. A descrição da implementação desse módulo é abordada no próximo capítulo. 


\section{Capítulo 4}

\section{Módulo de Pré-processamento de}

\section{Texto}

Como mencionado. este trabalho tem como meta a investigação de estratégias que permitam preparar os textos para a extração de conhecimento. Essa investigação foi voltada para textos em portuguès, uma vez que os mesmos podem conter informações importantes e novas. mas não são considerados na maioria dos trabalhos que em geral utilizam-se de estratégias voltadas para o idioma inglês.

Para que outras pesquisas envolvendo Text Mining possam ser apoiadas no Labic ${ }^{1}$ (Laboratório de Inteligência Computacional) de forma a reduzir os esforços, alguns dos principais métodos para pré-processamento de textos estudados foram implementados para serem integrados ao Ambiente Computacional para Extraçāo de Conhecimento de Dados e Textos, denominado Discover. Esse ambiente integra várias funcionalidades de Aprendizado de Máquina, Mineração de Dados e Mineração de Textos para apoiar todas as etapas do processo de descoberta de conhecimento, como mostrado na Figura 4.1.

Visto que vários trabalhos realizados no Labic estão sendo integrados a esse ambiente. incluindo este, os métodos implementados como parte desse trabalho se deu na forma de scripts Perl e se encontram inseridos na estrutura do módulo de pré-processamento de texto, como mostrado na Figura 4.2 .

Como abordado. para identificar quais termos dos documentos podem ser utilizados

\footnotetext{
${ }^{1}$ http://labic.icmc.sc.usp.br
} 


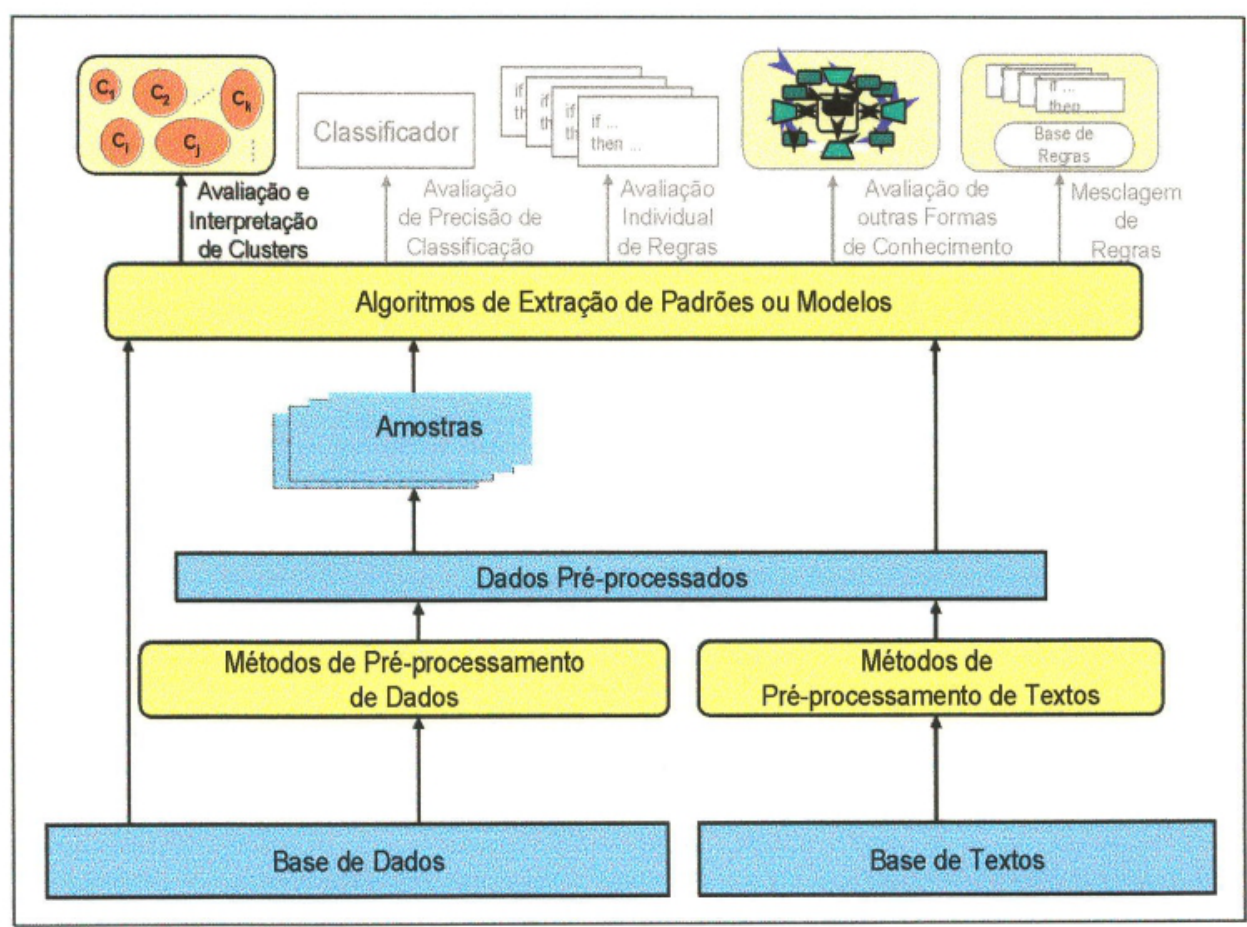

Figura 4.1: Visão geral do ambiente computacional Discover

como atributos é necessário que alguns passos sejam realizados, tais como, a construção de uma lista de stopwords e a normalização das palavras para um termo comum. Por se tratar de textos escritos em português, houve a necessidade de se construir uma lista de stopwords e pesquisar as estratégias envolvidas para prover a normalização das palavras, com o intuito de auxiliar na construção dos scripts para identificação dos atributos.

A descrição da realização dessas atividades é abordada nas duas seções subseqüentes, e nas demais seções são tratados os algoritmos referentes a cada script.

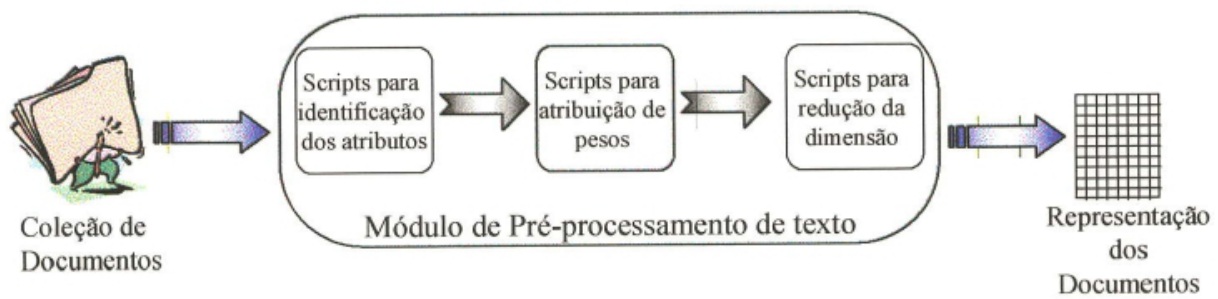

Figura 4.2: Estrutura do módulo de pré-processamento de texto 


\subsection{Lista de Stopwords}

A construçào da lista de stopwords foi readizada. inicialmente. com base em uma lista disponível em (OpenMuscat. 2000) contendo 117 palavras. entre elas: a. e. o. da. de e do. Com o propósito de incrementar a lista. foram analisados trinta documentos jornalísticos de diferentes assuntos em portugues. coletados aleatoriamente na web.

()s trinta documentos foram individualmente processados, e através desse processamento foram gerados para cada um deles um arquivo correspondente contendo cada palavra diferente encontrada e a quantidade de vezes que a mesma aparece nos documentos. Os arquivos resultantes foram processados. então. para a formação de uma lista única onde as palavras aparecem ordenadas de acordo com sua freqüencia total.

A partir dessa ordenaçăo foi possível verificar que as palavras que apareciam com grande freqüência, geralmente. são classificadas como preposições. conjunçôes. artigos, entre outros. Além disso, foi percebido que algumas das palavras que ocorriam poucas vezes (como as de frequiencia igual a 1) poderiam ser consideradas de raro uso, o que constata a lei de Zipf (Zipf, 1949). citada na página 35.

Por meio de uma prévia observação e análise da lista resultante, concluiu-se que as palavras que apareciam mais que 99 vezes poderiam ser consideradas muito comuns, não tendo relevância para a tarefa de classificação. Estabelecendo um ponto de corte de valor 100. foram selecionadas 73 palavras dentre as 13.650 palavras existentes. Dessas 73 palavras, 18 não foram acrescentadas à lista. como as palavras lei. software, computação; 48 já se encontravam na lista de stopwords, como as palavras da. de. na, em: e 7 palavras foram consideradas irrelevantes e não estavam presentes na lista.

Mesmo que algumas das palavras que apresentavam freqüência igual a 1 fossem consideradas de raro uso, essas não foram incluídas na lista de stopwords. Isso porque objetivon-se, neste trabalho, a construção de uma lista de stopwords genérica, que fosse utilizada para qualquer domínio. e as palavras de frequiencia igual a 1 poderiam ser de raro uso para algum domínio. mas talvez não para outros. Vale ressaltar que tendo uma lista genérica de stopwords, a modificação dessa para $11 \mathrm{~m}$ domínio específico pode ser consideravelmente fácil, justificando assim o fato de não serem adicionadas as 73 palavras com frequiência superior a 99 e as 7.415 palavras com frequiência ignal a 1, sem uma análise 
prévia.

Além do acréscimo de novas palavras à lista de stopwords. o procedimento acima foi realizado com o objetivo de verificar a aplicação da lei de Zipf. caso não se tivesse 1 ma lista de stopwords. Se o ponto de corte superior fosse estimado para 200, todas as palavras removidas estariam na lista anteriormente definida. e se o ponto de corte inferior fosse 1. muitas palavras escritas de forma errada e em grande maioria os números também seriam removidos. Desta forma. se o domínio dos documentos for bem definido, a lei de Zipf pode ser útil em casso de năo existência da lista de stopwords previamente.

Após o acréscimo das sete palavras, a lista de stopwords foi acrescida com mais 298 palavras. fazendo-se $ı$ so de ım dicionário para o portıguês (Ferreira. 2001). Mais tarde, fazendo uso de uma lista existente na dissertação de mestrado que aborda a construção de IIm sistema para classificaçăo de páginas de publicações (Neves, 2001), a lista de stopwords resultante passou a ser formada por 613 palavras. Essa é a lista que foi utilizada neste trabalho.

\subsection{Abordagens para Normalização das Palavras}

Para tornar a representação menor e até mesmo mais coesa, geralmente, as palavras que possuem uma estrutura morfológica semelhante são associadas a um termo comum. Por questão de convenções e para evitar dúvidas. neste trabalho esse termo comum é chamado de stem. se a estratégia que o designa não envolver um tratamento lingüístico mais complexo (através de análise léxica ou sintática) que possibilite. muitas vezes, que o termo resultante seja o que dá origem à palavra. Caso contrário, chamamos o termo de forma canônica.

Portanto, neste trabalho, para realizar a normalização das palavras foram considerados dois métodos: um baseado no algoritmo de Porter, para identificar os stems, e outro baseado em análise morfológica da palavra e análise gramatical da sentença em que se encontra. para identificar as formas canônicas.

() algoritmo utilizado para obtenção de stem adaptado para o português encontrava-se disponível em (OpenMuscat, 2000) c está implementado na Linguagem C. O 
algoritmo é muito semelhante ao usado para o idioma inglês. dependendo da mesma métrica $m$ baseada na ocorrência de sequêencias de vogais e consoantes (pag. 35). A adaptaçào diesse algoritmo para o portıguès consiste na modificaçào de algumas regras para adequá-las aos sufixos comumente encontrados na língua portuguesa.

Outro tratamento diferencial no algoritmo de stemming para o português é a existência de uma lista de flexões. geralmente as mais usadas. dos principais verbos irregulares. As flexões são comparadas à palavra que se deseja normalizar e caso o resultado dessa operação seja positivo. o stem retornado pelo algoritmo é o índice correspondente da lista onde a flexão se encontra. Por exemplo. a palavra ser é o índice das flexões é, foi. são. foram. etc. Se a palavra a ser normalizada fosse são. então o stem retornado seria ser.

Pela característica intrínseca dos verbos irregulares. seria muito difícil, ou mesmo impossível. o uso da métrica $m$ e de um conjunto de regras que pudesse fazer o correto mapeamento para o verbo original. Assim, essa lista de flexões facilita bastante o processamento. Para exemplificar as diferentes abordagens utilizadas para normalização das palavras é considerado o seguinte trecho².

"Busca por informação deve congestionar sites. No dia da eleição de 1996, milhões de pessoas acessaram o ciberespaço pela primeira vez para buscar informações de último minuto sobre a corrida presidencial."

Em relação ao texto descrito, o uso do algoritmo baseado no de Porter resulta na normalização mostrada na Tabola 4.1.

Além da conversão das palavras para stems. foi considerada a associação das palavras a sua forma canônica, ou seja, ao termo que a gera. Para que isso fosse possível, contou-se com $11 \mathrm{~m}$ etiquetador ${ }^{3}\left(N_{1} n e s, 1996\right)$, que foi adaptado para o propósito de retornar a identificação da função gramatical das palavras e sua forma canônica. Essa ferramenta tem como entrada os parágrafos de um texto, que são analisados para a identificação dos tokens léxicos, que são as formas canônicas dos termos encontrados associados a sua provável funcionalidade na sentença, como: adjetivo. substantivo. etc. Levando-se

\footnotetext{
${ }^{2}$ Extraido da página http://www.estado.com.br/editorias/2000/11/05/int867.html.

${ }^{3}$ Ferramenta cedida pelo NILC (http://nilc.icmc.sc.usp.br) para realização desta pesquisa.
} 


\begin{tabular}{|l||l|l|}
\hline $1996 \rightarrow 1996$ & deve $\rightarrow$ dev & pela $\rightarrow$ pel \\
\hline $\mathrm{a} \rightarrow \mathrm{a}$ & dia $\rightarrow$ dia & pessoas $\rightarrow$ pesso \\
\hline acessaram $\rightarrow$ acess & eleição $\rightarrow$ eleiçã & por $\rightarrow$ por \\
\hline Busca $\rightarrow$ busc & informação $\rightarrow$ inform & presidencial $\rightarrow$ presidencial \\
\hline buscar $\rightarrow$ busc & informações $\rightarrow$ inform & primeira $\rightarrow$ primeir \\
\hline ciberespaço $\rightarrow$ ciberespac & milhões $\rightarrow$ milhõ & sites $\rightarrow$ sit \\
\hline congestionar $\rightarrow$ congestion & minuto $\rightarrow$ minut & sobre $\rightarrow$ sobr \\
\hline corrida $\rightarrow$ corr & No $\rightarrow$ no & último $\rightarrow$ últim \\
\hline da $\rightarrow$ da & o $\rightarrow o$ & vez $\rightarrow$ vez \\
\hline de $\rightarrow$ de & para $\rightarrow$ par & \\
\hline
\end{tabular}

Tabela 4.1: Exemplificação da saída do algoritmo para stemming baseado no algoritmo de Porter

em consideraçào o trecho abordado anteriormente. na Tabela 4.2 é mostrado o resultado gerado pelo etiquetador.

\begin{tabular}{|l||l|}
\hline Busca $\rightarrow$ VERBO[buscar] & de $\rightarrow$ PREPOSICAO \\
\hline para $\rightarrow$ PREPOSICAO & por $\rightarrow$ PREPOSICAO \\
\hline milhões $\rightarrow$ NUMCARD[milhão] & buscar $\rightarrow$ VERBO[buscar] \\
\hline informação $\rightarrow$ SUBSTANTIVO[informação] & de $\rightarrow$ PREPOSICAO \\
\hline informações $\rightarrow$ SUBSTANTIVO[informação] & deve $\rightarrow$ VERBO[dever] \\
\hline pessoas $\rightarrow$ SUBSTANTIVO[pessoa] & de $\rightarrow$ PREPOSICAO \\
\hline congestionar $\rightarrow$ VERBO [congestionar] & acessaram $\rightarrow$ VERBO[acessar] \\
\hline último $\rightarrow$ ADJETIVO[último] & sites $\rightarrow$ NOMPRO \\
\hline$o \rightarrow$ ARTIGO & minuto $\rightarrow$ SUBSTANTIVO[minuto] \\
\hline No $\rightarrow$ PREPOSICAO & ciberespaço $\rightarrow$ SUBSTANTIVO[ciberespaço] \\
\hline sobre $\rightarrow$ PREPOSICAO & dia $\rightarrow$ SUBSTANTIVO[dia] $]$ \\
\hline pela $\rightarrow$ PREPOSICAO & a $\rightarrow$ ARTIGO \\
\hline da $\rightarrow$ PREPOSICAO & primeira $\rightarrow$ ADJETIVO[primeiro] \\
\hline corrida $\rightarrow$ SUBSTANTIVO[corrida] & eleição $\rightarrow$ SUBSTANTIVO[eleição] \\
\hline vez $\rightarrow$ SUBSTANTIVO[vez & presidencial $\rightarrow$ ADJETIVO[presidencial] \\
\hline
\end{tabular}

Tabela 4.2: Exemplificação da saída do etiquetador

O uso do etiquetador é justificado pela necessidade de se investigar o quanto a representação pode se tornar mais significativa. on mesmo tornar o resultado de uma tarefa de Text Mining mais eficiente, se for adicionado $1 \mathrm{~m}$ processamento lingüístico mais complexo. Isso porque os algoritmos para gerar stem são normalmente constituídos por regras que em geral foram bastante observadas no idioma ao qual o algoritmo está relacionado. Assim. ele é bastante generalista e por não se basear na análise da função 
sintática da palavra no texto. muitas vezes. palavras que possuem um mesmo padrão de prefixo são indexadas a $1 \mathrm{~m}$ mesmo stem. mesmo que o significado das mesmas sejam completamente distintos.

() verbo casar. os substantivos casa e caso são exemplos clássicos de palavras com o mesmo prefixo (cas). mas que possuem significados diferentes. Vesse aspecto, um etiquetador utilizando sta base léxica e uma análise da função gramatical dos termos no parágrafo poderia identificar que a palavra casar é um verbo. portanto a sua forma canônica seria casar. enquanto casa é um substantivo o tem a si mesmo como forma canônica. sendo que esta situação se repete para a palavra caso.

\subsection{Scripts para Identificação dos Atributos}

Levando-se em consideração os aspectos abordados nas seções anteriores, foram implementados seis scripts $\mathrm{cm}$ Perl para identificar os atributos, que consiste no primeiro passo do módulo de pré-processamento de texto como ilustrado na Figura 4.2. Dois desses scripts, ScpDStem e ScpDCan, são baseados no algoritmo utilizado em (Mladenić, 1998), sendo que o primeiro utiliza o programa para identificar stem e o segundo utiliza o etiquetador. Seguindo esse mesmo raciocínio. baseado no algoritmo utilizado na ferramenta Kea (Witten et al. 1999), foram construídos o terceiro e quarto scripts, denominados de ScpKStem e SpcKCan. respectivamente.

()s quatro scripts mencionados são semelhantes pelo fato de que procuram formar atributos compostos por mais que uma palavra. chamados n-grams. Enquanto os dois restantes. ScpNStem e ScpNCan, foram implementados com base nas definições de pré-processamento de textos encontradas em (Weiss and Indurkhya, 1997) e identificam apenas atributos formados por uma única palavra. Todos esses scripts são descritos, dois a dois. nas próximas subseções.

\subsubsection{Scripts ScpDStem e ScpDCan}

Para a implementação dos scripts ScpDStem e ScpDCan, foram realizadas algumas alterações no Algoritmo 1 Cálculo dos n-grams (pag. 38), como a chamada de um método 
que possa realizar a normalização e de um método para contabilizar a freqüência dos atributos identificados de modo a facilitar a atribuição de pesos. () algoritmo derivado do Algoritmo 1 e que conta com as alteraçōes mencionadas é descrito no Algoritmo 2.

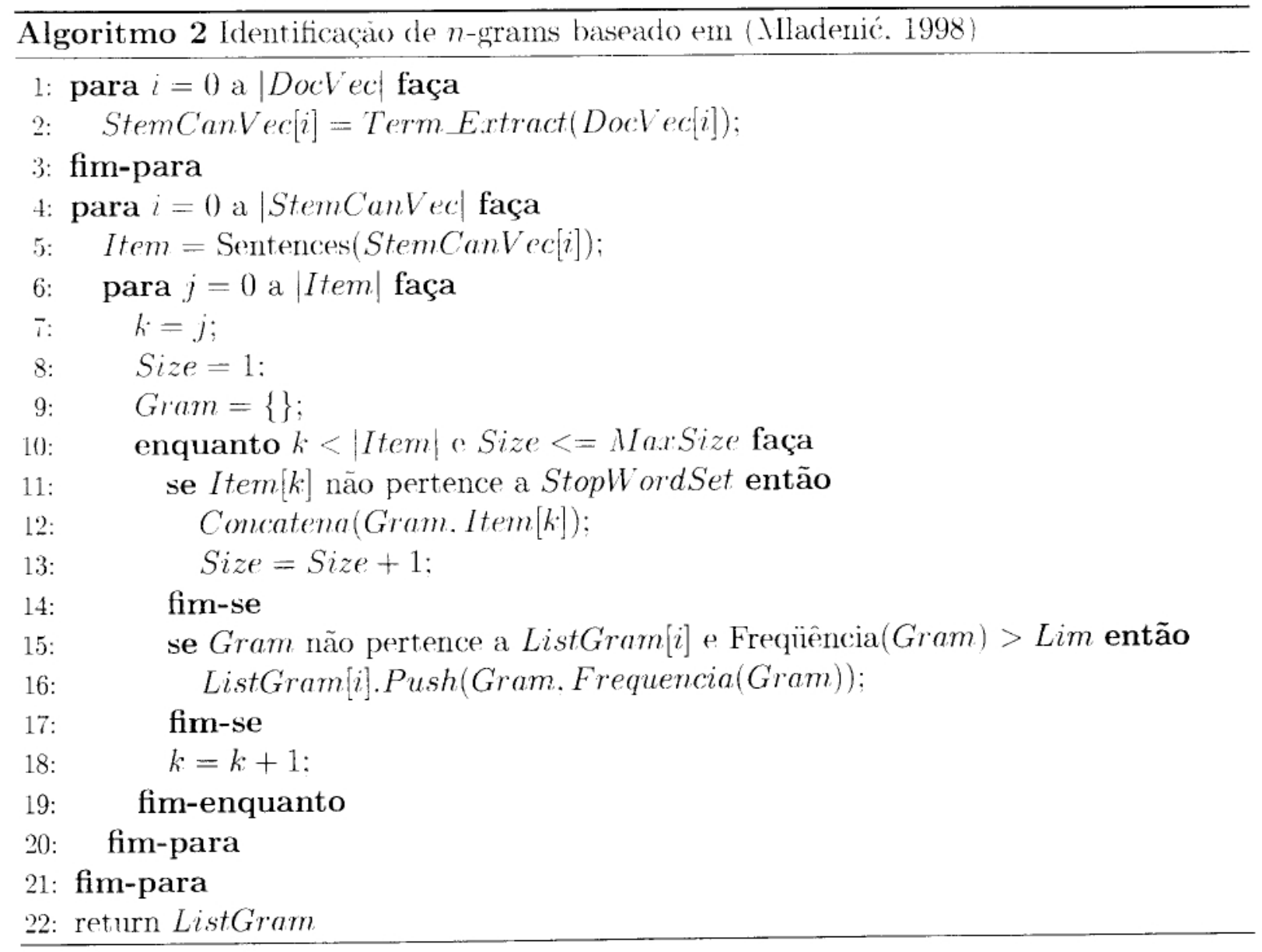

O Algoritmo 2 tem como entrada a coleção de documentos representada por DocVec e a lista de stopword identificada por StopWordSet. que deve ser convertida para o stem se a função Term Extract fizer uso do algoritmo para gerar stem. Caso Term_Extract fizer uso do etiquetador e as palavras de DocVec[i] forem convertidas para a forma canônica, então, a lista de stopwords pode ser mantida como a original.

A decisão sobre a transformação da lista de stopwords para seus respectivos stems deve-se ao fato de se ter escolhido primeiro converter todas as palavras dos documentos para stem ao invés de fazer a remoção das palavras da lista de stopword. Se a remoção das palavras de tal lista for realizada primeiro, possivelmente deve-se utilizar uma lista bem maior e mais completa de stopwords englobando todas as possíveis flexões de cada palavra considerada não relevante. 
Por outro lado. quando as palavras sào transformadas para a forma canônica. poder-se-ia utilizar a lista de stopwords também já convertida para as respectivas formas canonicas. Porém. como o etiquetador além de fazer uso de um analisador léxico, também analisa a funçăo de uma palavra baseada em algumas palavras vizinhas, o resultado da conversăo de palavras isoladas. como as da lista. para a forma canônica pode ser pouco diferente da lista original.

A função Term_Extract é o que diferencia os stipts SpcDStem e SpcDCan. Nesse passo o script SpcDStem utiliza um recurso para converter as palavras para os stem, enquanto o SpeDCan utiliza o etiquetador para associar as palavras a suas formas canônicas. Em ambos os scripts. o tamanho máximo do $n$-gram a ser formado é 5 e estes devem ter frequïencia de pelo menos 4. como abordado em (Mladenić. 1998). Portanto, utiliza-se MaxSize igual a je Lim igual a 3 para o Algoritmo 2.

As sentenças de um documento pertencente a DocVec são divididas em tokens que săo analisados. e caso não forem uma stopword podem fazer parte de um n-gram que possivelmente formará um atributo. ()s atributos encontrartos em cada documento são gravados em arquivos distintos, associados a suas respectivas freqüencias. Os arquivos resultantes, são representados por cada elemento de ListGram.

As sentenças consideradas para exemplificação desses. bem como dos outros quatro scripts são:

"Nesta eleição. os internautas não precisarão nem mesmo de um computador com um modem para acompanhar os resultados. Vários sites, incluindo o Yahoo!. transmitirão boletins diretamente para telefones celulares com tecnologia para tanto. A rápida expansão dos sites de notícia. como os portais do Yahoo!. MSN e America (Online, devem dar mais opções para os internautas e, à medida que os números forem sendo liberados, esses sites poderão interpretar os resultados com equipes próprias de comentaristas. Os internautas terão acesso a uma Internet muito mais completa. capaz de oferecer sofisticadas imagens e áudio mais puro ao sempre crescente número de internautas de conexões de alta velocidade."

O resultado produzido pela utilização dos scripts ScpDStem e ScpDCan pode ser 
observado na Tabela 4.3.

\begin{tabular}{|l||l|}
\hline \multicolumn{1}{|l|}{ script ScpDStem } & script ScpDCan \\
\hline \hline numer & resultado \\
\hline naho & resultado equipe próprio \\
\hline acompanh & opção internautas \\
\hline internaut & resultado vário sites yahoo boletim \\
\hline comput acompanh & sites \\
\hline comput & resultado vário \\
\hline numer send & internet completo \\
\hline acompanh result & resultado equipe próprio comentarista \\
\hline opçõ internaut & yahoo \\
\hline sit & número \\
\hline comput acompanh result & internet completo capaz sofisticado \\
\hline opçõ & computador modem \\
\hline veloc & internautias \\
\hline port yaho & opção internautas medida número liberado \\
\hline result & internet completo capaz sofisticado imagem \\
\hline port & internet completo capaz \\
\hline & opção \\
\hline & resultado vário sites \\
\hline & computador modem resultado vário \\
\hline & opção internautas medida \\
\hline & computador modem resultado vário sites \\
\hline & computador \\
\hline & internet \\
\hline & computador modem resultado \\
\hline & resultado vário sites yahoo \\
\hline & opção internautas medida número \\
\hline & resultado equipe \\
\hline
\end{tabular}

Tabela 4.3: Exemplificação da saída dos scripts ScpDStem e ScpDCan

\subsubsection{Scripts ScpKStem e ScpKCan}

O algoritmo utilizado na ferramenta Kea (Witten et al., 1999) considera os atributos formados por até 3-grams, sendo que os termos que compõem o primeiro e o último gram não devem ser stopwords. Uma versão adaptada desse algoritmo. utilizada nos scripts ScpKStem e ScpKCan. é mostrada no Algoritmo 3. 


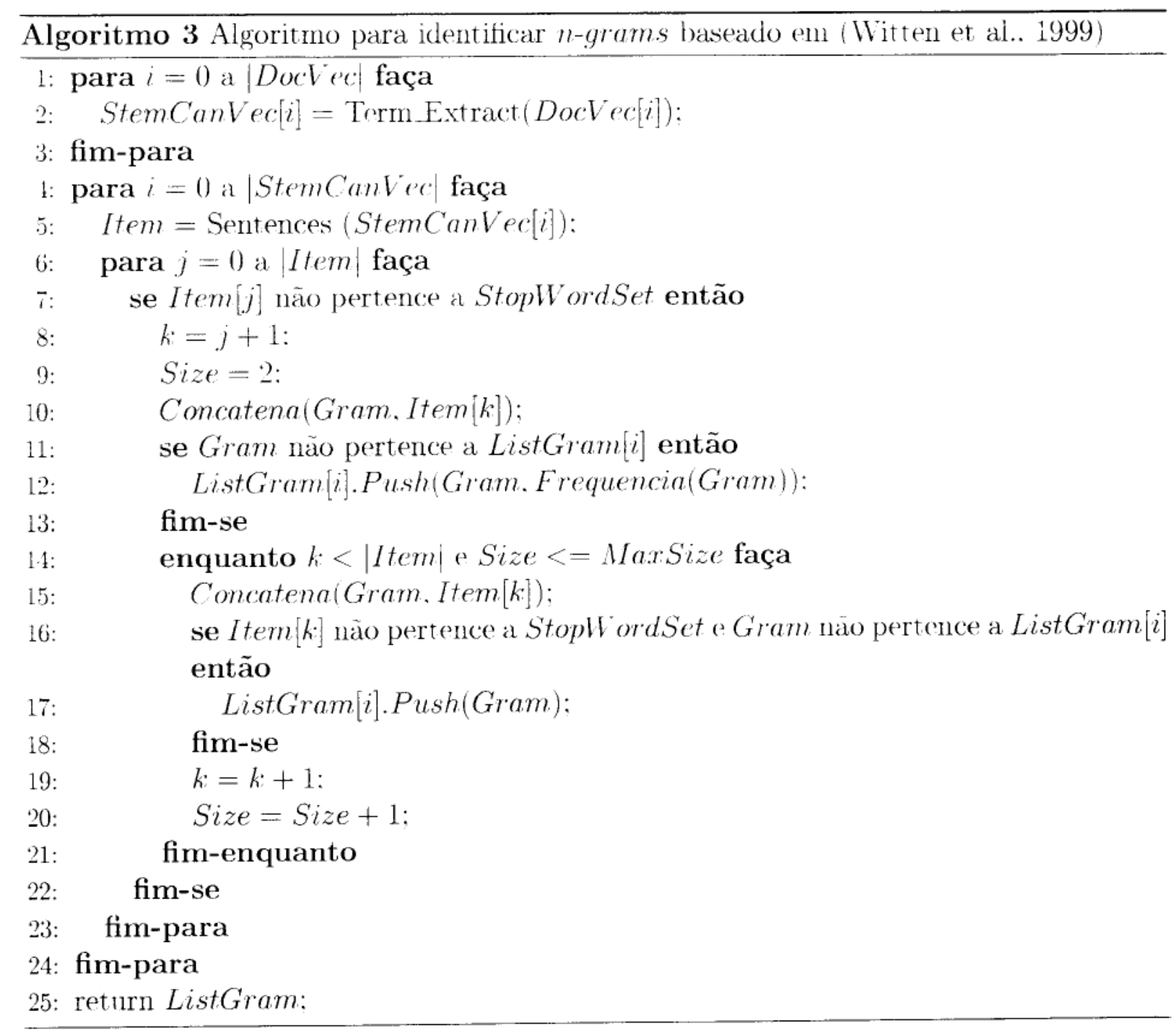

Como utilizado na ferramenta Kea. foi considerado MaxSize igual a três. As demais variáveis utilizadas possuem os mesmos valores e funcionalidades que no Algoritmo 2. A diferença, no entanto. não se resume ao número de termos que são considerados na formação do gram. Pela característica do algoritmo da ferramenta Kea, os grams formados por um e por dois termos estarão contidos no conjunto de atributos retornados pelo Algoritmo 2, porém os 3-grams identificados no Algoritmo 3 não necessariamente estarão. pois não é garantido que o segundo termo não seja uma stopword. Além disso, nesse algoritmo não há um limitante inferior de freqüêencia que determine se o gram será um atributo.

Uma boa justificativa para o uso da abordagem de Kea é a construção de atributos menores. sendo portanto um algoritmo menos custoso. Além disso. o fato de possibilitar 
que as palavras intermediárias sejam stopwords pode ser importante. por exemplo, no caso da representação de sentenças negativas. Cono a palavra "não" faz parte da lista de stopwords. com os scripts baseados no Algoritmo 1. náa é possivel definir se o atributo foi on nāo construído a partir de uma sentença negativa.

Com base no Algoritmo 3. a saída resultante para os sertipts SepKStem e SepKCan pode ser vista nas Tabela 4.4 e 4.5 . respectivamente.

\begin{tabular}{|c|c|c|}
\hline acess & complet & internant de conexó \\
\hline oferec & sit & acompanh \\
\hline comput & internaut nà precis & onlin \\
\hline sit de notic & acompanh os result & conexõ \\
\hline internaut ter acess & opçõ & sit pod interpret \\
\hline amer & crescent & internet \\
\hline port & sofistic & andi \\
\hline crescent numer & interpret & port do yaho \\
\hline sofistic imag & andi mais pur & diret \\
\hline interpret os resilt & precis & tecnolog \\
\hline boleti & eleiçã & liber \\
\hline pur & telefon & boleti diret \\
\hline equip & msn & rap \\
\hline telefon celul & capaz & expansáa \\
\hline msn e amer & rap expansã & transmit \\
\hline capaz de oferec & expansã dos sit & notic \\
\hline result & transmit boleti & celul \\
\hline imag & numer & resint \\
\hline transmit boleti diret & celul com tecnolog & imag e andi \\
\hline Inumer de internaut & resut com equip & veloc \\
\hline comentar & internault & numer ser send \\
\hline send & yaho & \\
\hline
\end{tabular}

Tabela 4.4: Exemplificação da saída do script ScphStem 


\begin{tabular}{|c|c|c|}
\hline acessar & dever & modem \\
\hline resutados com equltipe & acompanhar & dever dar \\
\hline msn & sites & acompanhar os resultado \\
\hline diretamente & msn e america & sites de notícia \\
\hline america & eleiçào & noticia \\
\hline sites incluir & áudio & eleição os internautas \\
\hline número & sites poder & áudio mais puro \\
\hline 'quipes & número de internautas & sites poder interpretar \\
\hline boletim & expansão & número ir verbo \\
\hline sofisticar & boletim diretamente & expansão dos sites \\
\hline oferecer & sofisticar imagem & capaz \\
\hline imagem & online & tecnologia \\
\hline capaz de oferecer & imagem e áudio & online dever \\
\hline telefone & celular & incluir \\
\hline online dever dar & telefone celular & celular com tecnologia \\
\hline incluir o vahoo & opçào & transmitir \\
\hline comentarista & internautas & poder \\
\hline transmitir boletim & completo & internautas de conexão \\
\hline poder interpretar & transmitir boletim diretamente & completo capaz \\
\hline internautas nāo precisar & portal & vário sites \\
\hline computador & internautas ter acessar & portal do vahoo \\
\hline vário sites incluir & conexão & internet \\
\hline precisar & velocidade & crescente \\
\hline interpretar & puro & yahoo \\
\hline crescente número & interpretar os resutados & rápido \\
\hline yahoo msn & dar & liberado \\
\hline rápido expansão & vahoo transmitir & dar mais opção \\
\hline liberado esses sites & resultado & yahoo transmitir boletim \\
\hline resultado vário & resultado vário sites & resutados \\
\hline
\end{tabular}

Tabela 4.j̃: Exemplificação da saída do script ScpKCan

\subsubsection{Scripts ScpNStem e ScpNCan}

De acordo com (Weiss and Indurkhya, 1997), para representar os documentos no formato atributo-valor, podem ser seguidos três passos:

1. Encontrar os atributos preliminares, on seja, os $N$ termos mais frequientes.

2. Realizar um filtro para remover as palavras consideradas stopword da lista de termos obtidas no passo anterior.

3. Considerar os $j$ termos restantes, após o filtro, como atributos e associar as medidas de peso a cada um desses. 
De forma a liniformizar os experimentos e comparaçós com os demais algoritmos, foi considerado ainda a transformação dos j termos em stem on na forma canônica, para implementação dos scripts ScpNStem e ScpNCan que utilizam o Algoritmo 4.

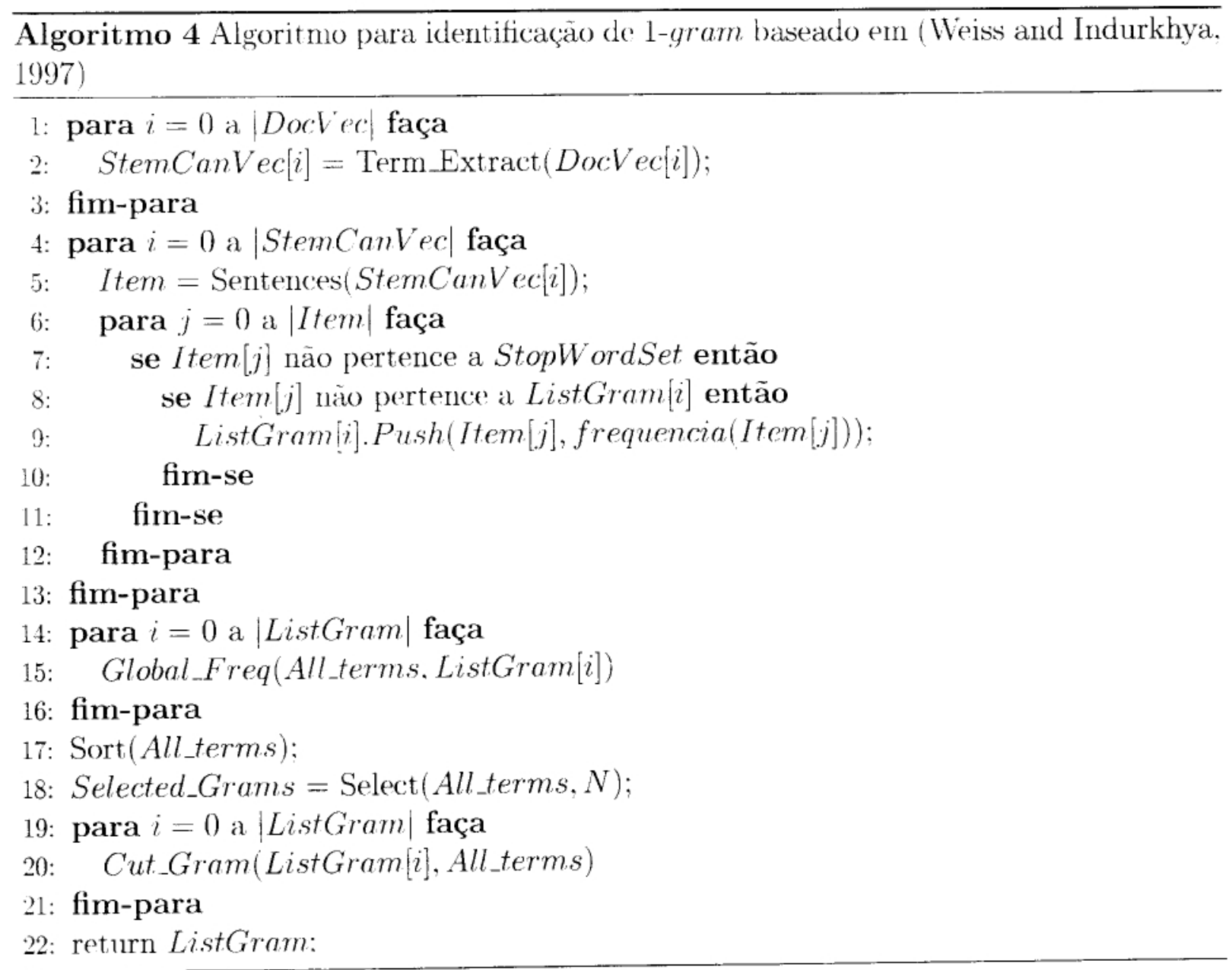

Nesse algoritmo. inicialmente, são retiradas de cada arquivo as palavras consideradas stopwords, as palavras restantes e sua freqüencia relativa a cada documento são armazenadas em um elemento de ListGram. que é a lista de possiveis atributos. Com a função Global_Freq é calculada a frequêencia global dos atributos, ou seja, a quantidade de vezes que aparece em todos os documentos, que é reportada em All_terms.

A lista All_terms é ordenada de forma decrescente de acordo com a frequiência de cada elemento pela função Sort. Com base nessa ordenação, um processamento para selecionar os $N$ termos é realizado, sendo esse $N$ definido pelo usuário. Essa seleção é feita com a chamada da função Select que retorna como resultado os $N$ termos selecionados armazenados em Selected_Grams. 
É importante lembrar que alguns elementos de ListGram podem ter freqüencias iguais. Como nesse passo não é possível verificar que atributos seriam mais importantes, são selecionadas as $N$ freqüiencias superiores e os termos que são associadas a essas. Desta forma. a quantidade de atributos resultantes pode ser superior a $N$. como pode ser observado no resultado obtido com a designação de $N=10$ e mostrado na Tabela 4.6.

Os termos que não foram selecionados são removidos de cada arquivo de ListGram, pela função Cut_Gram. A ListGram. cntão. é retornada como resiutado do algoritmo.

Nessa adaptação, inverten-se os passos 1 e 2, do algoritmo original apresentado em (Weiss and Indurkhya. 1997). Essa escolha foi feita. pelo fato de que quando a freqüência global é calculada. os termos que consistem a lista de stopwords são na grande maioria mais frequientes. Por exemplo. se o usuário definisse que gostaria de obter os cinco atributos mais freqüentes. em muitas situações o resultado seria uma lista vazia, caso fossem realizados os passos 1 e 2 na ordem original.

\begin{tabular}{|l|l||l|l|l|}
\hline \multicolumn{2}{|c|}{ script ScpNStem } & \multicolumn{3}{c|}{ script ScpNCan } \\
\hline \hline sit & boleti & internautas & oferecer & acessar \\
\hline internaut & diret & sites & completo & notícia \\
\hline yaho & notic & resultado & velocidade & telefone \\
\hline celul & msn & yahoo & portal & msnn \\
\hline nuımer & eleiçã & número & áudio & ir \\
\hline telefon & send & liberado & expansão & boletim \\
\hline result & comentar & computador & dever & inchiir \\
\hline liber & expansã & eleição & precisar & capaz \\
\hline port & equip & comentarista & vário & modem \\
\hline amer & precis & poder & sofisticado & rápido \\
\hline resut & rap & internet & conexão & celular \\
\hline interpret & comput & dar & americaonline & diretamente \\
\hline onlin & opçõ & tecnologia & opção & crescente \\
\hline acompanh & transmit & interpretar & puro & imagem \\
\hline tecnolog & & transmitir & acompanhar & equipe \\
\hline
\end{tabular}

Tabela 4.6: Exemplificaçāo da saída do scripts ScpNStem e ScpNCan 


\subsection{Scripts para Atribuição de Pesos}

Considerando os arquivos gerados pelo nso de algum dos scripts mencionados, é possível atribuir pesos baseando-se nos valores da frequiência associada a cada atributo. Assim, foram construidos seis scripts. 1 m para cada medida definida na Seção 3.2 (pag. 39).

() algoritmo comum à construção dos seis scripts para atribuição de pesos pode ser representado pelo Algoritmo 5. () hash Hash_Atrib é construído a partir dos atributos de todos os arquivos. formando uma tabela tal qual a ilustrada na Tabela 2.1 (pag. 6).

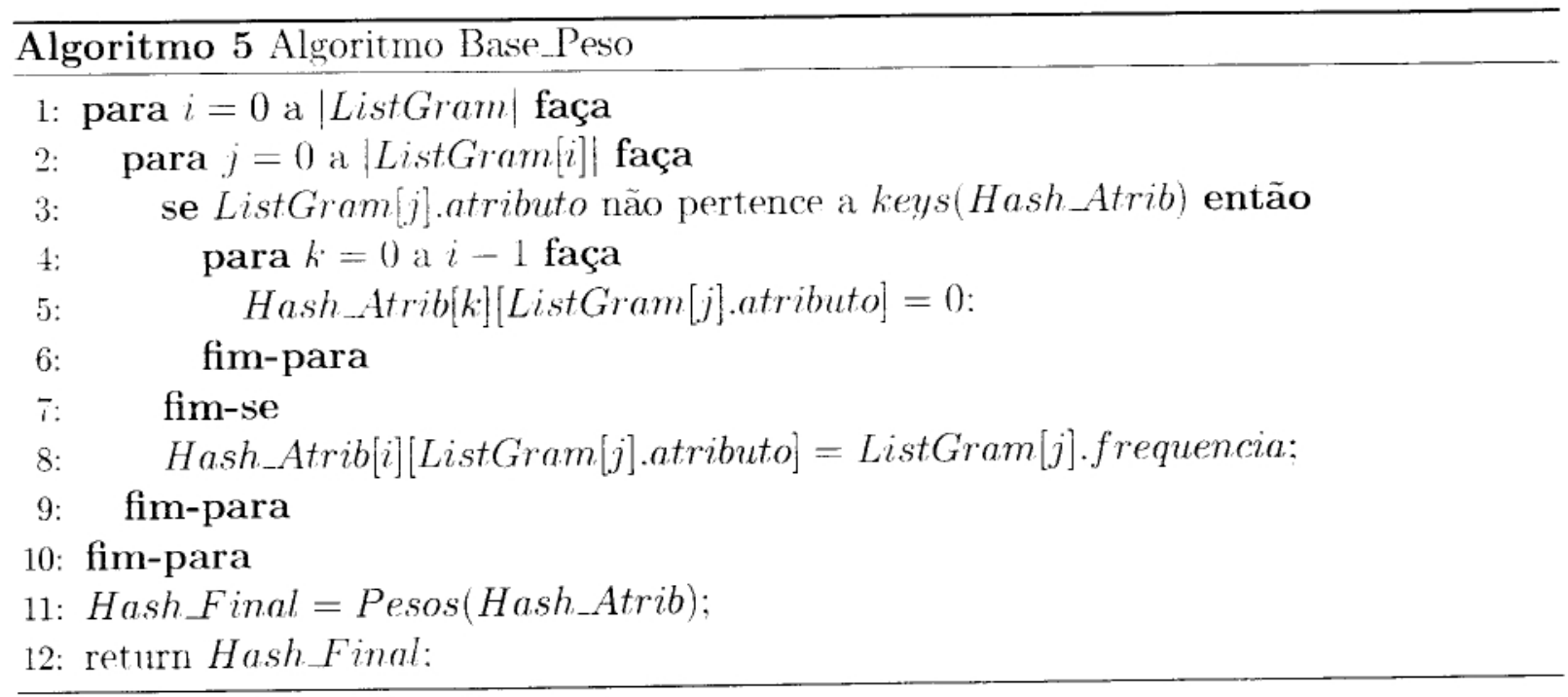

Nesse algoritmo é realizada uma chamada à Pesos que é uma função que aplica à Hash_Atrib uma das medidas abordadas na Seção 3.2 para associar os pesos e obter a representação atributo-valor. referenciada como Hash_Final. A chamada da função para cada medida é que distingue um script do outro, sendo esses denominados de Scp_Bool, em que é atribuído o peso booleano; Scp_Freq. cm que o peso corresponde à freqüência do atributo: Scp_tfidf; Scp_tfc; Scp_ltce Scp_entropia. Esses quatro últimos tem a função peso associada às quatro medidas restantes: $t f \times i d f, t f \times i d f$ normalizado. $\log t f \times i d f$ normalizado e entropia. respectivamente.

() arquivo obtido da estrutura Hash_Final ainda pode ser considerado grande, e portanto o uso de algumas técnicas de redução de sula dimensão pode ser necessário. Para isso. foram construídos quatro scripts compreendendo cada uma das medidas de redução por seleção de atributos, descritas na Seção 3.3 (pag 46). 


\subsection{Scripts para Redução do Número de Atributos}

Levando-se em consideração a construçăo dos script.s para atribuição de pesos. foi utilizada ‘ mesma idéia de se ter um algoritmo comum e uma função que pode executar o cálculo da importancia de cada peso de acordo com a medida empregada em cada script. Esse algoritmo comum a todos os scripts é descrito no Algoritmo 6.

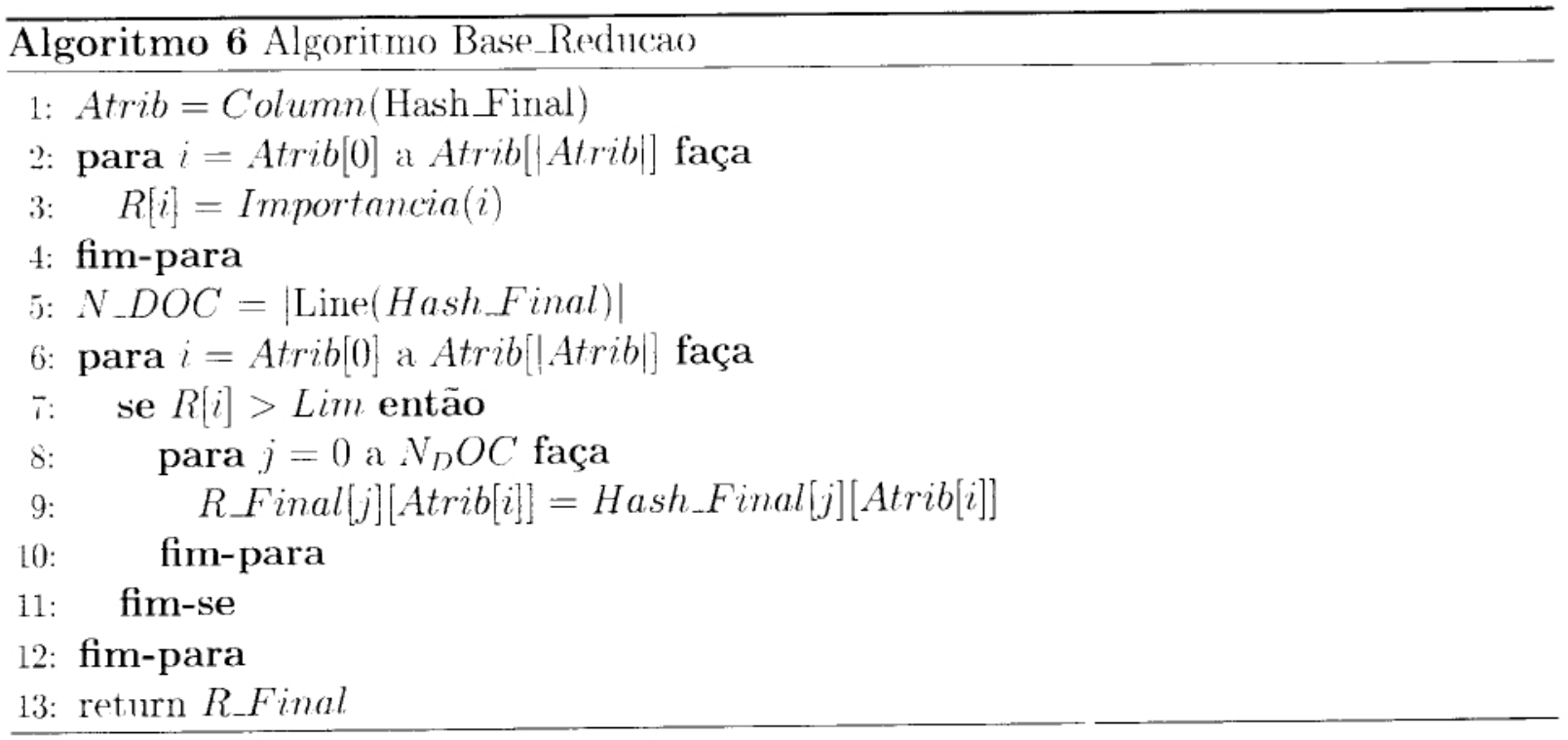

Como entradas. o algoritmo possui a representação obtida pelo uso de algum dos scripts de atribuição de pesos e o limiar que definirá se o atributo deve ser considerado na nova representação. Tais entradas são referenciadas por Hash Final e Lim, respectivamente.

Inicialmente. então, são considerados todos os atributos de Hash_Final assumindo que uma função possa retornar o valor de suas colunas. ou seja, seus atributos, a um outro vetor auxiliar Atrib. Considerando todos os atributos da representação é necessário saber quais podem ser mais relevantes na descrição do documento. Assim, uma função para identificar a importância de cada ım deles é chamada. A função Importancia simboliza a chamada de um método que aplicará uma das medidas usadas para redução da dimensão da representação (Seção 3.3. pag 46).

A importância de cada atributo é comparada ao limiar, estabelecido pelo usuário. Se o valor do limiar for inferior à importância associada ao atributo. a coluna da representação original Hash_Final referente ao mesmo é copiada para a nova representação. 
R.Final. Dessa forma. R_Final conterá apenas parte da representação original. correspondente aos atributos identificados como mais relevantes.

\subsection{Considerações Finais}

Veste capitulo foi descrita a implementação dos recursos necessários para a conversão dos documentos na representação atributo-valor. Desses recursos fazem parte os algoritmos presentes nos scripts de identificação dos atributos, atribuição de pesos e redução da dimensão. Tendo em vista que. para identificar os atributos de um documento, pode-se ter que considerar alguns aspectos lingüísticos decorrente do idioma presente no mesmo. é possível que alguns recursos devam ser adaptados. ou mesmo aprimorados. Esse é o caso da lista de stopwords que foi construída a partir de fontes como (Neves, 2001; OpenMuscat, 2000) e a aplicaçào da lei de Zipf (Zipf, 1949) sobre textos jornalísticos coletados da web.

Além disso. também é considerado o uso de uma ferramenta para converter as palavras em seus stem e para a forma canônica, ambos para o português. () uso dessas duas ferramentas é justificado pela necessidade de se investigar o quanto uma análise lingüistica gramatical pode auxiliar na obtenção de uma representação mais coerente e mais eficaz para o processo de Text Mining, em relação ao uso de uma ferramenta que não dispõe de uma análise morfológica mais complexa.

Para construção dos scripts que designam os atributos da representação, foram utilizados três algoritmos baseados em (Madenić, 1998: Witten et al.. 1999: Weiss and Indurkhỵa. 1997). Levando-se em consideração o interesse de se analisar os aspectos quanto ao uso de um algoritmo para stemming e um analisador morfológico e gramatical. foram construídos seis scripts para identificação dos atributos, como pode ser observado no passo 1 da Figura 4.3.

Dois dos algoritmos utilizados como base, (Mladenić, 1998) e (Witten et al., 1999), consideram que um atributo pode ser constituído por mais que uma palavra, formando assim os chamados n-grams. Como mencionado. a diferença entre eles não está apenas no $n$ a ser considerado. mas no que pode consistir um gram. No algoritmo baseado em 
(Mladenić, 1998), os grams são constituídos por palavras que não são stopwords, enquanto que no algoritmo baseado em (Witten et al., 1999) essa exigência restringe-se ao primeiro e ao último termo. A razão de considerar esses dois algoritmos é analisar se um método menos complexo como o de (Witten et al., 1999) poderia trazer o mesmo, ou melhor desempenho que o método baseado em (Mladenić, 1998).

Por outro lado, também deve ser investigado se representações formadas por atributos compostos de uma só palavra degradaria, ou não, o desempenho de um sistema de classificação. Em virtude disso, um algoritmo baseado em (Weiss and Indurkhya, 1997) também foi considerado. Esse algoritmo tem como entrada, um número $N$ que determina quantos atributos o usuário acha que seja interessante identificar. De acordo com o autor, a determinação do $N$ é feita de forma empírica, através de avaliações experimentais ou em função da dimensão suportada pelos métodos de extração de conhecimento.

Com base nas medidas para atribuição de peso e redução da representação, abordadas no capítulo anterior, foram construídos dez scripts, como abordado na etapa 2 e 3 da Figura 4.3. A investigação de qual dessas medidas, e qual estratégia de identificação de atributos é melhor para algum problema envolvendo classificação binária, é tratada no próximo capítulo por meio da descrição dos experimentos realizados.

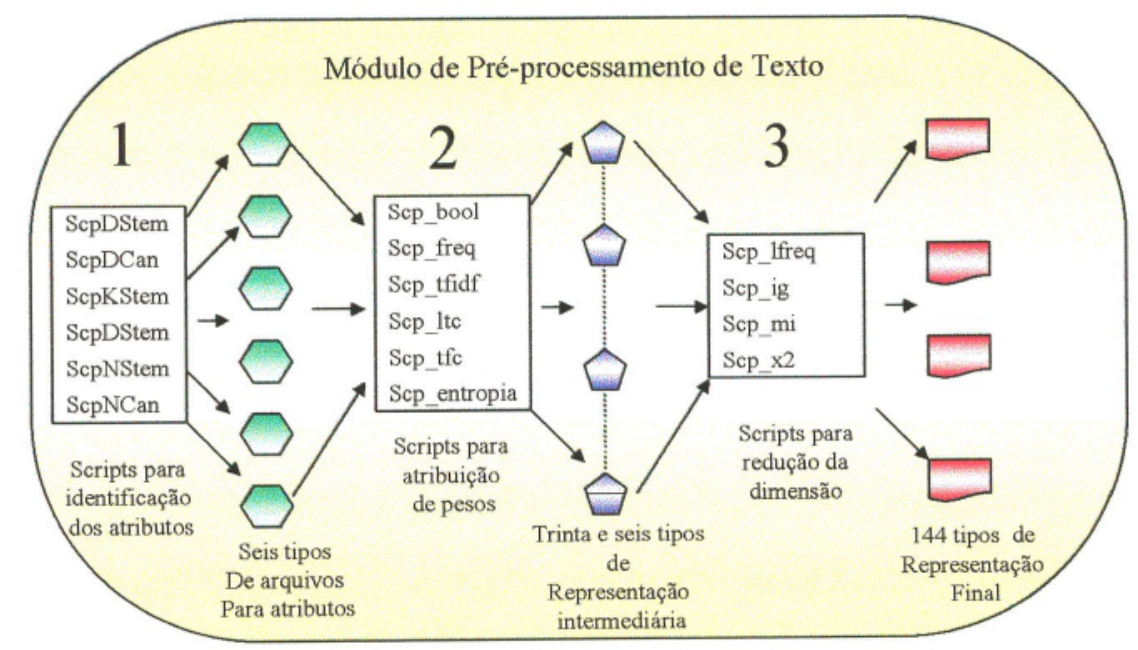

Figura 4.3: Scripts que integram o módulo de pré-processamento de texto do Ambiente Computacional Discover 


\section{Capítulo 5}

\section{Validação do Módulo de}

\section{Pré-processamento de Textos}

\section{Através de Estudo de Casos}

Como mostrado no Capítulo 4. neste trabalho foi projetado e implementado um módulo de pré-processamento de textos como parte do Ambiente para Extração de Conhecimento Discover. Para validar esse módulo foram utilizados dois estudos de casos envolvendo diferentes aplicações: categorização de textos e análise de patentes. voltada para inteligência competitiva.

Como visto na Seção 2.1. uma das aplicações de Text Mining mais citadas na literatura é a categorização de texto. Seu uso tem sido útil para tornar mais fácil o acesso a informaçõos relevantes, principalmente no que diz respeito à Web.

No entanto, a extração de conhecimento de bases textuais não se resume apenas a categorização de texto. Segundo Hearst (Lucas, 2001) a atividade de tornar mais rápido e fácil o acesso a documentos que contenham informações relevantes pertence ao domínio de Recuperação de Informação. e a descoberta de conhecimento envolve muitos outros aspectos. sendo ainda por ela chamada de Text Data Mining (TDM). Essas observações podem ser confirmadas no trecho extraído de uma de suas entrevistas.

-Recuperaçăo de Informaçào é o processo de encontrar informações conhecidas e inseridas no documento pelo autor. (...) A mineração de dados textuais é 
um modo de examinar uma coleção de documentos e descobrir informaçöes que nào estão explicitamente contidas em qualquer um deles. (...) Pesquisas sobre novas hipóteses de causa e efeito para uma doença, utilizando jornais com informações médicas, é um caso ideal em que mineração de dados textuais pode ser aplicada."

Diante desses aspectos, para a validação do módulo de pré-processamento desenvolvido, optou-se pela realização de dois estudos de casos com aplicações reais. Um envolvendo a categorização de documentos em português sobre Aquisição de Conhecimento e Redes Neurais, e outro envolvendo a análise de patentes farmoquímicas. Esses dois estudos de casos são melhor detalhados nas próximas seçöes.

\subsection{Estudo de Caso 1 - Categorização de Textos sobre Aquisição de Conhecimento e Redes Neurais}

Como citado, um fato bastante evidente na bibliografia é que as pesquisas voltadas para textos em inglês estão bastantes avançadas e contam com o apoio de diversos recursos para sua realização. Entre esses recursos estão desde ferramentas até bases de textos online $^{1}$. Já para o português, não foi encontrada na bibliografia nenhuma menção sobre uma base que pudesse servir como um benchmark, ou seja, que pudesse ser utilizada como referência ou respaldo sobre os resultados das técnicas aqui abordadas.

Assim, para validar os scripts desenvolvidos neste trabalho, foi necessário inicialmente construir uma base de documentos. A descrição de como se deu a construção da base de documentos, o pré-processamento dos mesmos e a tarefa de categorização, pode ser vista nas próximas subseções.

Ressalta-se que o objetivo principal deste estudo de caso é investigar as diferenças entre as seis abordagens para identificação de atributos através dos scripts aqui implementados e denominados de ScpDStem, ScpDCan, ScpKStem, ScpKCan, ScpNStem e

\footnotetext{
${ }^{1}$ Como exemplos de bases utilizadas tem-se WebKB em http://www.cs.cmu.edu/afs/cs.cmu.edu/project/theo-11/www/wwkb/, Reuters em http://www.research.att.com/ lewis/ ou OHSUMED em ftp://ftp.ohsu.edu/
} 
ScpNCan. bem como os diferentes métodos para atribuição de pesos. como o peso booleano, freqüencia. $t f \times$ idf, tf $\times$ idf normalizado, $\log t f \times$ idf normalizado e baseado em entropia. Para tanto, foi escolhida a tarefa de categorização como suporte para a investigação.

\subsubsection{Coleta de Documentos}

Como mencionado, na tarefa de categorização de textos, normalmente, conta-se com uma base de textos rotulados com as devidas classes. Numa tarefa mais simples, como a categorização bi-valorada. os documentos podem ser exemplos rotulados como positivos ou negativos em relação a uma classe. Assim sendo, para construção de uma base de documentos. é necessário identificar quais são as classes às quais os documentos podem estar relacionados.

Neste estudo de casos foram considerados textos de dois domínios: Aquisição de Conhecimentos e Redes Neurais ${ }^{2}$. Ao contrário do que possa parecer, esses domínios não foram escolhidos por acaso. O motivo dessa escolha decorre de que os documentos a serem coletados devem conter assuntos os mais relevantes possíveis para a aplicação desejada. Além disso, para saber se o conhecimento encontrado é útil, compreensível e novo, uma etapa de avaliação dos padrões é realizada. Mas como saber, inicialmente, quais documentos são ou não relevantes? E como saber se os padrões encontrados, ao final do processo, são bons?

Numa aplicação real, a realização das etapas de coleta de documentos e avaliação dos resultados obtidos pode ser auxiliada por 11 m especialista do domínio. Nesse caso, pela ausência de um benchmark ou de um especialista, foi escolhido $11 \mathrm{~m}$ domínio cujo assunto fosse o mais familiar possível, podendo assim atuar como especialista. Por essa razão foi escolhido temas relacionados a Inteligência Artificial, como Aquisição de Conhecimento e Redes Neurais, que são bem distintos, mas contem alguns termos em comum.

Para tanto, foram coletados manualmente 152 documentos da Web, sendo 76 rotulados como Aquisição de Conhecimento e 76 rotulados como Redes Neurais, logo trata-se de um problema de categorização bi-valorada.

\footnotetext{
${ }^{2}$ Os documentos coletados e utilizadas neste estudo de caso estão disponiveis, no formato texto. em http://labic.icmc.sc.usp.br/
} 


\subsubsection{Preparação de Documentos}

Tendo em vista que os documentos coletados são dos mais variados tipos: HTML. Post Script, ASCII, entre outros, como passo inicial todos os documentos foram processados e transformados para arquivos ASCII. retirando-se qualquer tag html. figuras. etc. Todos os arquivos originais foram transformados para extensão "txt".

Para identificação dos atributos. foram utilizados os scripts ScpDStem. ScpDCan, ScpKStem, ScpKCan, ScpNStem e ScpKStem (Seçāo 4.3, pag. 4.3), sendo que para cada documento da base foi gerado $11 \mathrm{~m}$ documento contendo os atributos encontrados. Para fins de organização, os arquivos resultantes da aplicação dos respectivos seripts foram agrupados em seis conjuntos denominados, respectivamente, DStem_Set. DCan_Set, KStem_Set, KCan_Set, NStem_Set e Ncan_Set.

É importante ressaltar que para os scripts NStem_Set e VCan_Set é necessário definir o valor do parâmetro $k$, de forma a serem apenas considerados os $k$ atributos de maior frequiência. Nos experimentos realizados com esses scripts optou-se por selecionar os 100 atributos mais freqüientes, por considerar que grande parte dos atributos relevantes estariam dentro desse escopo.

A ilustração da identificação de atributos, com o uso desses seis scripts é mostrada na Figura 5.1. Algumas das características dos documentos resultantes podem ser vistas na Tabela 5.1, na qual a segunda coluna contém a quantidade de atributos encontrados, e na terceira coluna são mostrados alguns exemplos desses atributos. Vale ressaltar que o tamanho médio dos arquivos originais (padronizados para o formato ASCII) é de 9,7 Kb.

Para os experimentos de extração de conhecimento de dados, ao se utilizar $k$ fold cross validation. o conjunto de dados é dividido em $k$ partes e são realizadas $k$ etapas de treinamento e teste, sendo que a cada etapa é escolhida uma das $k$ partes do conjunto de dados para realização do teste. No caso do processamento de textos, o $k$-fold cross validation também pode ser utilizado, mas deve-se estar atento pois dependendo da medida de atribuição de peso a ser considerada, em cada uma das $k$ iterações, os pesos das representações utilizadas para treinamento e teste pode ser afetado, de forma que deve-se ter uma representação distinta a cada iteração.

Esse fato inviabiliza, por exemplo, que se construa uma única representação e que a 


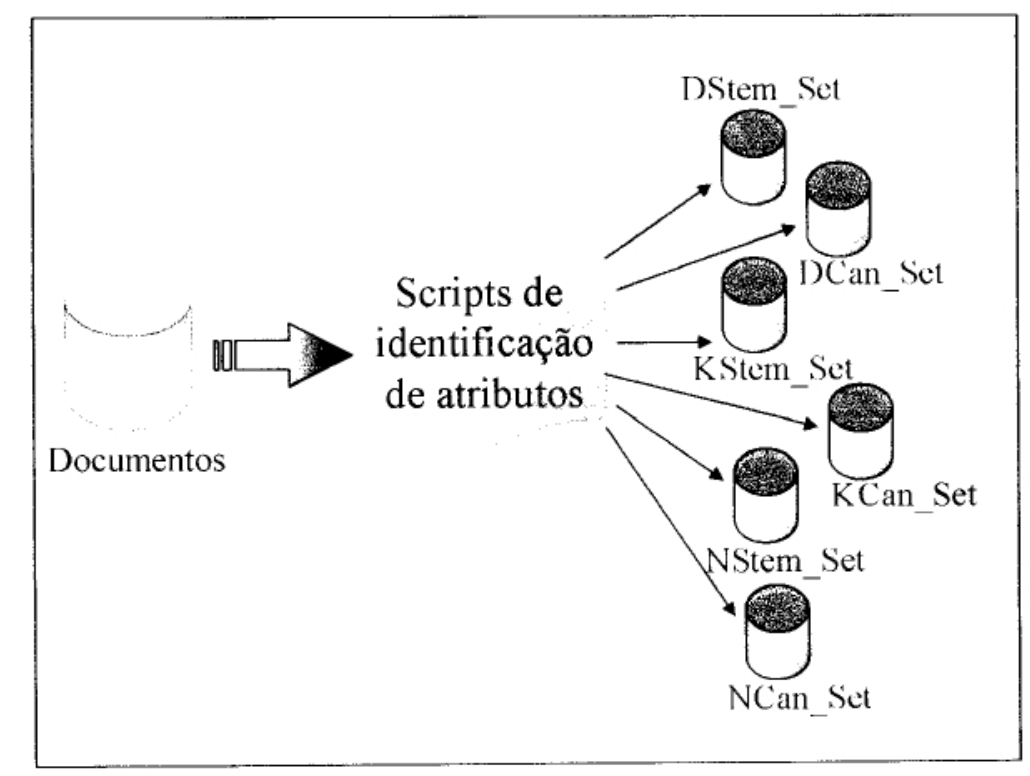

Figura 5.1: Resultado da aplicação dos scripts para identificação de atributos

cada iteração do k-fold cross validation seja apenas retirada la representação a parte que será utilizada para teste, exceto quando utilizado métodos booleano e por frequïencia para atribuição de pesos aos atributos. Isso deve-se ao fato de que os métodos de atribuição de pesos booleano e por freqüiencia verificam, respectivamente, apenas a presença e a quantidade de vezes de $11 \mathrm{~m}$ atributo em $11 \mathrm{~m}$ documento $d_{j}$. As demais medidas levam em consideração a presença dos atributos nos outros documentos. Dessa forma, após a identificação dos atributos de cada documento, é necessário que antes da execução dos scripts de atribuição de peso sejam identificadas as $k$ combinações em que os documentos estarão dispostos.

Dependendo do script a ser considerado e da quantidade de atributos distintos, a execução dos scripts para atribuição dos pesos pode despender muito tempo, tendo em vista que muitos acessos a disco podem ser necessários no caso de não haver memória RAM suficiente. Assim, nos experimentos aqui realizados, em função do tempo de execução, optou-se por escolher apenas três combinações distintas dos documentos para treinamento e teste. O conjunto de documentos de treinamento sempre foi formado por $75 \%$ dos documentos, escolhidos aleatoriamente, encuanto que os $25 \%$ restantes foram considerados como documentos de teste. Nas três combinações os conjuntos de teste são distintos entre 


\begin{tabular}{|l||c|l|}
\hline Conjuntos & \# atributos & exemplos de atributos identificados \\
\hline \hline DStem_Set & 15.358 & $\begin{array}{l}\text { algoritm_treinament. caract_model, } \\
\text { red_neur, red, descobr. } \\
\text { descobert_automat_relaçõ }\end{array}$ \\
\hline DCan_Set & 22.706 & $\begin{array}{l}\text { algoritmo_classificação, rede_neuronal, } \\
\text { sistema_especialista, neurônio. } \\
\text { predizer, sistema_reconhecimento_padrão }\end{array}$ \\
\hline KStem_Set & 56.886 & $\begin{array}{l}\text { tecnolog_de_inteligenc. red_conex. } \\
\text { aquisiçã_e_represent, red, conhec. } \\
\text { inteligenc_artificial_simbol }\end{array}$ \\
\hline KCan_Set & 77.271 & $\begin{array}{l}\text { sistema_tutorial, problema_de_aprendizado, } \\
\text { abordagem_conexionista, rede, aprendizado, } \\
\text { sistema_de_neurônio }\end{array}$ \\
\hline NStem_Set & 1.956 & $\begin{array}{l}\text { conexã, neurolog, hipotes, cognitiv. heurist, } \\
\text { treinament }\end{array}$ \\
\hline NCan_Set & 2068 & $\begin{array}{l}\text { aprendizado, heurístico, conexionista, } \\
\text { topologia, aquisição neurônio }\end{array}$ \\
\hline
\end{tabular}

Tabela 5.1: Algumas informações sobre os arquivos gerados pelos scripts de identificação de atributos.

si.

Além disso, foram considerados os documentos relacionados ao domínio de Aquisição de Conhecimento como exemplos positivos, e os relacionados a Redes Neurais como exemplos negativos. Levando-se em consideração as asserções supracitadas, a divisão de cada conjunto (DStem_Set. DCan_Set, KStem_Set, KCan_Set. NStem_Set e NCanSet) em três resultou na obtenção de 18 novos conjuntos distintos, denominados DStem1_Set, DStem2_Set, DStem3_Set, DCan1_Set, DCan2_Set.DCan3_Set, KStem1_Set, KStem2_Set, KStem3_Set, KCan1_Set, KCan2_Set, KCan3_Set, NStem1_Set, NStem2_Set, NStem3_Set, NCan1_Set, NCan2_Set e NCan3_Set. O resultado dessa divisão e de outras ações para preparação dos textos, realizados neste estudo de caso, são ilustradas na Figura 5.2.

Sobre cada um desses novos conjuntos foram utilizados os seis scripts de atribuição de pesos, com base nas medidas booleana, por freqüência, tf $\times$ idf, tf $\times$ idf normalizado, log de tf $\times$ idf normalizado e baseado em entropia. Desse modo, 108 representações distintas poderiam ser utilizadas e analisadas. Porém, em virtude de não ter sido possível a execução de quatro dos scripts (pesos tf $\times$ idf, tf $\times$ idf normalizado, $\log$ de $t f \times$ idf normalizado 


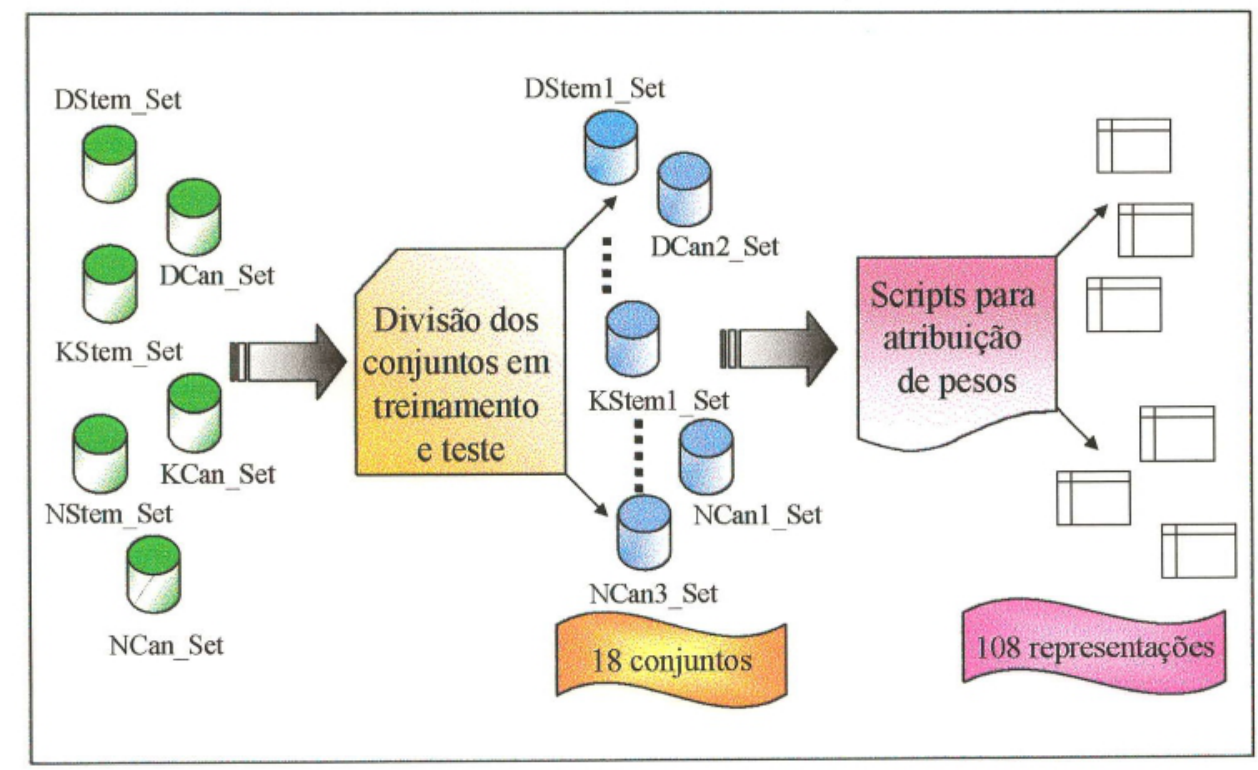

Figura 5.2: Esquema para preparação de textos utilizada para categorização de textos dos domínios de Redes Neurais e Aquisição de Conhecimento realizado durante o estudo de caso

e baseado em entropia) para os conjuntos obtidos de KCan_Set (com 77.271 atributos). Portanto, o total de 96 representações foram investigadas.

Nos experimentos abordados neste trabalho, o tempo para execução dos scripts para pesos booleano e baseado na freqüência variou de alguns minutos a 12 horas, para uma máquina com 256 Mbytes de memória RAM, considerando os atributos gerados a partir dos scripts ScpDStem, ScpDCan, ScpNStem e ScpNCan. Em função da elevada quantidade de atributos, os scripts ScpKStem e ScpKCan para o peso booleano e baseado em freqüência só puderam ser utilizados com pelo menos 512 Mbytes de memória.

Para os outros scripts de atribuição de pesos ( $\mathrm{tf} \times \mathrm{idf}, \mathrm{tf} \times \mathrm{idf}$ normalizado, log tf $\times$ idf normalizado e baseado em entropia), como o valor do peso depende dos valores de todos os atributos, algumas variáveis auxiliares foram utilizadas na implementação dos scripts para apoiar o cálculo. Assim, mais memória foi exigida, e por conseqüência mais memória virtual foi utilizada e mais lento foi o processamento. O tempo, normalmente, despendido para a execução desses scripts variou de 1 a 2 dias para os conjuntos de atributos gerados a partir dos scripts ScpDStem, ScpDCan, e ScpKStem. Enquanto que para os atributos gerados através de ScpNStem e ScpNCan, o tempo médio foi de 
três horas. já que a quantidade de atributos é bem menor. como mostrado na Tabela 5.1. Para os atributos obtidos utilizando o seript ScpKCan. como mencionado, não foi possível gerar a representação em virtude da grande quantidade de memória necessária e a falta de equipamento disponível no momento dos testes.

\subsubsection{Experimentos Realizados e Resultados}

Para verificar a eficiência de cada abordagem de identificação de atributos e os métodos de atribuição de pesos, as representações geradas foram submetidas ao algoritmo de classificação Support Virtual Machine, disponível na ferramenta SVM ${ }^{\text {light }}$ (Joachims, 2000). Ressalta-se que para essa análise estão sendo considerados os parâmetros de configuração defaults da ferramenta.

Uma análise do comportamento dos métodos para atribuição de pesos pode ser realizada observando-se a média e o desvio-padrão dos resultados das medidas de avaliação de conhecimento, explicadas na Seção 2.6, agrupados por abordagem de identificação de atributo e conjunto original de dados da qual as 3 partições foram obtidas. Nas Tabelas 5.2 e 5.3 estão presentes os resultados obtidos com os diferentes scripts de atribuição de peso, considerando os atributos identificados, respectivamente, pelos scripts ScpDStem e ScpDCan. Ambos possuem como base o algoritmo para encontrar n-grams $(\mathrm{n} \leq 5)$ de Mladenić (Mladenić, 1998), mostrado no Algoritmo 1, utilizando respectivamente stem e forma canònica.

Nas Tabelas 5.4 e 5.5, são mostrados os resultados obtidos com a utilização dos conjuntos KStem_Set e KCan_Set, respectivamente. Tais conjuntos foram obtidos com uso dos scripts ScpKStem e ScpKCan, que são baseados no algoritmo utilizado na ferramenta Kea (Witten et al., 1999). Os atributos identificados com esses scripts podem ser formados por até 3-grams, sendo que o primeiro e último gram não devem ser stopwords.

Os resultados gerados pelas representações derivadas dos conjuntos NStem_Set e NCan_Set podem ser vistos, respectivamente, nas Tabelas 5.6 e 5.7. Os atributos gerados nesses casso são atributos não compostos, ou seja, formados por apenas um termo que não deve ser uma stopword. 


\begin{tabular}{|l||c|c|c|c|}
\hline \hline peso & Accuracy(\%) & precisão (\%) & Recall $(\%)$ & $F_{1}(\%)$ \\
\hline booleano & $90.35 \pm 7.60$ & $96.83 \pm 5.50$ & $84.21 \pm 18.97$ & $88,96 \pm 9,99$ \\
freqüência & $92.11 \pm 6.96$ & $98.25 \pm 3.04$ & $85.97 \pm 15,20$ & $91.10 \pm 8,62$ \\
tf $\times$ idf & $87.72 \pm 5.48$ & $100,00 \pm 0.00$ & $75,44 \pm 10.96$ & $85,70 \pm 7,34$ \\
tf $\times$ idf normalizado & $87.72 \pm 6.08$ & $94.74 \pm 9.12$ & $80.70 \pm 10.96$ & $86,63 \pm 6,92$ \\
$\log$ tf $\times$ idf normalizado & $88.60 \pm 6.62$ & $98,04 \pm 3.39$ & $78,95 \pm 13.92$ & $86,92 \pm 8,68$ \\
entropia & $84.21 \pm 6.96$ & $100.00 \pm 0.00$ & $68.42 \pm 13.93$ & $80,73 \pm 9,49$ \\
\hline
\end{tabular}

Tabela 5.2: Resultados obtidos utilizando as representações geradas a partir do conjunto DStem_Set

\begin{tabular}{|l||c|c|c|c|}
\hline \hline peso & Accuracy $(\%)$ & precisão $(\%)$ & Recall $(\%)$ & $F_{1}(\%)$ \\
\hline booleano & $87.72 \pm 6.62$ & $96.30 \pm 6.41$ & $78.95 \pm 13,92$ & $86,12 \pm 8,52$ \\
frequiência & $91.23 \pm 6.08$ & $96,83 \pm 5.50$ & $85.96 \pm 16.08$ & $90,23 \pm 7,78$ \\
tf $\times$ idf & $85,09 \pm 6.62$ & $97.78 \pm 3.85$ & $71,93 \pm 13,25$ & $82,37 \pm 9,05$ \\
tf $\times$ idf normalizado & $86.84 \pm 6.96$ & $94.74 \pm 9,12$ & $78,95 \pm 13.92$ & $85,36 \pm 8,57$ \\
$\log$ tf $\times$ idf normalizado & $86.84 \pm 5.27$ & $96.30 \pm 6.41$ & $77,19 \pm 12.15$ & $85,11 \pm 7,10$ \\
entropia & $79,83 \pm 4,02$ & $100,00 \pm 0,00$ & $59.65 \pm 8,04$ & $74,51 \pm 6,23$ \\
\hline
\end{tabular}

Tabela 5.3: Resultados obtidos utilizando as representações geradas a partir do conjunto DCan_Set

\begin{tabular}{|l||c|c|c|c|}
\hline peso & Accuracy $(\%)$ & precisão (\%) & Recall $(\%)$ & $\overline{F_{1}(\%)}$ \\
\hline booleano & $96.49 \pm 1,52$ & $94,91 \pm 0,15$ & $98,25 \pm 3,04$ & $96,54 \pm 1,56$ \\
frequiência & $94,74 \pm 5,27$ & $98,25 \pm 3,04$ & $91,23 \pm 10,96$ & $94,33 \pm 5,89$ \\
tf $\times$ idf & $93,11 \pm 3.86$ & $98,15 \pm 3.21$ & $85,96 \pm 10,96$ & $91,34 \pm 6,24$ \\
tf $\times$ idf normalizado & $94,74 \pm 2,63$ & $94,73 \pm 0,28$ & $94,74 \pm 5,27$ & $94,69 \pm 2,77$ \\
log tf $\times$ idf normalizado & $94,74 \pm 2.63$ & $94.73 \pm 0.28$ & $94,74 \pm 5,27$ & $94,69 \pm 2,77$ \\
entropia & $82,46 \pm 23.59$ & $98,33 \pm 2.89$ & $66.67 \pm 48,90$ & $70,31 \pm 44,42$ \\
\hline
\end{tabular}

Tabela 5.4: Resultados obtidos utilizando as representaçǒes geradas a partir do conjunto KSterm_Set

\begin{tabular}{|l||c|c|c|c|}
\hline \hline peso & Accuracy $(\%)$ & precisão (\%) & Recall $(\%)$ & $F_{1}(\%)$ \\
\hline booleano & $94,74 \pm 2,63$ & $93,25 \pm 2,81$ & $96,49 \pm 3,04$ & $94,83 \pm 2,56$ \\
freqüência & $94,74 \pm 5,27$ & $98,25 \pm 3,04$ & $91,23 \pm 10,96$ & $94,33 \pm 5,89$ \\
\hline
\end{tabular}

Tabela 5.5: Resultados obtidos utilizando as representações geradas a partir do conjunto KCan_Set 


\begin{tabular}{|l||c|c|c|c|}
\hline \hline peso & Accuracy $(\%)$ & precisão (\%) & Recall $(\%)$ & $F_{1}(\%)$ \\
\hline booleano & $96.49 \pm 1.52$ & $94.91 \pm 0.15$ & $98.25 \pm 3.04$ & $96.54 \pm 1.56$ \\
freqüuencia & $94.74 \pm 5,27$ & $98,25 \pm 3.04$ & $91.23 \pm 10.96$ & $94.33 \pm 5,89$ \\
tf $\times$ idf & $95.62 \pm 4.02$ & $96.39 \pm 3.13$ & $94.74 \pm \tilde{5} .27$ & $95.54 \pm 4,12$ \\
tf $\times$ idf normalizado & $95.62 \pm 1.52$ & $94.83 \pm 0.15$ & $96.49 \pm 3.04$ & $95.64 \pm 1.56$ \\
$\log$ tf $\times$ idf & $93.86 \pm 1.52$ & $93.22 \pm 2.38$ & $94.74 \pm 5.27$ & $93.88 \pm 1,73$ \\
entropia & $56.14 \pm 47.83$ & $66.67 \pm 57.74$ & $43.86 \pm 44.76$ & $51.24 \pm 47.73$ \\
\hline
\end{tabular}

Tabela 5.6: Resultados obtidos utilizando as representações geradas a partir do conjunto NStem_Set

\begin{tabular}{|l||c|c|c|c|}
\hline \hline peso & Accuracy $(\%)$ & precisão (\%) & $\operatorname{Recall}(\%)$ & $F_{1}(\%)$ \\
\hline booleano & $91.23 \pm 5,48$ & $92,79 \pm 6.25$ & $89,47 \pm 5.27$ & $91,09 \pm 5,58$ \\
freqüência & $85.09 \pm 8,04$ & $91.30 \pm 4,85$ & $77,19 \pm 13,24$ & $83,44 \pm 9,78$ \\
tf $\times$ idf & $85.97 \pm 8,46$ & $87,13 \pm 6,71$ & $84,21 \pm 13.93$ & $85,39 \pm 9,66$ \\
tf $\times$ idf normalizado & $87.72 \pm 5,48$ & $87.83 \pm 5,85$ & $87,72 \pm 8,04$ & $87,66 \pm 5,77$ \\
log tf $\times$ idf normalizado & $89,47 \pm 2,64$ & $86,29 \pm 7,07$ & $94,74 \pm 5,27$ & $90,06 \pm 2,07$ \\
entropia & $29,82 \pm 37,98$ & $36,67 \pm 55,08$ & $19,30 \pm 24,87$ & $24,85 \pm 34,54$ \\
\hline
\end{tabular}

Tabela 5.7: Resultados obtidos utilizando as representaçoes geradas a partir do conjunto NCan_Set

Essa avaliação permite analisar a melhora propiciada pelos diversos métodos de atribuição de peso. Por outro lado, pode-se notar que em geral a diferença na accuracy entre os diversos métodos investigados não foram significativos, menos quando é considerada a atribuição de peso baseado em entropia.

Um fato que merece ser ressaltado é que, comparando-se as diversas Tabelas 5.2, $5.3,5.4,5.5,5.6$ e 5.7, vê-se que o comportamento dos seis métodos para atribuição de pesos são praticamente uniforme quando a identificação dos atributos é baseado na abordagem da ferramenta Kea utilizando o Stemming (Tabela 5.4).

Pode-se observar ainda que, mesmo utilizando uma abordagem bem simples, baseada no Algoritmo 4 adaptado de (Weiss and Indurkhya, 1997) para a identificação de atributos, os experimentos foram capazes de gerar bons resultados para a atribuição de peso booieano, frequiência, tf $\times$ idf, tf $\times$ idf normalizado e $\log$ tf $\times$ idf normalizado como mostrado nas Tabelas 5.6 e 5.7. Apenas o método baseado em entropia teve uma variação 
muito grande em relação às medidas de accuracy, precisão, recall e $F_{1}$.

\subsubsection{Algumas Considerações}

() primeiro ponto a ser analisado com base nos resultados obtidos é o uso do algoritmo de stemming e o uso do etiquetador para realizar a identificaçào dos atributos. Como pode ser visto na Tabela 5.1. a quantidade de atributos resultantes do uso do etiquetador foi sempre superior ao uso do algoritmo de stemming. Provavelmente. o uso da análise léxica e sintática providas pelo etiquetador pode fazer com que palavras agrupadas em um único stem sejam mapeadas para diferentes formas canonicas, tendo em vista que, embora a morfologia seja parecida, as funçǒes gramaticais possam ser diferentes. Um exemplo disso são as palavras conhecido e conhecimento (encontradas em um dos textos considerados como exemplos negativos, neste estudo de caso) que são mapeadas para o stem conhec e que possuem formas canônicas equivalentes às respectivas palavras, quando usado o etiquetador.

Para facilitar a análise dos resultados obtidos com uso đo SVM, reportados anteriormente, são apresentados na Tabela 5.8 apenas aqueles referente a medida accuracy. Comparando os resultados de DStem_Set e DCan_Set, ou KStem_Set e KCan_Set, ou ainda NStem_Set e NCan_Set, pode-se verificar que, na maioria dos casos, o uso de stemming gerou melhores valores em relação ao uso do etiquetador.

Em relação às estratégias utilizadas nos scripts para identificação dos atributos, que dizem respeito ao número de termos que um atributo pode ser composto e de que forma esses são arranjados pode-se concluir que as representações compostas por atributos formados por apenas 1-gram estão relacionadas com os melhores resultados. Além disso, se os resultados de KStem_Set e DStem_Set forem confrontados, percebe-se que o primeiro conjunto apresenta os melhores resultados. Assim, para este estudo de caso, quanto menor for a quantidade de termos que compõe os atributos das representações, melhor será a accuracy. Se forem analisados, ainda, os resultados de cada conjunto, pode ser percebido que o peso booleano apresenta os melhores resultados, em grande parte dos experimentos.

Com base nos resultados descritos na Tabela 5.9, pode-se observar que as representações geradas com o uso do stemming foram mais precisas que aquelas fornecidas pelo 


\begin{tabular}{|l||c|c|c|c|c|c|}
\hline \hline peso & DStem_Set & DCan_Set & KStem_Set & KCan_Set. & NStem_Set & NCan_Set \\
\hline booleano & $90,35 \pm 7.60$ & $87,72 \pm 6,62$ & $96.49 \pm 1.52$ & $94,74 \pm 2,63$ & $96.49 \pm 1,52$ & $91,23 \pm 5.48$ \\
freqüência & $92,11 \pm 6.96$ & $91,23 \pm 6,08$ & $94.74 \pm 5.27$ & $94.74 \pm 5.27$ & $94.74 \pm 5.27$ & $85.09 \pm 8.04$ \\
tf $\times$ idf & $87.72 \pm 5.48$ & $85.09 \pm 6.62$ & $93.11 \pm 3.86$ & & $95.62 \pm 4.02$ & $85,97 \pm 8.46$ \\
tfxidf normalizado & $87.72 \pm 6.08$ & $86.84 \pm 6,96$ & $94.74 \pm 2.63$ & & $95,62 \pm 1.52$ & $87,72 \pm 5,48$ \\
$\log$ tf $\times$ idf normalizado & $88,60 \pm 6.62$ & $86.84 \pm 5,27$ & $94.74 \pm 2.63$ & & $93.86 \pm 1.52$ & $89,47 \pm 2,64$ \\
entropia & $84.21 \pm 6.96$ & $79.83 \pm 4.02$ & $82.46 \pm 23.59$ & & $56.14 \pm 47.83$ & $29.82 \pm 37.98$ \\
\hline
\end{tabular}

Tabela 5.8: Valores obtidos para a medida aceuracy

\begin{tabular}{|l||c|c|c|c|c|c|}
\hline \hline peso & DStem_Set & DCan_Set & KStem_Set & KCan__Set & NStem_Set & NCan_Set \\
\hline booleano & $96,83 \pm 5,50$ & $96,30 \pm 6,41$ & $94,91 \pm 0.15$ & $93,25 \pm 2,81$ & $94,91 \pm 0.15$ & $92,79 \pm 6,25$ \\
frequência & $98,25 \pm 3.04$ & $96.83 \pm 5,50$ & $98,25 \pm 3.04$ & $98,25 \pm 3,04$ & $98.25 \pm 3,04$ & $91,30 \pm 4,85$ \\
tf $\times$ idf & $100.00 \pm 0$ & $97.78 \pm 3.85$ & $98.15 \pm 3,21$ & & $96.39 \pm 3,13$ & $87.13 \pm 6.71$ \\
tf $\times$ idf normalizadio & $94,74 \pm 9,12$ & $94,74 \pm 9.12$ & $94.73 \pm 0.28$ & & $94.83 \pm 0.15$ & $87,83 \pm 5,85$ \\
log tf $\times$ idf normalizado & $98.04 \pm 3,39$ & $96.30 \pm 6.41$ & $94.73 \pm 0.28$ & & $93.22 \pm 2.38$ & $86.29 \pm 7.07$ \\
entropia & $100,00 \pm 0$ & $100.00 \pm 0$ & $98,33 \pm 2.89$ & & $66,67 \pm 57.74$ & $36.67 \pm 55.08$ \\
\hline
\end{tabular}

Tabela 5.9: Valores obtidos para a medida precisão

etiquetador. De forma geral, os melhores resultados para a medida de precisão foram obtidos urilizando as representações cujos atributos foram identificados por ScpDStem. Quanto ao peso dos atributos, as representações com pesos baseados em frequiência obtiveram melhores resultados, embora a precisão máxima tenha sido alcançada pelas representaçōes com pesos baseado em entropia (DStem_Set e KCan_Set) e tf $\times$ idf (DStem_Set). Ao contrário do que ocorreu com a accuracy, as representações cujos atributos foram formados por mais termos. obtiveram resultados um ponco mais significativos.

Na Tabela j.10 são apresentados os valores para a medida recall obtidos neste estudo de caso. Assim como para a accuracy e precisão, em geral os resultados mais significativos estão associados ao uso dos scripts que tem como base a utilização do stemming ao invés do etiquetador. Os resultados correspondentes ao conjunto NStem_Set. na maioria dos casos apresentaram como os melhores. Entretanto, não se pode generalizar que o uso de atributos com menos termos resultam em valores melhores para recall, uma vez que, em geral, as representações obtidas pelos scripts baseados em Mladenić (base para DStem_Set e DCan_Set) e que podem contar com atributos bem maiores que as representaçoes que foram obtidas pelos scripts baseados em Kea (KStem_Set e KCan_Set). c mostraram uma eficiência pouco mais significativa. Quanto à medida para atribuição de peso. em geral. a freqüencia apresenton os melhores resultados. 


\begin{tabular}{|l|c|c|c|c|c|c|}
\hline \hline peso & DStem_Set & DCan_Set & KStem_Set & KCan_Set & NStem_Set & NCan_Set \\
\hline booleano & $84.21 \pm 18,97$ & $78.95 \pm 13.92$ & $78,95 \pm 13.92$ & $96.49 \pm 3,04$ & $98.25 \pm 3,04$ & $89,47 \pm 5,27$ \\
frequéncia & $85.97 \pm 15.20$ & $85.96 \pm 16.08$ & $85.96 \pm 16.08$ & $91.23 \pm 10.96$ & $91.23 \pm 10.96$ & $77,19 \pm 13,24$ \\
tfxidf & $75,44 \pm 10.96$ & $71.93 \pm 13.25$ & $71.93 \pm 13.25$ & & $94.74 \pm 5,27$ & $84,21 \pm 13.93$ \\
tfxidf normalizado & $80.70 \pm 10.96$ & $78.95 \pm 13.92$ & $78.95 \pm 13.92$ & & $96.49 \pm 3,04$ & $87,72 \pm 8,04$ \\
log tfxidf normalizado & $78.95 \pm 13.92$ & $77.19 \pm 12,15$ & $77,19 \pm 12.15$ & & $94.74 \pm 5,27$ & $94,74 \pm 5,27$ \\
entropia & $68.42 \pm 13.93$ & $59.65 \pm 8.04$ & $59,65 \pm 8,04$ & & $43.86 \pm 44.76$ & $19,30 \pm 24,87$ \\
\hline
\end{tabular}

Tabela 5.10: Valores obtidos para a medida recall.

\begin{tabular}{|l||c|c|c|c|c|c|}
\hline \hline peso & DStem_Set & DCan_Set. & KStem_Set & KCnn_Set & NStem_Set & NCan_Set \\
\hline booleano & $88.96 \pm 9.99$ & $86,12 \pm 8,52$ & $96,54 \pm 1.56$ & $94,83 \pm 2,56$ & $96.54 \pm 1,56$ & $91,09 \pm 5,58$ \\
frequència & $91.10 \pm 8.62$ & $90.23 \pm 7,78$ & $94,33 \pm 5.89$ & $94,33 \pm 5.89$ & $94.33 \pm 5,89$ & $83,44 \pm 9,78$ \\
tfxidf & $85,70 \pm 7,34$ & $82,37 \pm 9.05$ & $91.34 \pm 6,24$ & & $95.54 \pm 4,12$ & $85,39 \pm 9,66$ \\
tfxidf normalizado & $86.63 \pm 6.92$ & $85.36 \pm 8.57$ & $94,69 \pm 2.77$ & & $95.64 \pm 1,56$ & $87,66 \pm 5.77$ \\
$\log$ tf $x$ idf normalizado & $86.92 \pm 8.68$ & $85.11 \pm 7,10$ & $94,69 \pm 2.77$ & & $93.88 \pm 1.73$ & $90,06 \pm 2,07$ \\
entropia & $80.73 \pm 9.49$ & $74,51 \pm 6,23$ & $70,31 \pm 44,42$ & & $51.24 \pm 47.73$ & $24,85 \pm 34.54$ \\
\hline
\end{tabular}

Tabela 5.11: Valores obtidos para a medida $\mathrm{F}_{1}$

Observando os resultados obtidos para a medida $F_{1}$ com base na Tabela 5.11, embora não tão evidente como para as demais medidas, pode-se verificar que grande parte dos resultados com a aplicação do stemming são um ponco mais significativos ou bem próximos dos resultados associados ao uso do etiquetador. Os resultados correspondentes ao uso das representações contendo atributos apenas de 1-gram foram bem próximas das que poderiam ser formadas por até 3-grams, sendo que de forma geral, ambas obtiveram melhores resultados que as representações compostas por um número maior de termos. Nesse caso, também as representações com peso baseado em freqüência apresentaram melhores valores que as demais medidas.

É importante notar que se forem observadas todas as tabelas descritas nessa subseção, consegue-se identificar que as representações com peso baseado em entropia apresentam em todas as modidas melhor resultados quanto mais grams puderem constituir os atributos. Embora tenha-se alcançado o melhor valor para precisão com a entropia, vale ressaltar que os valores do desvio padrão são muito altos, a ponto de tornar o resultado das medidas irreal. Por exemplo, no caso da precisão obtida no conjunto NCan_Set a média foi de 36,67 enquanto o desvio padrão foi de 55,08. 


\subsection{Estudo de Caso 2 - Análise de Patentes Farmo- químicas}

Un domínio no qual existe intenso interesse na análise de informação e aquisição de conhecimento para anxílio na tomada de decisão está relacionado à indústria Farmoquímica.

O Brasil tem uma significativa demanda de medicamentos genéricos que, aliada a uma análise estratégica das forças competitivas do mercado internacional (rotas economicamente viáveis, estrutura de mercado de produtores mundiais, volume de mercado, dentre outras), poderia sinalizar oportunidades de desenvolvimento para empresas brasileiras. Complementarmente. a lei que regula os direitos e obrigações que são relativos à propriedade industrial no Brasil dispõe sobre a obrigatoriedade de concessão de licença compulsória a objetos de patentes que não sejam fabricados no país decorridos três anos da concessão das patentes.

O monitoramento (levantamento e análise) de dispositivo, como este, pode ser considerado uma oportunidade ímpar para a identificação das possibilidades de inovação das estratégias de negócios. Neste contexto, o tratamento de um grande volume de informações utilizando Text Mining para a obtenção de conhecimento útil para processos de tomada de decisão se torna fundamental para a área de Farmoquímicos. Assim, esse estudo de caso tem como objetivo investigar alguns padrões presentes nos documentos de patentes farmoquímicas depositadas no banco de dados do $\mathrm{INPI}^{3}$. Os documentos de patentes podem ser considerados estruturados, uma vez que podem ser convertidos diretamente para uma tabela de um banco de dados. Entretanto. por possuir campos com descrições textuais contendo detalhes sobre os produtos, um pré-processamento dos mesmos se torna necessário para que possa ser realizado o processo de Text Mining.

\subsubsection{Coleta de Documentos}

As patentes depositadas e armazenadas no banco de dados no INPI estão disponíveis online, e podem ser acessadas por meio de uma consulta, referenciando palavras que devem estar presentes no título ou resumo da patente, ou ainda outras informações como classi-

\footnotetext{
${ }^{3}$ Instituto Nacional de Propriedade Industrial - http://www.inpi.gov.br
} 
ficação, período de depósito, ete. Alguns desses campos podem ser vistos na Figura 5.3

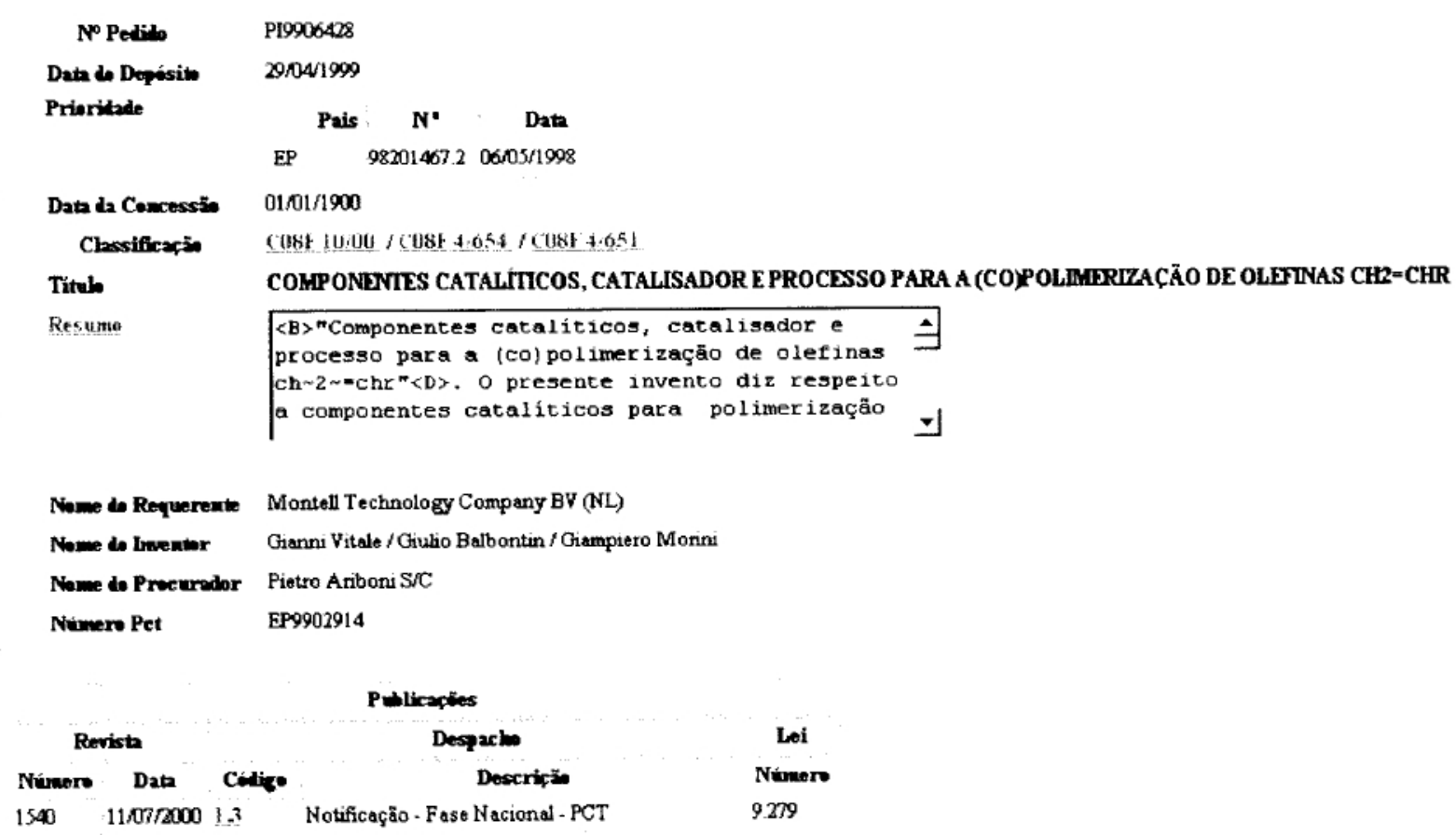

Figura 5.3: Exemplo de um documento de patente disponível no site do INPI.

O resultado de uma busca é retornado em forma de links de páginas da Web, que por sua vez referenciam os documentos de patentes. Dessa forma, para se realizar a recuperação e armazenamento dos documentos resultantes de uma busca, é necessário recuperar cada documento de patente individualmente. Isso pode vir a ser um problema quando o múmero de documentos retornado é muito grande.

Para evitar esse overhead na recuperação das patentes, foi utilizado o módulo de apoio a coleta de documentos do Minador (Oliveira, 2000) que permite estabelecer uma conexão com o servidor de patentes e oferece uma interface de consulta semelhante à disponívol no site do INPI, tendo a vantagem de que todas as patentes encontradas são recuperadas automaticamente. Por intermédio desta interface, foram coletados 109 documentos, que possuíam como palavras chaves os termos farmoquímica, farmoquímico, farmacêutico ou farmacêutica. 


\subsubsection{Preparação de Documentos}

Analisando os documentos de patentes, percebeu-se que a manipulação dos mesmos requer alguns cuidados quanto a sua preparação, a começar pela padronização do tipo de formato em que os documentos estão disponíveis. Neste trabalho, para a transformação dos documentos de patentes em uma representação atributo-valor, as tags HTML presentes neles não são consideradas como atributos. elas são apenas usadas para identificação de delimitação dos campos nas patentes. Assim, nesta etapa o Minador foi utilizado para prover a conversão dos documentos HTML em documentos ASCII sem a presença de marcadores.

Nos documentos coletados, foram encontrados campos multivalorados, como, classificação internacional, inventor, requerente e prioridade. Em muitos casos, as ferramentas utilizadas para extração de conhecimento não suportam a representação atributo-valor contendo atributos multivalorados. Dessa forma. contando com a utilização do sistema Minador foram criados cinco documentos ASCII a partir dos documentos HTML, um para cada tipo de atributo multivalorado, e outro para os demais atributos existentes na patente, incluindo o campo de título e resumo. A partir de cada arquivo, ainda com auxílio do Minador, foi gerada uma tabela correspondente que atualmente foi portada para o banco de dados MySQL, conforme as especificações do ambiente Discover.

Observando a ihıstração da patente, Figura 5.3, é possível notar que alguns campos como data de depósito e classificação internacional podem ser diretamente mapeados para valores simbólicos, enquanto os campos contendo descrições textuais não. Para prover a análise das patentes de forma a encontrar os padrōes e/ou relacionamentos, inicialmente foram considerados apenas os campos formados por textos, título e resumo.

Para a obtenção de uma representação, contando com tais campos, foi utilizado o módulo de pré-processamento de textos. Em virtude do tempo de processamento, estimado com base nos resultados obtidos durante o estudo de caso anteriormente abordado, e a quantidade de atributos que a ferramenta Mineset suporta. foi utilizado o script ScpDStem para identificação dos atributos. Além disso, a utilização desse script foi escolhida, pois com o uso de termos compostos espera-se que a interpretação dos resultados seja mais fácil que utilizando atributos compostos apenas por um único gram. 
Foram encontrados 1931 atributos e sobre esses foi utilizado o script Scp_tfidf, uma vez que na literatura tem sido freqüentemente referenciado. Dos 1931 atributos foram utilizados 59 , em virtude de que ao ser realizada a discretização. os domais atributos foram mapeados a um único intervalo cuja faixa de valores tendia a zero. Alguns dos 59 atributos são: acido. composto_famacentico. doença, dosagem. hidrogenio, infecção, polimero. processo_tratamento, tratamento, produto_famaceutico, e uso farmaceutico.

A representação obtida foi convertida em uma tabela e relacionada ao banco de dados no MySQL, contendo as outras cinco tabelas sobre as patentes geradas pelo Minador.

A possibilidade de fazer junções via comandos SQL entre as tabelas é muito importante. uma vez que facilita a construção de representações híbridas. Ou seja, representações formadas pelos atributos identificados nas descrições textuais e os valores simbólicos diretamente obtidos dos demais campos das patentes, aqui referenciados como dados estruturados.

A justificativa para utilização de uma representação híbrida é que no contexto das patentes, para identificar outros padrões ou mesmo tendências, por exemplo, a evolução de uma tecnologia, é interessante que campos como data de depósito, também sejam considerados na análise, ao invés de realizar apenas a análise de campos textuais.

\subsubsection{Experimentos Realizados e Resultados}

Com a finalidade de encontrar relacionamentos ou padrões que pudessem indicar tendências, foi escolhido realizar a descoberta de regras de associações, que é considerada uma tarefa descritiva. Para isso, foi utilizada a ferramenta para geração de regras de associação do Mineset, inicialmente, sobre a representação obtida considerando-se apenas os campos título e resumo das patentes.

Com a utilização dessa ferramenta foi extraído um total de 418.776 regras. Cada regra é descrita na forma LHS $\rightarrow$ RHS, que indica que se o LHS (Left Hand Side) for verdadeiro, então existe uma probabilidade de que o RHS (Right Hand Side) também seja. A importância de cada regra é medida através dos valores de support, confidence, expected confidence e lift, fornecidos pela ferramenta. 
O support descreve a quantidade de vezes que LHS e RHS aparecem juntos no total de registros. O valor de confidence indica o número de vezes que LHS e RHS ocorrem juntos no total de vezes que LHS aparece. () expected confidence é o número de vezes que o RHS ocorre. O lift é obtido dividindo-se o valor de confidence pela expected confidence, e quanto maior o lift maior o grau de surpresa da regra. on seja, maior o grau de interessabilidade da regra.

Estatisticamente, as regras encontradas apresentaram o valor médio de confidence $87 \pm 8,13$, e o de expested confidence igual a $81,6 \pm 7,9$. Já o valor médio de support foi de $70.3 \pm 8.46$ e o de lift de $1.07 \pm 0,015$. () número de atributos utilizados no antecedente e consequiente da regra foi de no máximo 2. Um exemplo de regras obtidas é mostrado na Tabela 5.12.

\begin{tabular}{|l||c|c|c|c|}
\hline regras & lift & confidence & expec. confidence & support \\
\hline \hline $\begin{array}{l}\text { acido }(\ldots 5,79917) \text { and uso }(\ldots 2,54342] \rightarrow \\
\text { farmaceutico }(\ldots 2.01178]\end{array}$ & 1,0695 & 89,29 & 83.49 & 68,8000 \\
\hline $\begin{array}{l}\text { composição }(\ldots 3,29365] \rightarrow \\
\text { farmaceutico }(\ldots 2,01178] \text { and hidrogenio }(\ldots 6,6101]\end{array}$ & 1,0757 & 75,00 & 69,72 & 60,5505 \\
\hline $\begin{array}{l}\text { composto }(\ldots 3,7785] \rightarrow \\
\text { hidrogenio }(\ldots 6.6101] \text { and peptide }(\ldots 6,6101]\end{array}$ & 1,0541 & 97,67 & 92,66 & 77,0642 \\
\hline
\end{tabular}

Tabela 5.12: Algumas regras extraídas do título e resumo das patentes farmoquímicas

A fim de prover uma análise de tendências ou relações existentes, por exemplo, entre os países e uso de alguma tecnologia, foram feitas consultas SQL para fazer a junção da tabela. correspondente à representação originalmente obtida (com 1931 atributos), com as quatro tabelas correspondentes aos campos multi-valorados, geradas pelo Minador. Dessa junção foi obtida uma tabela com 1082 registros, que é aqui tratada como uma representação híbrida, por ser formada por atributos provinientes de campos com descrições textuais e campos estruturados, que podem ser diretamente mapeados a um valor simbólico.

Com o auxílio do Mineset, esses atributos foram discretizados com base no atributo Classificação (multi-valorado). Esse atributo foi escolhido por estar diretamente relacionado à tecnologia envolvida nos produtos descritos nas patentes. Muitos dos atributos foram discretizados para um único valor tendendo a zero e, portanto. não foram considerados na análise. Assim. após a remoção dos atributos que apresentavam essa característica, 
restaram 217 atributos.

Com o gerador de regras de associação do Mineset foram obtidas 66.695 regras que apresentaram o valor médio para confidence e expected confidence ignal a 99,3 $\pm 4,41$ e $84,1 \pm 30,79$, respectivamente. O valor médio para lift foi de 5,47 pm 14,03 e o valor médio para o support foi de 14,34 $\pm 28,97$.

Na Tabela 5.13 são mostradas algumas das regras extraídas considerando uma representação híbrida formada pelos atributos gerados com uso do módulo de pré-processamento de texto e os atributos obtidos diretamente dos campos multi-valorados das patentes.

\begin{tabular}{|l||c|c|c|c|}
\hline regras & lift & confidence & expec. confidence & support. \\
\hline \hline $\begin{array}{l}\text { Pais=AT } \rightarrow \\
\text { corgulo_sanguíneo }=(14,0741 \ldots]\end{array}$ & 90,1667 & 100 & 1,11 & 1,1091 \\
\hline $\begin{array}{l}\text { Nome do Requerente }=\text { Astra Aktiebolog(SE) } \rightarrow \\
\text { doenca_provoca_defeito_sistema_munologico(14,0741... }\end{array}$ & 54,1 & 100 & 1,85 & 1,8484 \\
\hline $\begin{array}{l}\text { Datat do Deposito=09/30/1996 } \rightarrow \\
\text { profilax_tratamento }(14,0741 \ldots]\end{array}$ & 51,5238 & 100 & 1,94 & 1,9409 \\
\hline
\end{tabular}

Tabela 5.13: Algumas regras extraídas da representação híbrida

\subsubsection{Algumas Considerações}

Considerando as regras de associações encontradas com a representação gerada a partir dos campos de resumo e título das patentes, pode-se perceber que é difícil compreender o significado de cada uma delas. Em geral, uma regra como a primeira da Tabela 5.12:

$$
\operatorname{acido}(\ldots 5,79917] \text { and } u \mathrm{so}(\ldots 2,54342] \rightarrow \text { farmaceutico }(\ldots 2,01178]
$$

o que pode-se conchuir é que quando o atributo acido e o atributo uso possuem valores discretizados em $(\ldots 5,79917]$ e $(\ldots 2,54342]$, respectivamente, espera-se que o atributo famaceutico tenha valor discretizado $\mathrm{em}(\ldots 2,01178]$.

Oı seja, não se pode afirmar que essa regra indique que o ácido tem sido usado para finalidades farmacêuticas, uma vez que não se tem embutido nos atributos informações que nos permitam identificar quais substâncias são usadas nas patentes e quais atributos estão relacionados com finalidade das mesmas.

Talve, para melhorar a análise, poderiam ser considerados pesos booleanos on por freqüência, que são valores mais fáceis de compreender, e que poderiam tornar possível 
a análise de atributos que co-ocorrem nas patentes. Essa tarefa seria útil para dar uma visão de como estão distribuídos os termos entre as patentes. e auxiliar um usuário a identificar as patentes que sejam por ele consideradas possivelmente interessantes.

Considerando as regras de associação obtidas com uso da representação mista, têmse os mesmos problemas quanto a sua interpretação. Contudo, o que pode ser percebido é que melhores resultados são obtidos, desde a discretização dos atributos. Em geral, os valores para confiança das regras foi superior àqueles encontrados com a representação dos campos textuais. Entretanto, o valor médio da porcentagem de patentes que dá suporte às regras é muito inferior.

\subsection{Considerações Finais}

Os experimentos descritos neste capítulo, foram realizados com intuito de validar o módulo de pré-processamento de texto desenvolvido neste trabalho, quanto aos aspectos relacionados a identificação dos atributos e à utilização de diferentes medidas de atribuição de peso. Nesses experimentos foram utilizados duas aplicações importantes de Text Mining: categorização de documentos e análise de patentes para apoiar processo de inteligência competitiva.

Perante os resultados obtidos com a atividade de categorização de documentos, pôde ser observado que a utilização dos scripts para identificação dos atributos que fazem uso de stem provêm melhores resultados que aqueles que utilizam forma canônica. De forma geral, as abordagens mais simples tanto de identificação de atributos (como é o caso das que consideram apenas atributos compostos por 1-gram), quanto de atribuição de peso (como as que utilizam pesos booleano ou por freqüência), aparentemente apresentam melhores resultados.

Em relação aos resultados obtidos nos experimentos envolvendo análise de patentes, pode ser constatado que a presença de um especialista do domínio é fundamental para auxiliar a identificação dos atributos e talvez um forma mais adequada de representação dos documentos de patentes, principalmente no que diz respeito aos atributos obtidos dos campos textuais. 
Vale ressaltar que mesmo que os resultados dessa última análise não tenham sido muito satisfatórios. quando considerado o domínio da aplicação. é possível perceber que a representação híbrida é muito importante. 


\section{Capítulo 6}

\section{Conclusões}

Diante da chamada era da informação, muitas organizações vêm se deparando com a necessidade de obter, urgentemente, novas perspectivas e visões que lhes forneçam vantagens em relação a possíveis concorrentes. Para alcançar tais vantagens é de fundamental importância que se conheça, rapidamente, as características do mercado no qual a organização está inserida e prever em que direção este caminha.

No processo de tomada de decisão, é comum a utilização de técnicas para extração de conhecimentos de bases de dados. No entanto, tem-se percebido, principalmente com o advento da Internet, que existem muitas informações importantes divulgadas em documentos na forma de texto. Diante disso, o processo Text Mining torna-se importante para apoiar a extração de conhecimento.

Como abordado, o Text Mining pode ser dividido em quatro grandes etapas: coleta de documentos, pré-processamento, descoberta de conhecimento e avaliação e interpretação dos resultados. A etapa de pré-processamento, foco deste trabalho, é bastante importante por fornecer a representação com a qual é possível aplicar os algoritmos de extração de conhecimento.

Para que seja possível obter uma representação mais próxima do contexto real do documento, algumas das técnicas utilizadas são dependentes de idioma. Como grande parte dos trabalhos desenvolvidos são baseados no idioma inglês, ainda existem dificuldades para encontrar ferramentas de apoio para a extração de padrões em textos de outros idiomas. como é o caso do português. Esse fato foi comprovado no estudo das ferramentas 
disponíveis para apoiar as diversas aplicaçòes de Text Mining.

Assim o objetivo principal deste trabalho consistiu na investigação de técnicas que pudessem auxiliar a realização da preparação de textos em português. Para automatizar essa atividade foi projetado e desenvolvido um Módulo de Pré-processamento de Textos para esse idioma, que faz parte de um projeto maior para o desenvolvimento do Ambiente Computacional para Extração de Conhecimento em Dados e Textos, denominado Discover.

Para o desenvolvimento desse módulo foram implementados seis scripts para a identificação de atributos e seis scripts para atribuição de pesos, que são necessários para a construção da representação, que geralmente é fornecida na forma de atributovalor. Tendo em vista a grande quantidade de atributos que podem ser identificados, e a exaustão computacional dos métodos de extração de conhecimento diante de grandes representações, foram também implementados quatro scripts para redução da representação.

Para a construção dos scripts de identificação de atributos, foram utilizados como base três algoritmos distintos baseados em (Mladenić, 1998; Witten et al., 1999; Weiss and Indurkhya, 1997). Esses algoritmos utilizam diferentes estratégias para considerar que termos constituirão os atributos, por exemplo, o baseado em (Mladenić, 1998) considera que os atributos possam ser formados por até cinco termos que não sejam stopwords e que tenham ocorrido pelo menos quatro vezes. No caso do algoritmo baseado em (Witten et al., 1999), os atributos podem ser formados por até três termos, sendo que o primeiro e o ultimo não devem ser stopwords. E os atributos, considerados pelo uso do algoritmo baseado em (Weiss and Indurkhya, 1997), devem ser apenas formados por um único termo que não seja stopwords. Vale ressaltar que, para esse último algoritmo o usuário deve definir o valor de um parâmetro, que está associado a quantidade de atributos relevantes que serão identificados.

Para cada um desses três algoritmos foram considerados o uso de uma estratégia para a realização da normalização dos termos com base em stemming e outra com base na análise léxica e sintática, provida através de uma ferramenta (etiquetador) aprimorada e cedida pelo NILC. 
Para testar os scripts de identificação de atributos e atribuição de pesos foi realizado um estudo de caso envolvendo a classificação de textos dos domínios de Aquisição de Conhecimento e Redes Neurais. Tendo em vista a grande quantidade de atributos identificados. o tempo para a execução dos scripts de atribuiçăo de pesos, e considerando a quantidade de representaçōes obtidas da combinação dos diferentes scripts (veja Figura 3.4. pag. 51), optou-se por realizar os experimentos 11tilizando três combinações distintas do conjunto de documentos.

Através desses experimentos, pode ser percebido que a quantidade de atributos é muito elevada. principalmente quando utiliza-se atributos compostos de mais de um termo, chegando a ponto de tornar inviável a execução de certos scripts de atribuição de pesos.

A princípio suspeitava-se que identificando os atributos através de um processo lingüístico mais complexo, como o fornecido pelo etiquetador, poderia ser obtida maior eficiência na classificação dos documentos. Ao contrário do que era esperado, o uso do algoritmo de stemming proporcionou melhores resultados nos experimentos realizados.

Além dessas questões, também foram avaliados os resultados obtidos em relação à medida de peso utilizada para construção da representação. Muitos trabalhos, têm utilizado pesos gerados pela medida tf $\times$ idf ou tf $\times$ normalizado, pois levam em considerações algumas questões que tornariam a representação mais eficiente. No entanto, no estudo de caso realizado, medidas mais simples como para atribuição de peso booleano e por frequiência obtiveram bons resultados. Talvez, isso se deva a alguma característica dos domínios abordados ou quiça pela influência da escolha dos atributos e/ou quantidade dos mesmos.

Como parte deste trabalho também foi realizado um experimento envolvendo patentes farmoquímicas com o propósito de encontrar padrões que pudessem indicar a tendência sobre o uso de algum produto. Para que fosse possível a análise dos campos textuais desses documentos, foi utilizado o Módulo de Pré-processamento de Textos.

A ferramenta Mineset foi utilizada para encontrar regras de associações entre os registros da representação obtida dos documentos de patentes. E o que pode ser percebido é que a forma como a investigação foi conduzida talvez tenha que sofrer algumas alterações. 
pois contando-se apenas com uma representação atributo-valor, onde os atributos são palavras e os pesos são valores relacionados a sua freqüência no texto, é difícil obter regras significativas. Considerando a seguinte regra: acido $(\ldots 5,79917]$ and uso $(\ldots 2,54342]$ $\rightarrow$ farmaceutico $(\ldots .2,01178]$, pode-se concluir que é esperado que o atributo farmaceutico tenha peso até 2.01178, quando o atributo ácido tenha peso variando até 5,79917 e o atributo uso tenha peso variando até 2,54342 .

Assim, para verificar a utilidade dessa regra, assim como outras extraídas, é de extrema importância que se conte com um especialista do domínio.

Talvez seja interessante poder contar com uma representação que possa conter atributos que indiquem diretamente o produto utilizado na patente, ou a finalidade de seu uso. Entretanto, a identificação automática desses atributos exige um complexo processamento de língua natural.

Embora a análise de patentes tenha fornecidos resultados pouco significativos, pesquisas em torno de atividades como essa devem continuar, uma vez que consistem em aplicações de extremo interesse principalmente para apoiar o processo de inteligência competitiva. A afirmação de que o processo Text Mining possa vir a fazer mais do que classificar textos é comprovada numa entrevista recente com Hearst (Lucas, 2001).

Nessa entrevista, ela dá um parecer de que muitas pessoas pensam que Text Mining está relacionado com una maneira de encontrar informações mais facilmente na Web. Ela adverte que essa atividade, no entanto, concerne à Recuperação de Informação, enquanto que Text Mining tem um potencial de ser muito mais que recuperação de informação. Para a pesquisadora, pesquisa em jornais médicos para encontrar novas hipótese de causa e sintomas de uma doença é um dos casos ideais do que Text Mining é capaz de fazer.

No que diz respeito ao desenvolvimento do Módulo de Pré-processamento de Textos, pode-se considerar que este trabalho validou a maior parte dos conceitos abordados. Alguns pontos ainda deixados em aberto, referem-se à necessidade de:

- realização de experimentos utilizando 10-fold cross validation, caso houvesse viabilidade quanto ao tempo despendido;

- ıma investigação das características do algoritmo utilizado para a realização de 
stemming, envolvendo o levantamento das condicones que favorecem o se11 uso em relação ao de un processo lingüústico mais complexo:

- investigação dos métodos de redução de atributos, para verificar como eles afetam o desempenho dos algoritmos de extração de conhecimento de textos:

- utilizaçăo de dicionários com termos relacionados ao domínio da aplicação, a fim de propiciar a construção de uma representação mais próxima do contexto do documento. além de mais reduzida:

Assim, as sugestões feitas aqui focam-se nas atividades ligadas diretamente à continuação imediata dos trabalhos efetuados. 


\section{Referências Bibliográficas}

Aas, K. and Eikvil, L. (1999). Text categorization: A survey. Technical Report 941, Norweigian Computing Center, Oslo, Norweg. http://citeseer.nj.nec.com/ aas99text.html.

Agrawal, R., Psaila, G., Wimmers, E., and Zait, M. (1995). Querying shapes of histories. In Proceedings of the 21th International Conference on Very Large Databases, pages $502 \cdot 514$.

Agrawal, R. and Srikant, R. (1995). Mining sequencial patterns. In Proceedings of the 11th International Conference on Data Engineering.

Apté, C., Damerau, F., and Weiss, S. M. (1994). Automated learning of decision rules for text categorization. ACM Transactions on Information Systems, 12(3):233-251.

Baeza-Yates, R. A. (1998). Searching the www: Challenges and possible solutions. In Procedings of IBERAMIA'98 6th Iberoamerican Conference on Artificial Intelligence, pages 39-51, Lisboa, Portugal.

Braga, A. P., Carvalho, A. C. P. L. F., and Ludermir, T. B. (2000). Redes Neurais Artificiais: Teoria e Aplicações. Livros Técnicos e Científicos (LTC).

Buckley, C., Salton. G., Allan, J., and Singhal, A. (1994). Automatic query expansion using SMART: TREC 3. In Text REtrieval Conference, pages 69-80.

Cohen. W. W. (1996). Learning rules that classify e-mail. In AAAI Spring Symposium on Machine Learning in Information Access, pages 18-25.

Cohen, W. W. and Hirsch, H. (1998). Joins that generalize: text classification using whirl. In Proceedings of KDD'98 * 4th International Conference on Knowledge Dis- 
covery and Data Mining, pages 169-173.

Cohen. W. W. and Singer, Y. (1999). Context-sensitive learning methods for text categorization. ACM Transactions on Information Systems, 17(2):141 173.

Cutting. D. R. Kargerand, D. R., Pedersen, J. O., and Tukey. J. W. (1992). Scatter/gather: A cluster-based approach to browsing large document collections. In Proceedings of the 15th Annual International ACM/SIGIR Conference, pages 318329.

Fayyad. U. M., Piatestsky-Shapiro, G., and Smyth, P. (1996). From Data Mining to Knowledge Discovery: An Overview, pages 1-34. AAAI Press, Menlo Park, CA.

Feldman. R. and Dagan, I. (1995). Knowledge discovery in textual databases (KDT). In Proceedings of the First International Conference on Knowledge Discovery and Data Mining KDD '95, pages 112-117, Montreal, Canada.

Ferreira, A. B. H. (2001). Novo Dicionário da Língua Portuguesa. Editora Nova Fronteira, 28 edition.

FOCI (2001). Flexible organizer for competitive intelligence. http://textmining. kdrl . org.sg:8080/index_ie.html.

Froelich. J. (2000). Textanalyst tutorial. http://www.megaputer.com/products/ta/ tutorial/text_analyst_tutorial.htm\%1.

Goebel. M. and Gruenwald, L. (1999). A survey of data mining and knowledge discovery software tools. In Proceedings of ACM SIGKDD Explorations, volume 1, pages 20-33.

Good, I. J. (1965). The Estimation of Probabilities: An Essay on Modern Bayesian Methods. MIT press.

Hearst. M. A. (1994). Multi-paragraph segmentation of expository text. In Proceedings of the 32nd Meeting of the Association for Computational Linguistics, pages 9-16.

Hearst. M. A. (1995). Tilebars: Visualization of term distribution information in full text information access. In Proceedings of the ACM SIGCHI conference on Human Factors in Computing Systems, pages 59-66. 
Hearst, M. A. (1999). Untanglling text data mining. In Proceedings of ACL'99: 37th. Annual Meeting of the Association for Computational Linguistics.

Holland, J. H. (1986). Escaping brittleness: the possibilities of general-purpose learning algorithms applied to parallel rule-based systems. Machine Learning: An Artificial Intelligence Approach, 2(27):593 623 .

Hull, D. A. (1994). Improving text retrieval for the routing problem using latent semantic indexing. In Proceedings of SIGIR'94 - 17th ACM International Conference on Research and Development in Information. Retrieval, pages 282289.

IBM (1998). Intelligent miner for text, guia inicial, versão 2.3. http://www-4. ibm.com/software/data/iminer/fortext/publications/GETSTART\%/BRAZILIA/ IMOGOSOO.PDF.

Inquisit (2001). Inquisit the search engine with an iq technical overview. http://www.inquisit.com.

Joachims, T. (1997). A probabilistic analysis of the rochio algorithm with tfidf for text categorization. In International Conference on Machine Learning.

Joachims, T. (2000). Text categorization with supoort vector machines: Learning with many relevant features. I Congresso de Lógica Aplicadaà Tecnologia, pages 785789.

Joachims, T., Freitag, D., and T.Mitchell (1997). Webwatcher: A tour guide for the world wide web. In Proceedings of IJCAI97. http://citeseer.nj.nec.com/joachims97/ webwatcher.html.

John, G., Kohavi, R., and Pfleger, K. (1994). Irrelevant features and the subset selection problem. In Proceedings of the eleventh International Conference on Machine Learning, pages 167173.

Koster, M. (1997). Robots in the web: threat or treat. http://info.webcrawler.com/ mak/projects/robots/threat-or-treat.html.

Kupiec, J., Pedersen, J., and Chen, F. (1995). A trainable document summarizer. In Proceedings of SIGIR'95 - 18th Annual International ACM Conference on Research and Development in Information Retrieval, Seattle, WA USA. 
Lagus, K. (2000). Text Mining with the WEBSOM. PhD thesis, Department of Computer Science and Engineering, Helsinki University of Technology, Espoo, Finland. ISBN 951-22-5260-0.

Lee, H. D. (2000). Seleção e construção de features relevantes para o aprendizado de máquina. Master's thesis, ICMC-USP, São Carlos, SP.

Lent, B.. Agrawal, R., and Srikant, R. (1997). Discovering trends in text databases. In Heckerman, D., Mannila, H., Pregibon, D., and Uthurusamy, R., editors, Proc. 3rd Int. Conf. Knowledge Discovery and Data Mining, KDD, pages 227-230. AAAI Press.

Li, H. and Yamanishi. K. (1999). Text classification using esc-basead stochastic decision lists. In Proceedings of CIKM'99 - 8th ACM International Conference on Information and Knowledge Management, pages 122-130, Kansas City, US.

Li, Y. and Jain, A. K. (1998a). Classification of text documents. The Computer Journal, 41(8):537-546.

Li, Y. H. and Jain, A. K. (1998b). Classification of text documents. The Computer Journal, 41(8):537-546.

Loh, S. (1997). Descoberta de conhecimento em bases de dados textuais. http://atlas.

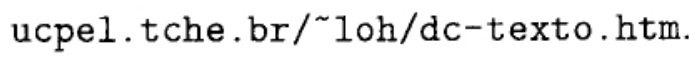

Loh, S., Wives, L. K., and Oliveira, J. P. M. (2000). Concept-based knowledge in text extracted from the web. In Proceedings of SIGKDD Explorations, volume 2, pages 29-39.

Losee, R. M. (2001). Term dependence: A basis for luhn and zipf models. Journal of the American Society for Information Science and Technology.

Lucas, M. (2001). Mining in textual mountains - an interview with marti hearst. http: //mappa.mundi.net/trip-m/hearst/.

Luhn, H. P. (1958). The automatic creation of literature abstracts. IBM Journal of Research and Development, 2:159-165. 
Martins, C., Pardo, T., Espina. A., and Rino, L. (2001). Introdução à sumarização automática. Technical Report RT-DC 002/2001, Departamento de Computação, Universidade Federal de São Carlos, São Carlos, SP.

Michalski, R. (1978). Pattern recognition as knowledge-guided computer induction. Technical Report 927, Department of Computer Science - University of Illinois, UrbanaChampaign, I11.

Miller, G., Beckwith, R., Fellbaum, C., Gross, D., and Miller, K. (1990). Introduction to wordnet: An online lexical database. International Journal of Lexicography (special issue), 3(4):235-312.

Mitchell, T. M. (1996). Machine Learning. McGraw Hill.

Mladenić, D. (1998). Machine Learning on non-homogeneous, distributed text data. $\mathrm{PhD}$ thesis, University of Ljubljana - Faculty of Computer and Information Science, Ljubljana.

Moulinier, I. and Ganascia, J. G. (1996). Applying an existing machine learning algorithm to text categorization. In Wermter, S., Riloff, E., and Schiler, G., editors, Connectionist, statistical, and symbolic approaches to learning for natural language processing, pages 343-354. Springer Verlag. Published in the Lecture Notes for Computer Science series, number 1040.

Neves, M. L. (2001). Pubsfinder - um agente inteligente para busca e classificação de páginas de publicações. Master's thesis, Centro de Informática -- Universidade Federal de Pernambuco, Recife, PE.

Nunes, M. G. V. (1996). The design of a lexicon for brazilian portuguese: Lessons learned and perspectives. In Proceedings of the II Workshop on Computational Processing of Written and Speak Portuguese, pages 61-70.

Oliveira, R. B. T. (2000). O processo de extração de conhecimento de base de dados apoiado por agentes de software. Master's thesis, ICMC-USP, São Carlos, SP.

Oliveira. R. B. T. and Rezende, S. O. (2001). Minador: a multi-agent system to support the knowledge discovery in databases process. 
OpenMuscat (2000). Search engine. http://open.muscat.com.

Peterson. R. E. (1997). Eight internet search engines compared. First Monday, 2(2). http://www.firstmonday.dk/issues/issue2_2/peterson.

Porter, M. F. (1980). An algorithm for suffix stripping. Program. 14(3):130-137.

Quinlan, J. R. (1990). Induction of decision trees. In Shavlik, J. W. and Dietterich, T. G., editors, Readings in Machine Learning. Morgan Kaufmann. Originally published in Machine Learning 1:81-106, 1986.

Quinlan, J. R. (1993). C4.5 programs for machine learning. Morgan Kaufmann, CA.

Rizzi, C. B., Wives, L. K., de Oliveira, J. P. M., and Engel, P. M. (2000). Fazendo uso de categorização de textos em atividades empresariais. In International Symposium on Knowlege Management/Document Management (ISKM/DM 2000), pages 251-268.

Salton, G. (1988). Term-weight approaches in automatic text retrieval.

Sebastiani, F. (1999). Machine learning in automated text categorisation: a survey. Technical Report IEI-B4-31-1999, Istituto di Elaborazione dell'Informazione, Consiglio Nazionale delle Ricerche, Pisa, Italy. http://faure.iei.pi.cnr.it/ fabrizio/ Publications/ACMCS00/ACMCS00.pdf.

SPSS (2001). Textsmart brochure. http://www . spss. com/PDFs/TSBRO-0498W.pdf.

Srikant, R. and Agrawal, R. (1996). Mining sequencial patterns: Generalizations and performance improvements. In Proceedings of the Fifth International Conference on Extending Database Technology, volume 1057, pages 3-17.

Tan, A. H. (1999). Text mining: The state of the art and the challenges. In Proceedings of the Pacific Asia Conference on Knowledge Discovery and Datamining PAKDD'99 workshop on Knowledge Discovery from Advanced Databases, pages 65-70.

Thomas, J. D. and Sycara, K. (1999). Integrating genetic algorithms and text learning for financial prediction. In Proceedings of the GECCO-2000 Workshop on Data Mining with Evoltionary Algorithms.

VanRijsbergen, C. J. (1979). Information Retrieval. (Second Edition). Butterworths, London. 
Vapnik. V. N. (1995). The Nature of Statistical Learning Theory. Springer-Verlag, New York.

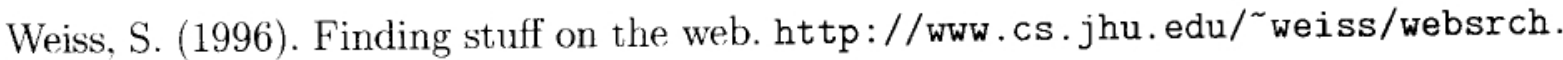
html.

Weiss. S. M. and Indurkhya, N. (1997). Predictive Data Mining - A Practical Guide. Morgan Kaufmann Publishers, Inc., San Francisco, California.

Witten. I. H., Paynter, G. W., Frank, E., Gutwin, C., and Nevill-Manning, C. G. (1999). KEA: Practical automatic keyphrase extraction. In ACM DL, pages 254-255.

Yang, Y. (1999). An evaluation of statistical approaches to text categorization. Information Retrieval, 1-2(1):69-90.

Yang, Y. and Chute, C. G. (1994). An example-based mapping method for text categorization and retrieval. ACM Transactions on Information Systems, 12(3):252-277.

Yang, Y. and Liu, X. (1999). A re-examination of text categorization methods. In Proceedings of SIGIR'99 - 22nd ACM International Conference on Research and Development in Information Retrieval, pages 42-49.

Yang, Y. and Pedersen, J. O. (1997). A comparative study on feature selection in text categorization. In Proceedings of ICML'97 - International Conference on Machine Learning, pages 412-420. Morgan Kaufmann.

Zipf, G. (1949). Human Behaviour and the Principle of Least Effort. Addison-Wesley. 